\title{
WestVirginiaUniversity
}

THE RESEARCH REPOSITORY @ WVU

Graduate Theses, Dissertations, and Problem Reports

2006

\section{IQGAP1 knockdown enhances the endothelial barrier in vitro}

Wentao Zhang

West Virginia University

Follow this and additional works at: https://researchrepository.wvu.edu/etd

\section{Recommended Citation}

Zhang, Wentao, "IQGAP1 knockdown enhances the endothelial barrier in vitro" (2006). Graduate Theses, Dissertations, and Problem Reports. 4283.

https://researchrepository.wvu.edu/etd/4283

This Dissertation is protected by copyright and/or related rights. It has been brought to you by the The Research Repository @ WVU with permission from the rights-holder(s). You are free to use this Dissertation in any way that is permitted by the copyright and related rights legislation that applies to your use. For other uses you must obtain permission from the rights-holder(s) directly, unless additional rights are indicated by a Creative Commons license in the record and/ or on the work itself. This Dissertation has been accepted for inclusion in WVU Graduate Theses, Dissertations, and Problem Reports collection by an authorized administrator of The Research Repository @ WVU.

For more information, please contact researchrepository@mail.wvu.edu. 


\title{
IQGAP1 KNOCKDOWN ENHANCES THE ENDOTHELIAL BARRIER IN VITRO
}

\author{
Wentao Zhang
}

Dissertation submitted to the School of Medicine at West Virginia University in partial fulfillment of the requirements for the degree of

\author{
Doctor of Philosophy \\ in \\ Physiology and Pharmacology \\ Fred L. Minnear, Ph.D., Chair \\ Steven M. Frisch, Ph.D. \\ Pingnian He, M.D., Ph.D. \\ Daniel C. Flynn, Ph.D. \\ Matthew A. Boegehold, Ph.D. \\ Department of Physiology and Pharmacology \\ Morgantown, West Virginia \\ 2006 \\ Keywords: IQGAP1, Endothelial barrier, Transcellular Electrical Resistance, VE- \\ cadherin, N-cadherin, Human Umbilical Vein Endothelial Cells
}




\title{
ABSTRACT \\ IQGAP1 Knockdown Enhances the Endothelial Barrier In Vitro
}

\author{
Wentao Zhang
}

IQGAP1 overexpression inhibits E-cadherin-mediated epithelial cell-cell adhesion by distabilizing the adherens junctions, and activated Rac1 and Cdc42 may prevent these effects by removing IQGAP1 from the adherens junction complex. In the present study, we determined if IQGAP1 associates with the adherens junction of endothelial cells and affects endothelial barrier function. In human umbilical vein endothelial cells (HUVECs), IQGAP1 associated with VE-cadherin, the catenins, $\beta, \gamma, \alpha$, and p120, but not with N-cadherin or the tight junction proteins, occludin, claudin-5, and ZO-1. Detergent extracted most of the IQGAP1 associated with VE-cadherin. Treatment of endothelial cells with sphingosine-1-phosphate (S1P), which increases the activity of Rac1, increased the association of IQGAP1 with Rac1, and the amount of insoluble VE-cadherin and $\beta$-catenin at intercellular junctions. To determine if the increased localization of junctional VE-cadherin induced by S1P occurred via the removal of IQGAP1, the protein level of IQGAP1 was reduced with small interfering RNA or siRNA. Reduction of IQGAP1 by transfection of siRNA resulted in a higher endothelial electrical resistance in HUVECs as compared to transfection of a scrambled siRNA. Reduction of IQGAP1 also induced an increase and a decrease, respectively, in the protein levels of VE-cadherin and N-cadherin. Also, more VEcadherin and less N-cadherin were associated with p120 and $\beta$-catenin. Furthermore, more insoluble (cytoskeletal-associated) VE-cadherin was localized at intercellular junctions and less insoluble N-cadherin was present in HUVECs. Overexpression of a VE-cadherin- $\alpha$-catenin fusion protein, which lacked the binding sites for $\beta$-catenin on VE-cadherin and $\alpha$-catenin, diminished the localization of junctional IQGAP1. These findings suggest that IQGAP1 knockdown positively influences the endothelial barrier by increasing the protein level of VE-cadherin and the interaction of VEcadherin with the cytoskeleton, possibly by enhancing the p120-VE-cadherin association. 


\section{DEDICATED TO}

My wife, Minghui Hou, and My parents, Zuyun Liu \& Hansheng Zhang 
Page No.

TITLE i

$\begin{array}{lll}\text { ABSTRACT } & \text { ii }\end{array}$

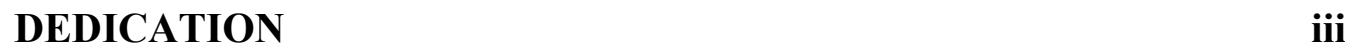

TABLE OF CONTENTS iv

TABLE OF FIGURES vi

ABBREVIATIONS vii

I. LITERATURE REVIEW 1

A. Endothelial Cell-cell Junctions 1

1. Vascular Permeability 1

2. Adherens Junctions 3

$\begin{array}{ll}\text { a. Cadherins } & 3\end{array}$

b. Catenins

c. Rho Subfamily GTPases and Adherens Junctions 9

d. Adherens Junctions and Vascular Permeability 10

$\begin{array}{lr}\text { 3. Tight Junctions (Zonula Occludens) } & 10\end{array}$

4. Endothelial Junctions (Complexus Adherens) 11

5. Immunoglobulin (IgG) Superfamily of Adhesion Proteins 12

B. IQGAP1 and Adherens Junctions 13

$\begin{array}{lr}\text { 1. Introduction } & 13\end{array}$

2. IQGAP1 and Cell-cell Adhesion 16

3. IQGAP1 and Cell Migration 16

a. Rho GTPases, Cell Polarization and Directional Migration 19

b. IQGAP1, Cell Polarization and Directional Migration 20 
4. IQGAP1 and Distant Metastasis of Cancer Cells 20

C. Sphingosine-1-Phosphate (S1P) and Cell-cell Adhesion 21

1. Biosynthesis and Metabolism of S1 P 21

2. G protein-coupled receptors (GPCRs) for S1P: EDG family 21

3. S1P Enhances Endothelial Barrier Function 22

II. INTRODUCTION 25

$\begin{array}{lr}\text { III. METHODS } & 28\end{array}$

$\begin{array}{ll}\text { IV. RESULTS } & 34\end{array}$

$\begin{array}{lr}\text { V. DISCUSSION } & 88\end{array}$

$\begin{array}{lr}\text { VI. CONCLUSION } & 98\end{array}$

$\begin{array}{ll}\text { VII. REFERENCES } & 101\end{array}$

VII. BIOGRAPHICAL SKETCH 


\section{TABLE OF FIGURES}

Figures

Fig. 1. IQGAP1 structure and interacting proteins

Fig. 2. Kaibuchi's hypothesis: IQGAP1 inhibits cell-cell adhesion

Fig. 3. S1P rapidly increased transcellular electrical resistance

Fig. 4. S1P increased insoluble VE-cadherin and insoluble $\beta$ catenin at intercellular junctions

Fig. 5. S1P increased IQGAP1 association with Rac1

Fig. 6. IQGAP1 colocalized with Rac1 at membrane ruffles and in the cytoplasm in subconfluent monolayers

Fig. 7. IQGAP1 complexed with calmodulin in the cytoplasm

Fig. 8. Insoluble IQGAP1 colocalized with actin filaments at membrane ruffles of subconfluent cell monolayers

Fig. 9. Interaction of IQGAP1 with VE-cadherin and catenins, $\beta$, $\gamma, \alpha$, and p120

Fig. 10. IQGAP1 did not complex with tight junction proteins, occludin, claudin-5, and ZO-1

Fig. 11. IQGAP1 was Triton-soluble at intercellular junctions

Fig. 12. Junctional IQGAP1 colocalized with cortical actin filaments after permeabilization

Fig. 13. Reduction of IQGAP1 by siRNA

Fig. 14. Toxicity and Knockdown Effect of IQGAP1 siRNA

Fig. 15. Basal electrical resistance was higher in IQGAP1 knockdown cells

Fig. 16. IQGAP1 knockdown increased VE-cadherin

Fig. 17. IQGAP1 knockdown decreased N-cadherin

Fig. 18. IQGAP1 knockdown did not change protein levels of p120-, $\beta$-, and $\alpha$ - catenins

Fig. 19. N-cadherin formed complexes with all four catenins and was less bound to cytoskeleton

Fig. 20. IQGAP1 knockdown increased association of VEcadherin with p120 and $\beta$-catenin; opposite effect occurred with $\mathrm{N}$-cadherin

Fig. 21. VE-cadherin- $\alpha$-catenin expression increased the electrical resistance across HUVECs

Fig. 22. VE-cadherin- $\alpha$-catenin expression diminishes junctional IQGAP1

Fig. 23. Our hypothesis
Page No. 


\begin{tabular}{|c|c|}
\hline $\mathrm{Lp}$ & Hydraulic conductivity \\
\hline $\mathrm{Pd}$ & Diffusional permeability coefficient \\
\hline$\sigma$ & Reflection coefficient \\
\hline N-cadherin & Neural cadherin \\
\hline P-cadherin & Placental cadherin \\
\hline VE-cadherin & Vascular endothelial cadherin \\
\hline PCDH12 & Protocadherin 12 \\
\hline S1P & Sphingosine-1-phosphate \\
\hline APC & Adenomatous polyposis coli \\
\hline $\mathrm{TCF}$ & $\mathrm{T}$ cell factor \\
\hline LEF & Lymphocyte enhancer binding factor \\
\hline PP2A & Protein phosphatase $2 \mathrm{~A}$ \\
\hline GSK3 $\beta$ & Glycogen synthase kinase $3 \beta$ \\
\hline CK1 & Casein kinase 1 \\
\hline Dsg & Desmoglein \\
\hline Dsc & Desmocollin \\
\hline GEF & Guanine nucleotide exchange factor \\
\hline GDI & Guanine nucleotide dissociation inhibitor \\
\hline GAP & GTPase activating protein \\
\hline HUVEC & Human Umbilical Vein Endothelial Cells \\
\hline MDCK & Madin Darby Canine Kidney epithelial cells \\
\hline EL cells & Mouse L fibroblasts expressing wild type E-cadherin \\
\hline $\mathrm{nE} \alpha \mathrm{CL}$ cells & $\begin{array}{l}\text { Cells expressing the cytoplamic domain of E-cadherin and the c- } \\
\text { terminal domain of } \alpha \text {-catenin }\end{array}$ \\
\hline MAGUK & Membrane associated guanylate kinase \\
\hline CAMs & $\mathrm{Ca} 2+$-independent cell-cell adhesion molecules \\
\hline JAMs & Junctional adhesion molecules \\
\hline IgCAMs & Ig cell adhesion molecules \\
\hline $\mathrm{POZ} / \mathrm{ZF}$ & Pox Virus and Zinc Finger Family \\
\hline PECAM & Platelet Endothelial cell-cell adhesion molecule \\
\hline MAPK & Ras-mitogen-activated protein kinase \\
\hline $\mathrm{CH}$ domain & Calponin homology domain \\
\hline GRD domain & G-protein binding protein domain \\
\hline CLIP170 & Cytoplasmic linker protein 170 \\
\hline MTOC & Microtubule-organizing center \\
\hline EB1 & End-binding protein 1 \\
\hline GFP & Green fluorescent protein \\
\hline GPCRs & G protein-coupled receptors \\
\hline EDG & Endothelial Differentiation Gene \\
\hline eNOS & Endothelial nitric oxide synthase \\
\hline PI3K & Phosphatidylinositol 3-kinase \\
\hline ERK & Extracellular signal regulated kinase \\
\hline JNK & c-Jun N-terminal kinase \\
\hline ALI & Acute lung injury \\
\hline MLC & Myosin light chain \\
\hline MLCK & Myosin light chain kinase \\
\hline FAK & Focal adhesion kinase \\
\hline
\end{tabular}


SiRNA Small interfering RNA

ECIS Electric cell-substrate impedance sensing

CSK Cytoskeleton preserving buffer 


\section{LITERATURE REVIEW}

\section{A. Endothelial Cell-Cell Junctions}

Intercellular junctions, including adherens junctions (or zonula adherens), tight junctions (or zonula occludens) and gap junctions, connect adjacent vascular endothelial cells and impart a semi-permeable barrier to the passage of water and proteins. The presence and organization of these junctional complexes depend on the type of blood vessel and the permeability requirements of the perfused organs. Gap junctions mediate cell-to-cell communication by allowing the passage of small molecular weight solutes between neighboring cells. Tight junctions as "a barrier" and "a fence" are responsible, respectively, for regulating paracellular permeability and maintaining cell polarity. Endothelial adherens junctions are involved in cell-cell recognition, contact inhibition of cell growth, and paracellular permeability to circulating leukocytes and solutes (4). This dissertation focuses mainly on molecular organization and functions of adherens junctions in endothelial cells. The regulation mechanisms of adherens junctions will also be discussed in this literature review.

\section{Vascular Permeability}

Vascular endothelia form a selective barrier between blood and the extravascular space that controls the passage of fluid, electrolytes, proteins and even cells. As a barrier, vascular endothelia regulate many biological processes such as inflammation, white cell emigration, and angiogenesis. Disruption of the endothelial barrier leads to accumulation of fluid and macromolecules in the interstitial space, resulting in edema and dysfunction of tissues and organs and distant metastasis of cancer cells. In normal (undisturbed) tissues, proteins are transported by transcytosis through plasmalemmal vesicles and channels and their uncharged diaphragms and paracellularly through intercellular junctions (61). During normal inflammatory 
processes, plasma and some blood cells can pass paracellularly through intercellular junctions transiently separated by vasoactive mediators, such as histamine, bradykinin, serotonin, and platelet-activating factor.

An excessive inflammatory response as well as growth factors, cytokines, and reactive oxygen species can activate the microvascular and venular endothelia to elicit intracellular signaling reactions that compromise endothelial barrier function (112). Activated leukocytes and cancer cells of high metastatic capacity also have the potential to breakdown the integrity of the vascular endothelial barrier. Vascular endothelial growth factor (VEGF)-expressing ID8 murine ovarian carcinoma cells, injected intravenously into the tail vein of mice, formed more metastatic lesions in the lung than did injection of control cells. The high level of VEGF disrupted endothelial cell-cell junctions and contributed to tumor cell extravasation and metastasis (103). Therefore, the maintenance and regulation of the endothelial barrier is important physiologically and pathologically.

Water, electrolytes, and small molecules can exchange freely between blood and extravascular compartments by diffusion and bulk flow. They may pass through the cell via vesicles and membrane channels or parcellularly via fenestrae and intercellular junctions. The rate of exchange is determined by hydrostatic pressure, oncotic pressure, and the permeability of the capillary wall. Permeability is usually assessed by hydraulic conductivity $\left(\mathrm{L}_{\mathrm{p}}\right)$, the diffusional permeability coefficient $\left(\mathrm{P}_{\mathrm{d}}\right)$, and/or the reflection coefficient $(\sigma)$. Hydraulic conductivity is the flow of water through a unit area of vessel wall per unit difference in hydrostatic pressure across the wall $\left(\mathrm{L}_{\mathrm{p}}=\left(\mathrm{J}_{\mathrm{v}} / \mathrm{A}\right) / \Delta \mathrm{P}\right.$, when the osmotic pressure is held constant or $\left.\Delta \pi=0\right)$. The diffusional permeability coefficient is the mass transport of a substance per unit concentration difference, under conditions when the net fluid flow through the 
capillary wall is zero $\left(\mathrm{P}_{d}=\left(\mathrm{J}_{\mathrm{s}} / \mathrm{A}\right) / \Delta \mathrm{C}\right.$, when $\left.\mathrm{J}_{\mathrm{v}}=0\right)$ or held constant. The reflection coefficient compares the penetration of a solute with that of the solvent through a membrane $\left(\sigma_{\mathrm{f}}=1-\mathrm{Js} / \mathrm{JvC}\right.$, when $\left.\Delta \mathrm{C}=0\right)$. If the membrane is impermeable to a solute, $\sigma=1$; if the membrane is totally permeable to a solute, $\sigma=0(60)$.

\section{Adherens Junctions}

Along the vascular tree, adherens junctions are ubiquitously distributed and expressed at the periphery of endothelial cells. Adherens junctions consist mainly of cadherin-catenin complexes.

\section{a. Cadherins}

Over 80 members of the cadherin superfamily are expressed within a single mammalian species and each cadherin has a unique tissue-distribution pattern. Endothelial cells express at least five cadherins: N-cadherin (neural cadherin), Pcadherin (placental cadherin) (54), T-cadherin (78), Cadherin-5 or VE-cadherin (vascular endothelial cadherin) and VE-cadherin 2 (or protocadherin 12, PCDH12) (79). Among these cadherins, VE-cadherin is specifically localized to the interendothelial cell junction (49) and mediates calcium-dependent, homophilic binding of endothelial cells through five extracellular cadherin repeats, a transmembrane region, a juxtamembrane region, and a highly conserved cytoplasmic tail $(1,49)$. In the presence of calcium, extracellular domains bind laterally to each other, forming cisdimers, or in a head-to-head manner with cadherins on adjacent cell, forming transdimers. Actually, VE-cadherin can confer strong cell-cell adhesion by forming cisdimers, trans-dimers, lateral clusters, and linkage with the actin cytoskeleton (101). So, VE-cadherin plays an important role in the regulation of vascular permeability (27). But when Carmeliet et al. (1999) generated mice that lacked a functional Cadherin-5 (VE-cadherin) gene, which expressed a mutant Cadherin-5 gene lacking 
the beta-catenin binding cytoplasmic tail, or that did not express a detectable Cadherin-5 level, they found in all of these mice that deletion or truncation of the Cadherin-5 gene affected the assembly of endothelial cells in vascular plexi, but not completely, suggesting that other cadherin(s) may also mediate endothelial cell-cell adhesion (9).

$\mathrm{N}$-cadherin, another member of the classical cadherin family, is usually found at cell-cell contact sites in tissues where it is expressed. In endothelial cells, Ncadherin remains diffusely distributed at the cell membrane (67) and is necessary for sphingosine 1-phosphate (S1P)1 receptor-induced endothelial-mural cell interaction (74). Thus, N-cadherin may promote endothelial cell adhesion and communication with pericytes or smooth muscle cells expressing N-cadherin. Recent evidence shows that $\mathrm{N}$-cadherin also localizes to endothelial cell-cell junctions, indicating a possible role of N-cadherin in mediating endothelial cell-cell adhesion (56). However, little is known about $\mathrm{N}$ cadherin-mediated homotypic cell adhesion. Once calcium-dependent homophilic binding of VE-cadherin or N-cadherin is disrupted, VE-cadherin or Ncadherin is internalized, possibly recycled or degraded (40), lowering the protein level in cells.

Both VE- and N-cadherins can directly bind to shc, an adapter protein in the Ras signaling pathway. And expression of VE-cadherin in confluent endothelial cell monolayers induced Rac activation and Rho inhibition, but N-cadherin expression induced the opposite and promoted cell migration (68).

The specific transmembrane protein of endothelial cells called cadherin-5 or vascular endothelial (VE)-cadherin (15) binds p120 via its juxtamembrane domain, and binds $\beta$-catenin and plakoglobin ( $\delta$-catenin) through its cytoplasmic tail or catenin-binding domain. $\beta$-catenin and plakoglobin in turn link $\alpha$-catenin, which also 
binds linker proteins such as vinculin, $\alpha$-actinin, and ZO-1. These linker proteins and the adhesion modulation domain of $\alpha$-catenin link the VE-cadherin/ $\beta$-catenin complex to the actin cytoskeleton (48). The current dogma that the VE-cadherin/ $\beta$ catenin complex links to to actin via $\alpha$-catenin, however, has recently been challenged. Two back-back publications by Drees et al. (16) and Yamada et al. (109) suggest that $\alpha$-catenin does not bind simultaneously to both the VE-cadherin $/ \beta$-catenin complex and to actin and that this purported linkage is more dynamic than originally thought. Additional studies are required to determine the validity of this new hypothesis.

\section{b. Catenins}

Catenins $(\alpha, \beta, \gamma$, and p120) are members of the Armadillo family, which is characterized by a central domain that is composed of a series of imperfect 45 -amino acid repeats. Each catenin exerts several functions through interactions of its armadillo repeat domain with diverse binding partners. The cytoplasmic tail of VEcadherin binds to $\beta$-catenin, which in turn binds to $\alpha$-catenin to form a complex that links to the actin cytoskeleton. $\gamma$-Catenin (plakoglobin) also interacts with VEcadherin and links the VE-cadherin complex with the actin cytoskeleton and/or connects VE-cadherin to intermediate filaments (84). A fourth catenin, p120 (p120cas), was originally characterized as a substrate of v-Src kinase $(81,97,111)$ and associates with the juxtamembrane domain of VE-cadherin, inducing cadherin clustering and stabilization of adherens junctions $(14,39,105)$. In the complex of VE-cadherin and catenins, $\alpha$-catenin appears to be the only catenin that directly or indirectly links to the actin cytoskeleton through linker proteins such as $\alpha$-actinin, vinculin, ZO-1, spectrin and a number of other molecules associated with the cadherin complex (108). 
The incorporation of $\alpha$-catenin into cadherin-catenin complexes was thought to be necessary for cadherins to mediate cell-cell adhesion. $\alpha$-Catenin binds to either $\beta$ - or $\gamma$-catenin through the same region, amino-terminal residues 54-148. The aminoterminal domain (aa 82-279) of $\alpha$-catenin is also important for dimerization. Its central segment can associate with $\alpha$-actinin (through aa 325-394) and vinculin (through aa 327-402). Amino acids 509-643 of $\alpha$-catenin is called the adhesion modulation domain. The carboxyl terminal fragments of $\alpha$-catenin bind to actin filaments and vinculin (through aa 697-906), as well as ZO-1 (through aa 631-906). By interacting with all these proteins, $\alpha$-catenin can not only link cadherin-catenin complexes to the actin cytoskeleton but also regulate actin binding, bundling, and polymerization $(36,100)$. But contrary to this notion, recent studies reported that $\alpha-$ catenin did not interact simultaneously with actin filaments and the E-cadherin- $\beta$ catenin complex (109).

$\beta$-Catenin contains N-terminal Ser/Thr phosphorylation sites (aa 33-45), an $\alpha$ catenin binding region (aa 118-146), an APC (adenomatous polyposis coli) binding domain, a Tcf (T cell factor)/LEF (lymphocyte enhancer binding factor) binding region, a cadherin binding region, and a C-terminal transactivator region (aa 671781). In addition to mediating adherens junction assembly, $\beta$-catenin also transduces Wnt/Wingless intracellular signals, which regulate embryonic cell fates and, if inappropriately activated, contribute to tumorigenesis. In the absence of Wnt signaling, the cytoplasmic level of $\beta$-catenin is kept low through interaction with a degradation complex comprised of APC, Axin, PP2A (protein phosphatase 2A), and GSK3 $\beta$ (glycogen synthase kinase $3 \beta$ ), as well as CK1 (casein kinase 1). Progressive phosphorylation by CK1 and GSK $3 \beta$ leads to ubiquitination and proteasomal degradation of $\beta$-catenin. $\mathrm{F}$ box/WD-40-repeat protein, $\beta$-TrCP, serves 
as an intracellular receptor for phosphorylated $\beta$-catenin, forming a Skp1/Cullin/F box protein ${ }^{\beta-\operatorname{TrCP}}\left(\mathrm{SCF}^{\beta-\operatorname{TrCP}}\right)$ ubiquitin ligase complex that ubiquitinates $\beta$-catenin (99). When Wnt, a secreted glycoprotein, binds to Frizzled receptors and activates Wnt signaling, GSK3 $\beta$ is removed from the degradation complex, resulting in accumulation of unphosphorylated $\beta$-catenin in the cytoplasm, allowing the translocation of $\beta$-catenin to the nucleus and subsequent gene induction via binding to $\mathrm{TCF} / \mathrm{LEF}(5,85)$. In tumors, degradation of $\beta$-catenin is blocked due to mutation of $\beta$-catenin or APC, which results in the formation of TCF/ $\beta$-catenin complexes and activation of oncogenes (85).

It is proposed that binding of cadherins to $\beta$-catenin prevents recognition of degradation signals that are exposed in the unstructured cadherin cytoplasmic domain, favoring a cell surface population of catenin-bound cadherins capable of participating in cell adhesion (32). When $\beta$-catenin binds to cadherins, it is also stabilized and retained at the cell membrane, reducing the pool of free $\beta$-catenin in the cytosol and decreasing its transcriptional activity. Tyrosine phosphorylation of $\beta$-catenin, especially tyrosine 654 , decreases the affinity of $\beta$-catenin to the cytoplasmic tail of E-cadherin, which may induce the detachment of $\beta$-catenin from the cadherin and increase cytoplasmic and nuclear $\beta$-catenin. In contrast, serine phosphorylation of specific residues in the cytoplamic tail of cadherins increases $\beta$-catenin association with cadherins (33).

$\gamma$-Catenin is a major component of both adherens junctions and desmosomes. Via its 13 central repeats, $\gamma$-catenin binds to desmoglein (Dsg), desmocollin (Dsc), $\alpha$ catenin, and classical cadherins. When $\gamma$-catenin is linked to intermediate filaments instead of actin filaments, it may be involved in formation of endothelial junctions known as complexus adhaerentes, a novel desmosomal-like structure that is specific 
for endothelial cells because it consists of VE-cadherin, $\gamma$-catenin, desmoplakin, vimentin, and intermediate filaments, but not desmocollin or desmoglein $(83,84)$. The functional role of complexus adhaerentes is still not clear. $\gamma$-Catenin can also form cytosolic protein complexes with APC to determine cell fate (76).

p120 ctn can be found at intercellular junctions, in the cytoplasm, and in the nucleus. Epidermal growth factor, platelet-derived growth factor, colony stimulating factor-1, vascular endothelial growth factor, and nerve growth factor all phosphorylate tyrosines on p120 via src or a receptor tyrosine kinase; and epidermal growth factor also induces extensive serine phosphorylation of p120. Phosphorylation of the N-terminus of p120 may affect the function of p120. Hypophosphorylated p120 facilitates cadherin clustering $(97,111)$, and hyperphosphorylation of p120 inhibits cell-cell adhesion as does deletion of the Nterminus $(72,73)$. In the cytoplasm, p120 inhibits RhoA, but activates Rac1 and Cdc42, which may increase cell motility (69). The cytoplasmic roles of p120 can be regulated by cadherins, which are able to sequester it at cell junctions. Nuclear p120 binds to Kaiso, a novel transcriptional factor of POZ/ZF (Pox Virus and Zinc Finger) family (101). Via its C-terminal C2H2-type zinc-finger motif, Kaiso can bind to a specific DNA sequence and repress DNA transcription (90). Within the past two years, a series of papers have highlighted the importance of p120 in the stabilization and turnover of VE-cadherin $(39,80,105)$. Collectively, these papers demonstrated that binding of p120 to the juxtamembrane domain of cadherins regulates the protein levels of these cadherins. Decreasing the protein level of p120 by siRNA or overexpression of the juxtamembrane region of VE-cadherin reduces VE-cadherin protein and decreases endothelial barrier function (39). Overexpression of p120 alone or co-expression with the juxtamembrane region increases VE-cadherin and its 
localization at intercellular junctions. Therefore, stabilization of VE-cadherin relies on the binding of $\mathrm{p} 120$. On the other hand, the lack of p120 binding targets VEcadherin to degradation through an endocytic pathway involving clathrin (106).

c. Rho Subfamily GTPases and Adherens Junctions

The Rho family of small GTPases belongs to the Ras superfamily, which is composed of more than 50 members and has been divided into six families: Ras, Rho, Arf, Sar, Ran, and Rab (94). At least 10 members of the Rho subfamily are known in mammals: Rho A-E, Rho G, Rac1 and -2, Cdc42, and TC10. Rho A, -B, and -C, Rac 1 and-2, and Cdc42 are the best studied members, which exhibit guanine nucleotidebinding activity and function as molecular switches, cycling between an inactive GDP-bound state and an active GTP-bound state. Dissociation of GDP is facilitated by a guanine nucleotide exchange factor (GEF), and inhibited by a guanine nucleotide dissociation inhibitor (GDI). Hydrolysis of bound GTP is accelerated a hundredfold by a GTPase-activating protein (GAP) $(47,66)$. Rho small GTPases participate in regulation of the actin cytoskeleton and various cell adhesion events. Rho has been implicated in the formation of stress fibers and focal adhesions, cell aggregation, cell motility, membrane ruffling, smooth muscle contraction, neurite retraction in neuronal cells, and cytokinesis. Rac is involved in membrane ruffling, cell motility, actin polymerization, and cadherin-mediated cell-cell adhesion. Cdc42 plays an important role in the formation of filopodia, in cell motility, and in actin polymerization (28).

Rho family small GTPases regulate cadherin mediated cell-cell adhesions in many ways $(7,31,43,95)$. Microinjection of dominant negative Rac1 $\left(\operatorname{Rac}^{\mathrm{N} 17}\right)$ or C3 botulinum exoenxyme, a RhoA inhibitor, reduced the level of cadherin at sites of cell-cell contact upon $\mathrm{Ca}^{2+}$-induced intercellular adhesion in keratinocytes (7). In contrast, Rac1 (wild-type, dominant-neg. or dominate-pos.) disrupts cell-cell 
adhesion in small preconfluent colonies of keratinocytes (6). Overexpression of Rac1 ${ }^{\mathrm{N} 17}$ in MDCKII cells decreased the amounts of actin filaments, E-cadherin and $\beta$-catenin to the cell-cell adhesion sites (95). Both Rac1 and Cdc42 are required for E-cadherin-mediated cell-cell adhesion in MDCKII cells (43). Expression of Rac1 ${ }^{\mathrm{N} 17}$ and $\mathrm{Cdc} 42{ }^{\mathrm{N} 17}$ dramatically decreased E-cadherin-mediated cell adhesion in EL cells (mouse L fibroblasts stably expressing wild-type E-cadherin) but not in $\mathrm{nE} \alpha \mathrm{CL}$ cells (cells expressing an E-cadherin mutant in which the cytoplasmic domain was replaced by the $\mathrm{C}$-terminal domain of $\alpha$-catenin), which suggests that Rac 1 and Cdc42 regulate E-cadherin activity through the cadherin-catenin complexes (21).

d. Adherens Junctions and Vascular Permeability

Although tight junctions have been considered the key regulators of barrier function, at least in epithelial cells, the role of the adherens junction, in particularVEcadherin, in maintaining vascular integrity and permeability of vascular endothelia has been proven by in vivo studies. Intravenous administration of mAb BV13, an antibody against mouse VE-cadherin, induced an increase in vascular permeability within a few hours in heart and lungs, but not in other organs, such as brain, muscles, and skin (12). These findings indicate that the regulation of vascular permeability by VE-cadherin may be cell and tissue specific but that vascular endothelial permeability may also depend in some tissues on the type and organization of other intercellular junctions like tight junctions.

\section{Tight Junctions (Zonula Occludens)}

Tight junctions appear to be a network of ridges under electron microscopy. And each ridge is a continuous strand of transmembrane junctional proteins (protein model) or lipid domains (lipid model) that bind tightly with those of another cell. These ridges consist of occludin, claudins, and small junctional immunoglobulins 
like Junctional Adhesion Molecule-A. Through their cytoplasmic tails, these integral membrane proteins are associated with ZO-1, -2, -3, members of MAGUK (Membrane Associated Guanylate Kinase) family, and are connected to actin microfilaments. By occluding the lateral intercellular space, tight junctions restrict both the diffusion of solutes across intercellular spaces (barrier function) and the movement of membrane molecules between the apical and basolateral domains of the plasma membrane (fence function). Therefore, tight junctions are important in maintaining cell polarity and cell barrier function (4).

Tight junctions are found in both epithelial and endothelial cells. But in most endothelial cells, adherens junctions are intermingled with tight junctions, and the precise localization of tight junctions and their separation from other junctional organelles is not as obvious as in epithelial cells. Also, there is considerable endothelial heterogeneity along the vascular tree. For example, tight junctions are well organized in arteries and arterioles, but less elaborate or loosely organized in veins or postcapillary venules (4). Finally, tight junctions are well developed in brain vessels, where they contribute to the blood-brain barrier, and less organized in more leaky vessels (88).

4. Endothelial Junctions (Complexus Adherens)

Endothelial cells do not form desmosomes but instead have specific endothelial junctions referred to as complexus adherens. This type of junction is linked to intermediate filaments and expresses VE-cadherin instead of desmosomallike proteins. When bound to desmoplakin, VE-cadherin only associates with intermediate filaments; when bound to plakoglobin, VE-cadherin can associate with either intermediate filaments or actin microfilaments. Junctional Adhesion Molecules and nectins support the formation of complexus adherens $(83,84)$. 
5. Immunoglobulin (IgG) Superfamily Adhesion Proteins

IgG superfamily of adhesion proteins are $\mathrm{Ca}^{2+}$-independent cell-cell adhesion molecules (CAMs) and consist of junctional adhesion molecules (JAMs) and Ig cell adhesion molecules (IgCAMs). JAMs are $\mathrm{Ca}^{2+}$-independent immunoglobulin (Ig)like cell-cell adhesion proteins, which localize to adherens, tight, and endothelial junctions. JAMs (-A, -B, -C, -D) are comprised of two extracellular Ig folds, a transmembrane domain and a short cytoplasmic tail. JAMs, except JAM-C, form cis-dimers and mediate both homotypic and heterotypic interactions. JAM-B is restricted to endothelial junctions, but JAM-A and -C also localize to immune cells. JAMs are important for the formation of tight junctions, leukocyte transepithelial migration, and platelet activation (3).

IgCAMs comprise a diverse group of adhesion receptors having one or several Ig folds (41). Nectins are novel members of the IgCAMs family. Nectins form cisdimers and trans-dimers on the cell membrane and bind to the PDZ-containing protein afadin (also called AF-6) inside the cell (92). Afadin binds ponsin, which in turn connects the complex to actin microfilaments through $\alpha$-catenin and vinculin. Nectins act cooperatively with cadherins in adherens junctions of epithelial cells (Ecadherin) and fibroblasts (N-cadherin) and initiate the formation of adherens and tight junctions (93). Therefore, the specific localization of these proteins at adherens junctions may depend on the cell type and/or they may play a more general role in the organization of both adherens and tight junctions.

Platelet endothelial cell-cell adhesion molecule (PECAM) is a transmembrane immunoglobulin concentrated at intercellular contacts but not specifically confined to adherens and tight junctions (64). PECAM mediates either homophilic or heterophilic cell-cell adhesion. Intracellular binding partners of PECAM include 
SHP-2 and $\beta$-catenin. SHP-2 may be involved in the Ras-mitogen-activated protein kinase (MAPK) pathway (34). PECAM may act similarly as cadherin through its binding to tyrosine phosphorylated $\beta$-catenin. Therefore, PECAM can modulate cadherin-mediated cell-cell interactions through its interaction with $\beta$-catenin and SHP-2. PECAM can also modulate cell adhesion with extracellular matrix and cell migration through its interaction with integrins (35).

B. IQGAP1 and Adherens Junctions

1. Introduction

Although the molecular mechanism for the regulation of cell-cell adhesion is largely unknown, IQGAP1 is now considered a key regulator. IQGAP1 (190 kDa) is a scaffolding protein that has multiple protein-interacting domains (Fig. 1). Via the calponin homology $(\mathrm{CH})$ domain at the N-terminus, IQGAP1 binds to filamentous actin and functions to cross-link and stabilize actin filaments $(2,57)$. Its IQ domain, a tandem repeat of four IQ motifs, mediates the association of IQGAP1 with calmodulin, myosin essential light chain, and $\mathrm{S} 100 \mathrm{~B}\left(\mathrm{a} \mathrm{Zn}^{2+}\right.$-and $\mathrm{Ca}^{2+}$-binding protein $)(53,104)$. Its G-protein binding domain (GRD) at the C-terminus binds to activated Rac and Cdc42, but not RhoA or Ras (20, 23). IQGAP1 interacts with guanosine 5-(3-O-thio) triphosphate (GTPrS) glutathione S-transferase (GST)-Cdc42 and GTP'S·GST-Rac1 but not with the GDP·GST-Cdc42, GDP·GST-Rac1, or GTPrS·GST-RhoA) (44). Through its C-terminal RasGAP domain, IQGAP1 binds directly to the adherens junction proteins, E-cadherin and $\beta$-catenin, and co-localizes with these proteins at cell-cell contacts in mouse L fibroblasts expressing E-cadherin (EL cells) and in Madin Darby Canine Kidney (MDCK) epithelial cells (45). Via the RasGAP domain, IQGAP1 also interacts with the microtubule-binding protein 
Figure 1

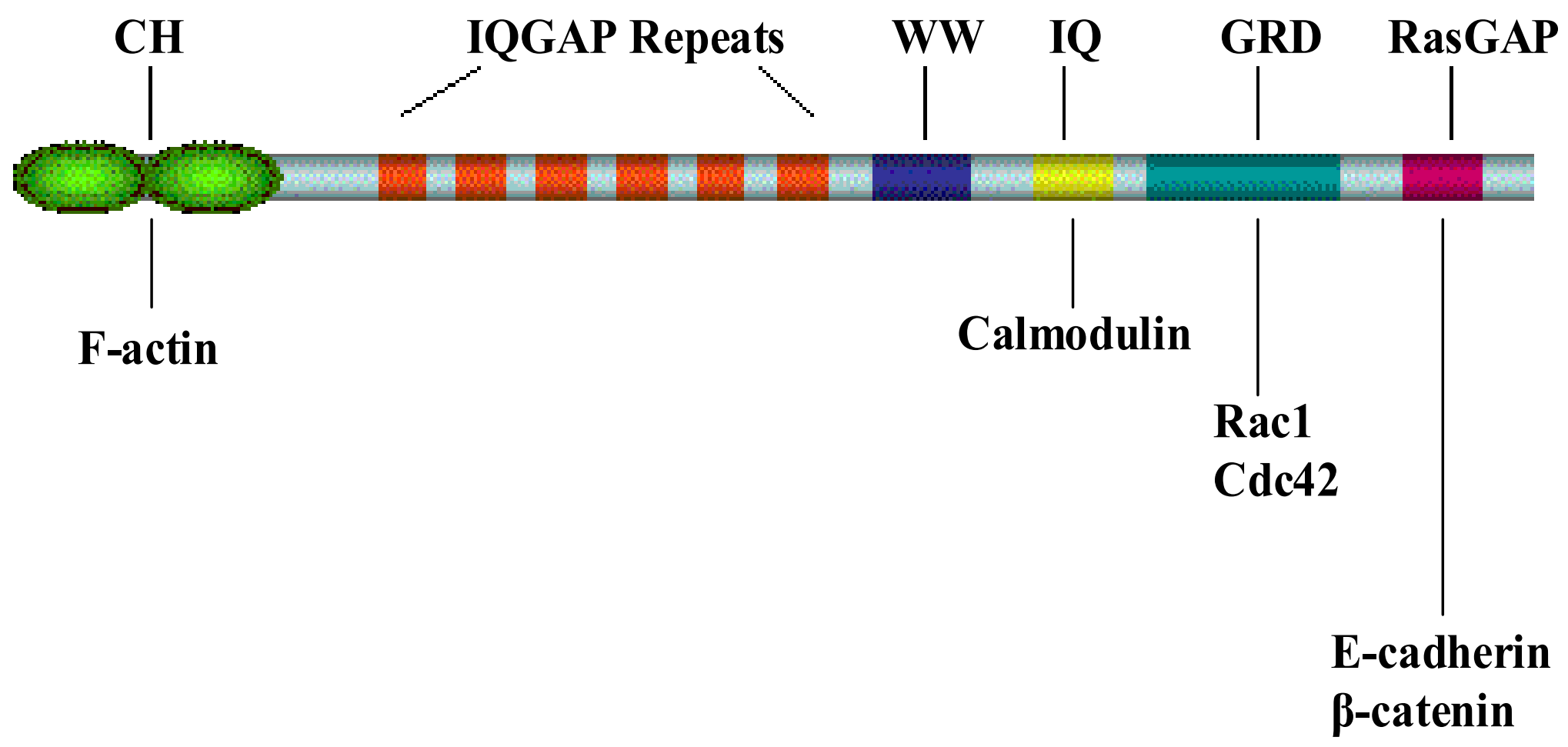


Figure 1. IQGAP1 structure and interacting proteins. IQGAP1 is a scaffolding protein that has multiple protein-interacting domains. Via the calponin homology $(\mathrm{CH})$ domain at the N-terminus, IQGAP1 binds to filamentous actin and functions to cross-link and stabilize actin filaments. Its IQ domain, a tandem repeat of four IQ motifs, mediates the association of IQGAP1 with calmodulin, myosin essential light chain, and $\mathrm{S} 100 \mathrm{~B}\left(\mathrm{Z}^{2+}\right.$-and $\mathrm{Ca}^{2+}$-binding protein). Its G-protein binding domain (GRD) at the C-terminus binds to activated Rac and Cdc42, but not RhoA or Ras. Through its C-terminal RasGAP domain, IQGAP1 binds directly to the adherens junction proteins, E-cadherin and $\beta$-catenin. Via the RasGAP domain, IQGAP1 also interacts with the microtubule-binding protein CLIP170 (cytoplasmic linker protein170). 
CLIP170 (cytoplasmic linker protein-170), capturing the growing microtubules at the leading edge of migrating fibroblasts, resulting in cell polarization (23).

2. IQGAP1 and Cell-Cell adhesion

Kaibuchi et al. (22) and others (52) have demonstrated that the relative content of IQGAP1 at the junction is important for the regulation of epithelial cell-cell adhesion through its interaction with $\beta$-catenin, Rac1, and Cdc42. Overexpressed IQGAP1 may inhibit E-cadherin-mediated cell-cell adhesion via its interaction with $\beta$ catenin, dissociating $\alpha$-catenin from the cadherin-catenin complex in EL cells (45). Activated Rac1 and Cdc42 may enhance E-cadherin-dependent cell adhesion by inhibiting the interaction of IQGAP1 with $\beta$-catenin (21) (Fig. 2). In contrast, treatment of MDCK cells with a phorbol ester reduces Rac1 activity, increases the association of IQGAP1 with $\beta$-catenin, and displaces $\alpha$-catenin from the adherens junction (22). In vivo, IQGAP1 knockout had hardly any effect on the cadherin-based adhesion of gastric cells in mice during embryogenesis, although it increased susceptibility to gastric hyperplasia (51). Therefore, the physiological processes in which IQGAP1 is involved needs to be determined. It would be interesting to demonstrate the phenotype of mice transgenically engineered to overepxress the IQGAP1 gene

3. IQGAP1 and Cell Migration

In general, directional cell migration begins with establishment of cell polarization, which includes membrane ruffling, lamellipodia, and filopodia at the leading edge, capture of microtubule plus-ends near the leading edge (which enables motor proteins such as dynein and kinesin to perform directed membrane trafficking), and reorientation of the microtubule-organizing center (MTOC) and the Golgi apparatus towards the direction of migration. The resultant asymmetric distribution of 
Figure 2

\section{Kaibuchi} Hypothesis

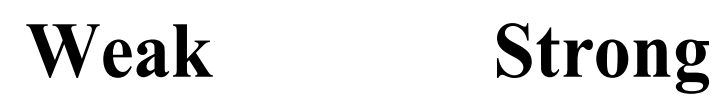

E-cadherin
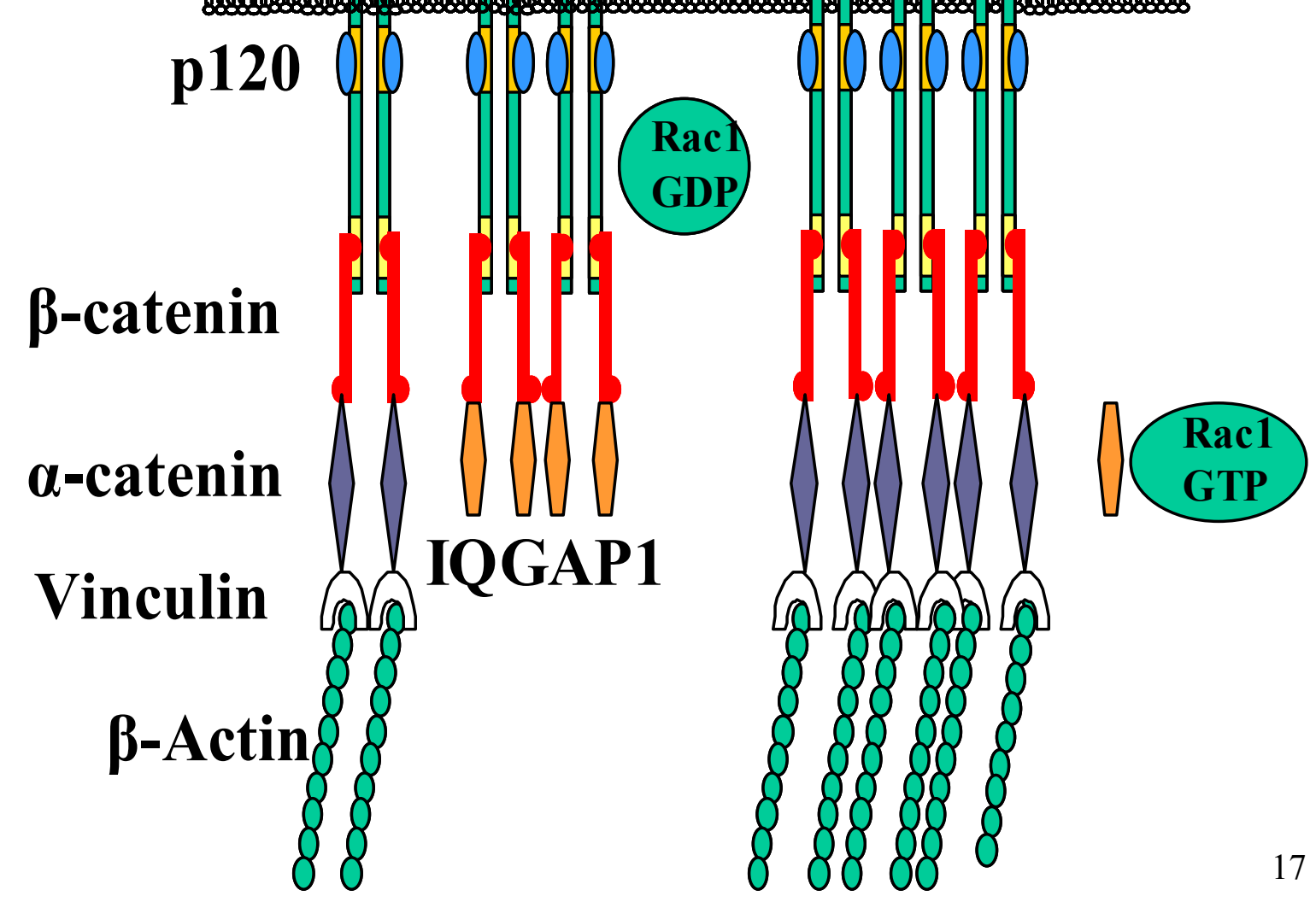
Figure 2. Kaibuchi's hypothesis: IQGAP1 inhibits cell-cell adhesion.

Overexpressed IQGAP1 inhibits E-cadherin-mediated cell-cell adhesion via its interaction with $\beta$-catenin, dissociating $\alpha$-catenin from the cadherin-catenin complex in EL cells. Activated Rac1 and Cdc42 may enhance E-cadherin-dependent cell adhesion by inhibiting the interaction of IQGAP1 with $\beta$-catenin. 
signaling molecules and the cytoskeleton facilitates the adherence of lamellipodia to the substratum via focal adhesions. After the forward attachments have been made, the bulk of the cytoplasm in the cell body flows forward. The trailing edge of the cell remains attached to the substratum until the focal adhesions at the rear are broken and the tail eventually detaches and retracts into the cell body. During this process, the reorganization of the actin cytoskeleton and microtubules is very important and must be well coordinated (26).

a. Rho GTPases, Cell Polarization and Directional Migration In migrating cells, Cdc42 and Rac1 are localized at the leading edge of the cells. The highest Cdc42 activity is at the tip of the leading edge, and the highest Rac1 activity is very close to the leading edge (38). Only Cdc42 is found at the Golgi apparatus, where it may regulate the secretory and endocytic transport of lipids and proteins to the leading edge (42). Rho A mainly localizes to the cytosol and is necessary and sufficient for lysophosphatidic acid-induced formation of detrypsinated tubulin (Glu-tubulin), a post-translational modified form of tubulin that accumulates in stable microtubules (10).

During cell polarization and migration, Rho GTPases capture and stabilize microtubules through their effectors near the cell cortex. mDia2, a RhoA effector, caps and stabilizes microtubules, and mDial induces longitudinal alignment of microtubules in parallel to F-actin bundles along the long axis of the cell $(37,75)$. Rac1 and Cdc42 can potentially stabilize microtubules through PAK, which phosphorylates and inactivates stathmin, a microtubule-destabilizing protein (13). Cdc42 can activate $\mathrm{PKC} \xi$, an atypical protein kinase C, through Par-6, leading to phosphorylation and inactivation of GSK-3 $\beta$ at the leading edge. Inactivation of GSK-3 $\beta$ removes the inhibition of APC, allowing it to stabilize microtubules at the 
leading edge $(17,18)$. APC can also interact with end-binding protein 1 (EB1), a member of plus-end-tracking proteins (+Tips) that localize to the growing microtubule plus end (17). As like other +Tips, such as the cytoplasmic linker protein 170 (CLIP-170) family and dynein-dynactin family, the EB1 family is necessary for sensing cortical capture sites.

b. IQGAP1, Cell Polarization and Directional Migration

Fukata et al. (2002) found that activated Cdc42/Rac1 complexes with IQGAP1 and CLIP-170, enhancing the interaction between IQGAP1 and CLIP-170, and recruiting green fluorescent protein (GFP)-CLIP-170 to the leading edge and the base of filopodia. Watanabe et al. (2004) also showed that IQGAP1 directly interacts with APC and both colocalize with Rac1 and Cdc42 at the leading edge. Therefore, IQGAP1 may promote cell polarization and migration by stabilizing both microfilaments and microtubules at the leading edge.

4. IQGAP1 and Distant Metastasis of Cancer Cells

In IQGAP1 knockout mice, a significant increase in late-onset gastric hyperplasia relative to wild-type animals of the same genetic background was observed (51). In human, gastric carcinoma is known to be associated with damage to a small region on chromsome 15, where the IQGAP1 gene is located. And four IQGAP1 mutations were found in multiple cases of highly invasive and metastatic diffuse type gastric carcinoma. IQGAP1 was also upregulated by gene amplification at $15 q 26$ in two cell lines established from diffuse types of gastric carcinomas, HSC39 and 40A (91). Similary, IQGAP1 overexpression was found in human colorectal carcinoma, particularly at the invasion front. Therefore, IQGAP1 is closely related to invasion and distant metastasis of some carcinomas, but the exact mechanism is still unknown. 
C. Sphingosine-1-Phosphate (S1P) and Cell-Cell Adhesion

1. Biosynthesis and Metabolism of S1P

Sphingosine-1-phosphate (S1P), a bioactive sphingolipid metabolite, is generated from the metabolism of sphingomyelin upon cellular activation.

Specifically, sphingomyelinase degrades sphigomyelin to ceramide, which is then degraded by ceramidase to sphingosine. Sphingosine kinase further converts sphingosine to S1P. Alternatively, ceramide can be synthesized de novo by fumonisin B1-sensitive ceramide synthase, which also contributes to S1P synthesis. Once formed, S1P is rapidly degraded by S1P phosphatase and S1P lyase (89). Since platelets have an abundance of sphingosine kinase and lack these S1P degradative enzymes, platelets may release $\mathrm{S} 1 \mathrm{P}$ in response to prothrombotic activation, increasing the S1P level from $100 \mathrm{nM}$ in plasma to $500 \mathrm{nM}$ or even $1,000 \mathrm{nM}$ in serum.

2. G Protein-Coupled Receptors (GPCRs) for S1P: EDG Family

$\mathrm{S} 1 \mathrm{P}$ acts as an extracellular mediator and an intracellular second messenger, binding to seven transmembrane GPCRs and intracellular receptors, respectively. GPCRs for S1P are five members of the EDG (or Endothelial Differentiation Gene) family: EDG-1/S1P1, EDG-5/S1P2, EDG-3/S1P3, EDG-6/S1P4, and EDG-8/S1P5. EDG-1 is a Gi-coupled receptor, through which S1P stimulates Rac1-induced cortical actin formation and enhances motility (23). The EDG-1 cDNA was originally isolated as a phorbol ester-induced immediate early transcript from vascular endothelial cells, and EDG-1 protein plays a role in endothelial cell differentiation and angiogenesis. EDG-5 is coupled to all G proteins, via which S1P induces stress fiber formation by activating Rho, and inhibits cell migration by decreasing Rac1 activity. And EDG-3 is coupled to $\mathrm{Gi}, \mathrm{Gq}$, and $\mathrm{G}_{12 / 13}$, via which S1P induces stress fiber 
formation by activating Rho, mediates neurite retraction and neuronal cell rounding, suppresses Bax expression and activates endothelial nitric oxide synthase (eNOS) and phosphatidylinositol 3-kinase (PI3K) (29).

As a second messenger, S1P can also promote cell proliferation and survival by mobilizing calcium, activating extracellular signal regulated kinase (ERK), andinhibiting c-Jun N-terminal kinase (JNK) activation. Thus, S1P can signal from outside the cell via S1P (EDG) receptors and from inside the cell upon activation of sphingosine kinase but can also be released from the cell and act on S1P receptors in an autocrine and/or paracrine manner (30).

3. S1P Enhances Endothelial Barrier Function

Vascular endothelial cells primarily express receptors for EDG-1 (S1P1) and EDG-3 (S1P3), but have little or no EDG-5 (S1P2) (55). Activation of EDG-1 and -3 promotes cell migration, vascular maturation, focal contact formation, and endothelial barrier function. Reduction in EDG-1 expression attenuates barrier enhancement induced by S1P, platelets, and platelet conditioned medium. In a mouse model of acute lung injury (ALI), S1P attenuates the formation of lung edema in vivo $(58,77)$. This effect of S1P on lung edema in vivo probably occurred via direct maintenance or enhancement of the endothelial barrier as S1P prevented the 6-fold increase in hydraulic conductivity induced by platelet-activating factor in venular microvessels of the rat mesentery (62). This inhibitory effect of S1P was reversible and involved the heterotrimeric G-protein, $G_{i}$.

S1P may affect the barrier function of the vascular endothelia by reorganizing the cytoskeleton, strengthening adherens junctions, and/or remodeling focal adhesions. To maintain an endothelial barrier, contractile forces, generated by the cytoskeleton, must be balanced by tethering forces generated by adherens junctions and focal 
adhesions. S1P treatment induces the formation of a cortical actin ring and a rapid redistribution of cortical actomyosin, phosphorylated myosin light chain (MLC), and myosin light chain kinase (MLCK). MLC phosphorylation may promote the interaction of myosin with actin filaments, stabilizing cortical cytoskeleton (25). S1P of physiologic concentration (less than 1-2 $\mu \mathrm{M}$ ) also activates Rac1 and Rho and induces lamellipodia formation, membrane ruffling, cortical actin ring formation, and cell spreading. Inhibition of Rac1 increases monolayer permeability and prevents the translocation of cortactin to the periphery, reducing actin polymerization (102). Rac1 also activates $\mathrm{p}^{21}$ activated kinase (PAK) subsequently phosphorylating LIM kinase and causing the phosphorylation and inactivation of cofilin, an actin-severing protein. Both PAK and cofilin translocated to the cell periphery after treatment with S1P (23). Expression of a dominant-negative PAK-1 or wild-type cofilin reduced the increase in cortical actin. The latter also blunted the increase in endothelial electrical resistance induced by S1P. These authors concluded that a thickened, cortical actin plays a prominent role in the enhanced endothelial barrier activity of S1P (23). Therefore, inactivation of cofilin via Rac1 to PAK signaling may be key to the activity of S1P. In confluent HUVECs, S1P also stimulates the localization of VE-cadherin and $\alpha-, \beta-$, and $\gamma$-catenins to sites of cell-cell contacts, forming functional adherens junctions within $1 \mathrm{~h}$ in one report (50) and within $30 \mathrm{~min}$ in another report (59). Dominant-negative Rac1 polypeptide prevented the S1P-induced localization of VEcadherin and $\beta$-catenin to intercellular junctions (50). S1P treatment also induces tyrosine phosphorylation of FAK, breaking down focal adhesion complexes, redistributing paxillin and focal adhesion kinase (FAK) to the periphery where they associate with the cortical actin ring (86). 
Together these findings suggest that S1P increases the barrier function of the vascular endothelia via a cell-signaling pathway involving the inhibitory $\mathrm{G}$ protein, Gi, and Rac1 and via targets of the cytoskeleton such as cofilin, MLC, and MLCK and of adherens junction proteins such as VE-cadherin and the catenins. 


\section{INTRODUCTION TO DISSERTATION STUDIES}

Vascular endothelium, as a semi-permeable barrier, restricts the passage of proteins from the blood to the extravascular compartment and also regulates many biological processes such as inflammation, white cell emigration, and angiogenesis. Disruption of the endothelial barrier leads to accumulation of fluid and macromolecules in the interstitial space, resulting in edema and dysfunction of tissues and organs. The junctional architecture between adjacent endothelial cells, comprised of adherens junctions as well as tight junctions, contributes significantly to the regulation of the endothelial barrier (4). The endothelial adherens junction, containing primarily vascular endothelial (VE)-cadherin and catenins, has been studied extensively. Modifications to VE-cadherin profoundly affect the integrity of the endothelial barrier. For example, antibodies directed toward the extracellular domain of VE-cadherin increased the permeability of endothelial cell monolayers (11) and the vascular permeability in heart and lungs of mice (12). Endothelial cells also contain tight junction proteins such as occludin, claudins, and $\mathrm{ZO}-1$, but the effects of these proteins on barrier function has been studied primarily in epithelial cells (4).

VE-cadherin is comprised of an extracellular domain, a transmembrane region, a juxtamembrane region, and a highly conserved cytoplasmic tail $(49,101)$. In the presence of $\mathrm{Ca}^{2+}$, extracellular domains of VE-cadherin of one cell bind to each other forming cis-dimers, and those of adjacent cells bind head-to-head forming transdimers. The cytoplasmic tail of VE-cadherin binds $\beta$-catenin or $\gamma$-catenin or plakoglobin, which in turn binds $\alpha$-catenin to form a cadherin-catenin complex that links to the actin cytoskeleton, although this latter linkage has recently been challenged $(16,109)$. A fourth catenin, p120, binds to the juxtamembrane region of 
VE-cadherin, inducing stabilization of VE-cadherin $(14,39,105)$ and cadherin clustering (111), although this latter notion is controversial (72).

IQGAP1 is a scaffolding protein that binds directly to the adherens junction proteins, E-cadherin and $\beta$-catenin, and co-localizes with these proteins at cell-cell contacts in mouse L fibroblasts expressing E-cadherin (EL cells) and in Madin Darby Canine Kidney (MDCK) epithelial cells (45). IQGAP1 also binds many other cellular proteins via its multiple protein-interacting domains. Via the calponin homology domain at the amino terminus, IQGAP1 binds to filamentous actin and functions to cross-link and stabilize actin filaments $(2,8,57)$. Its IQ domain mediates the association of IQGAP1 with calmodulin $(52,104)$ and its G-protein binding domain near the carboxy terminus binds to activated $\operatorname{Rac} 1$ and $\operatorname{Cdc} 42(21,22)$.

The involvement of IQGAP1 in the dynamic regulation of epithelial adherens junctions has been brought forth in a series of papers by Kaibuchi and co-workers (21, 22, 45, 71). These authors hypothesize that IQGAP1 overexpression inhibits Ecadherin-mediated epithelial cell-cell adhesion by dissociating $\beta$-catenin from $\alpha$ catenin, thus disconnecting the VE-cadherin/ $\beta$-catenin complex from the actin cytoskeleton. Furthermore, activated Rac1 and Cdc42 may prevent these effects by removing IQGAP1 from the complex $(22,45)$. The importance of the interaction of IQGAP1 with E-cadherin or VE-cadherin, however, has not been determined and is timely considering the recent papers by Yamada et al. (109) and Drees et al. (16). These authors concluded that $\alpha$-catenin does not bind simultaneously to the complex of E-cadherin $/ \beta$-catenin and to the actin cytoskeleton and that this purported linkage is more dynamic than originally thought.

In initial experiments, I determined by immunoprecipitation and immunofluorescence microscopy that IQGAP1 associated with the adherens junction 
proteins, VE- cadherin and the catenins, $\beta, \gamma, \alpha$, and p120, but not with the tight junction proteins, occludin, claudin-5, and ZO-1. To remove IQGAP1 from junctional complexes, I activated Rac1 by S1P treatment and examined the association of IQGAP1 with Rac1 and the presence of insoluble VE-cadherin and $\beta$ catenin at intercellular junctions. Also, I significantly reduced the protein level of IQGAP1 in human umbilical vein endothelial cells (HUVECs) by transfection of small interfering RNA (siRNA) and determined the effect on basal electrical resistance across cell monolayers by the measurement of electrical cell-substrate impedance sensing (ECIS). Since IQGAP1 associated only with adherens junction proteins and alterations in content of IQGAP1 have produced equivocal changes in Ecadherin or VE-cadherin in other cell types $(45,52,70)$, I assessed the protein levels of VE-cadherin and N-cadherin and the interactions of these two cadherins with the catenins, $\mathrm{p} 120, \beta, \gamma$, and $\alpha$, and with the insoluble cytoskeleton in IQGAP1 knockdown cells. To further determine the effect of IQGAP1 on the p120-VEcadherin association, a VE-cadherin- $\alpha$-catenin fusion protein lacking $\beta$-catenin binding sites was overexpressed in HUVECs and the distribution of IQGAP1 was detected by immunofluorescence microscopy. 


\section{MATERIALS AND METHODS}

Materials. Fetal bovine serum was purchased from Atlanta Biologicals (Norcross, GA), and gentamicin sulfate was from ICN Biomedicals, Inc (Aurora, OH). Newborn calf serum and bovine brain extract were from Cambrex Corporation (East Rutherford, NJ). Type I collagenase was from Worthington Biochemical Corporation (Lakewood, NJ). MDCK (Madin-Darby Canine Kidney) cells (Catalog No. CCL-34) were purchased from ATCC (Manassas, VA). Oligofectamine was from Invitrogen (Carlsbad, CA). Control (scrambled) siRNA (SC-37007), IQGAP1 siRNA (SC35700), and polyclonal antibodies to VE-cadherin, IQGAP1, and p120 were from Santa Cruz Biotechnology Inc (Santa Cruz, CA). Anti- $\beta$-actin monoclonal and anti- $\alpha-$ catenin polyclonal antibodies were from Alexis Biochemicals (San Diego, CA). Monoclonal antibodies directed against IQGAP1, Rac1, N-cadherin, and $\gamma$-catenin were from BD Biosciences (San Jose, CA). Polyclonal antibodies directed against human occludin and ZO-1 and a monoclonal antibody to human claudin-5 were from Zymed Laboratories (South San Francisco, CA). Anti-calmodulin and anti-IQGAP1 monoclonal (AF4) antibodies were from Upstate (Chicago, IL). Gold-coated ECIS electrodes were from Applied Biophysics (Troy, NY). Sphingosine-1-Phosphate (S1P) was from Avanti Polar Lipids, Inc. (Alabaster, AL). Peroxidase conjugated goat antimouse IgG, peroxidase conjugated goat anti-rabbit IgG, and peroxidase conjugated rabbit anti-goat IgG antibodies were from Chemicon International, Inc. (Temecula, CA). Alexa Fluor 488-labeled phalloidin, Alexa Fluor 594-labeled phalloidin, Alexa Fluor 488-labeled goat anti-rabbit IgG, and Alexa Fluor 594-labeled goat anti-mouse IgG were from Invitrogen Molecular Probes (Eugene, OR). Nitrocellulose membranes and ECL (enhanced chemiluminescence) Western Blotting detection 
reagents were from Amersham Biosciences (Buckinghamshire, England), and a miniProtean electrophoresis system was from Bio-Rad Laboratories (Hercules, CA). All other chemicals were from Sigma-Aldrich (St. Louis, MO).

Cell culture. HUVECs were isolated from fresh umbilical veins with $1 \mathrm{mg} / \mathrm{ml}$ of type I collagenase and serially passaged and maintained in MCDB-131 containing $20 \%(\mathrm{v} / \mathrm{v})$ newborn calf serum, $5 \%(\mathrm{v} / \mathrm{v})$ human serum, $7.5 \mu \mathrm{g} / \mathrm{ml}$ of endothelial cell growth supplement, $4.5 \mu \mathrm{g} / \mathrm{ml}$ of bovine brain extract, $20 \mu \mathrm{g} / \mathrm{ml}$ of porcine intestinal heparin, and $50 \mu \mathrm{g} / \mathrm{ml}$ of gentamicin sulfate. All experiments were performed on HUVECs passaged less than 8x. MDCK cells were cultured in Dulbecco's modified Eagles medium containing 10\% fetal bovine serum.

Transfection. IQGAP1 siRNA was transfected into HUVECs with oligofectamine. Briefly, HUVECs were seeded on $0.2 \%$ gelatin-coated 6-well culture dishes or on ECIS wells and grown to $50-80 \%$ confluence. IQGAP1 siRNA (0.27 to $0.40 \mu \mathrm{M})$ or scrambled siRNA was transfected into cells with oligofectamine in serum-free MCDB-131 for $4 \mathrm{~h}$. In most experiments, fresh HUVEC growth medium was added, and cells were placed in a humidified environment and maintained at $37^{\circ}$ $\mathrm{C}$ and $5 \% \mathrm{CO}_{2}$ for $2-3 \mathrm{~d}$. Although this transfection protocol resulted in a significant dilution of the oligofectamine, this lipd carrier was not removed by washing and there was concern about adverse effects of the remaining oligofectamine, especially if lipid micells were formed. Therefore, some of the experiments were repeated whereby cell monolayers were washed with culture medium after the initial $4 \mathrm{~h}$ - transfection period, then incubated in fresh culture medium for the remainder of the experiment. 
Assessment of endothelial barrier function by ECIS. Continuous measurement of electrical resistance across HUVEC monolayers with ECIS was used to assess changes in endothelial barrier function (24). HUVECs $(50,000-100,000$ cells) were seeded onto ECIS cultureware $\left(0.8 \mathrm{~cm}^{2} /\right.$ well) precoated with $0.2 \%$ gelatin for $24 \mathrm{~h}$. The measured electrical resistance is of those cells located on the small gold electrode $\left(5 \times 10^{-4} \mathrm{~cm}^{2}\right)$ in each of the wells. The culture medium was the electrolyte, and the small gold electrode, covered by confluent endothelial cells, and a larger gold counterelectrode $\left(\sim 2 \mathrm{~cm}^{2}\right)$ were connected to a phase-sensitive, lock-in amplifier. A $1-\mathrm{V}$, 4,000-Hz alternating current signal was supplied through a 1-M $\mathbf{\Omega}$ resistor to approximate a constant current source of $1 \mu \mathrm{A}$. The computer controlled the output of the amplifier and switched the measurements to different electrodes in each of two 8well arrays during the course of an experiment. The small size of the cell-seeded electrode is the critical feature of the system. When electrodes of $10^{-3} \mathrm{~cm}^{2}$ or smaller are used, the impedance at the small electrode dominates the system, allowing the morphology of the cells located at this interface to be assessed. Electrical resistance of the bare electrode is $\sim 2,000 \mathrm{ohms}$ and increases to 8,000 to $10,000 \mathrm{ohms}$ or greater when HUVECs have become confluent. Using a cell-covered electrical resistance of $7,000 \mathrm{ohms}$, corrected for the bare electrode, and the electrode surface area of $5 \times 10^{-4}$ $\mathrm{cm}^{2}$, the basal electrical resistance across the HUVEC cell monolayer is less than 5 ohms $\bullet \mathrm{cm}^{2}(98)$.

For experiments with S1P, HUVECs (100,000 cells) were seeded onto ECIS cultureware, then carefully washed $3 \mathrm{x}$ with MCDB-131 cell culture medium and incubated in MCDB-131 medium without serum for $2 \mathrm{~h}$. After these cells were treated with $1 \mu \mathrm{M} \mathrm{S1P}$ (once or $7 \mathrm{x}, 10 \mathrm{~min}$ each) or BSA as a control, transcellular electrical resistance was continuously measured for $2.5 \mathrm{~h}$. 
The method of transfection of IQGAP1 siRNA and measurement of electrical resistance were conducted in two different ways: either cells were seeded on 6-well culture dishes, transfected, re-seeded on ECIS wells, and monitored for changes in endothelial electrical resistance or cells were directly seeded on ECIS wells, transfected, and monitored for changes in electrical resistance. In the first method, oligofectamine was removed by the process of reseeding cells from the culture dish to the ECIS wells, as compared to the second protocol where oligofectamine, albeit in a diluted concentration, remained in the ECIS wells. One rationale for not changing the medium was not to disturb the continuous measurement of electrical resistance.

For the experiments with the infection of the adenoviral recombinant fusion protein, VE-cadherin- $\alpha$-catenin, HUVECs were grown on ECIS cultureware with 10 instead of 1 small gold electrode. In these 10-electrode wells, the electrical resistance signal is averaged among the 10 electrodes, and the baseline electrical resistance is lower than the 1-electrode wells.

Immunoprecipitation and immunoblotting. Cells were washed $2 \mathrm{x}$ in ice-cold phosphate buffered saline (PBS), lysed in buffer containing $30 \mathrm{mM} 4-(2-$ hydroxyethyl)-1-piperazineethanesulfonic acid (HEPES, pH 7.4), $50 \mathrm{mM} \mathrm{NaCl}, 1 \%$ Triton X-100, 10\% glycerol, $1 \mathrm{mM}$ ethylene glycol-bis(2-aminoethylether)N,N,N',N'-tetraacetic acid (EGTA), $1 \mathrm{mM}$ sodium vanadate, $10 \mathrm{mM}$ phenylmethanesulfonyl fluoride (PMSF), and $10 \mu \mathrm{g} / \mathrm{ml}$ of leupeptin. Samples were clarified by centrifugation at $14,000 \times \mathrm{g}$ for $5 \mathrm{~min}$ at $4^{\circ} \mathrm{C}$, and one-tenth of the whole cell lysate was saved for immunoblotting. Nine-tenth of the total cell lysate was immunoprecipitated overnight at $4^{\circ} \mathrm{C}$ with indicated antibodies. Immune complexes were collected with protein A- and G-Sepharose. After centrifugation, samples were 
washed $3 \mathrm{x}$ with lysis buffer. Proteins were resolved by sodium dodecyl sulfatepolyacrylamide gel electrophoresis (SDS-PAGE) and transferred to Nitrocellulose membrane using a mini-Protean electrophoresis system. Polyacrylamide gels $(7.5 \%)$ were used to detect IQGAP1, VE-cadherin, N-cadherin, the catenins, $\beta-, \gamma-, \alpha-$, p120 and ZO-1, and $12 \%$ gels were used to detect occludin and claudin-5. Blots were probed with indicated primary antibodies, followed by the appropriate horseradish peroxidase-conjugated secondary antibody, and developed by enhanced chemiluminescence.

Immunocytochemistry and confocal microscopy. HUVEC monolayers were fixed in 4\% formaldehyde in PBS for 15 min and permeabilized in PBS containing $0.18 \%$ Triton X-100 for 15 min. Fixed cells were stained with the indicated primary antibodies for $1 \mathrm{~h}$ and incubated with Alexa Fluor 488-labeled goat anti-rabbit IgG and/or Alexa Fluor 594-labeled goat anti-mouse IgG for $30 \mathrm{~min}$. Actin filaments were fluorescently stained with Alexa Fluor 488- or 594-labeled phalloidin. Images were generated by confocal laser scanning with a Zeiss LSM 510 upright confocal microscope. For the same group of images, the fluorescent signals were measured at emission wavelengths of 488 and $594 \mathrm{~nm}$ with the same pinhole (less than $1 \mu \mathrm{m}$ ) and the same detector gain, as well as the same amplifier offset. For all of the images, multitracking was used to prevent crosstalk of signals between channels, and the bandwidth of the emission filters was narrowed to avoid bleed-through from one channel to another.

Cytoskeleton preserving buffer containing $0.5 \%$ Triton X-100 (CSK-Tx buffer) was used to extract soluble proteins not linked to the cytoskeleton under near physiological conditions of ionic strength and $\mathrm{pH}$, and the Triton $\mathrm{X}$-100-insoluble proteins consistes of $65 \%$ of the total cell protein (19). Cells were first permeabilized 
in ice-cold CSK-Tx buffer (10 mM PIPES, pH 6.8, $3 \mathrm{mM} \mathrm{MgCl}_{2}, 100 \mathrm{mM} \mathrm{NaCl}$, and $300 \mathrm{mM}$ sucrose) for $1 \mathrm{~min}$ and then fixed in 4\% formaldehyde in PBS for $15 \mathrm{~min}$. Fixed cells were then processed as described above.

Infection. HUVECs were seeded onto precoated glass coverslips for $24 \mathrm{~h}$, then confluent HUVEC monolayers were infected with an adenoviral construct expressing green fluorescent protein (GFP)-labeled VE-cadherin- $\alpha$-catenin fusion protein for $48 \mathrm{~h}$. This adenoviral recombinant lacked the $\beta$-catenin binding site on VE-cadherin and on $\alpha$-catenin. Immunfluorescent staining was performed as described above.

Statistics. All values in the text are means \pm SE. Data on the quantification of immunoblots were analyzed with a single sample t-Test. Data on electrical resistance were analyzed with a 2-way analysis of variance with repeated measures. Differences between treatments at specific time points were further analyzed with a Bonferroni post-test. Significance was set at $\mathrm{P}<0.05$. 


\section{RESULTS}

S1P rapidly increased the electrical resistance across HUVEC monolayers.

S1P has been shown previously to enhance the barrier function of endothelial monolayers, as assessed by an increase in electrical resistance (25). I initially confirmed this result by the measurement of transcellular electrical resisatance using ECIS. After treatment with various doses of S1P, electrical resistance across HUVEC monolayers increased rapidly, peaked at $10 \mathrm{~min}$, and gradually came back to the baseline level after $1 \mathrm{~h}$. Electrical resistance across cell monolayers treated with the vehicle BSA did not change (Fig. 3A).

Increasing or decreasing the dosage of $\operatorname{S1P}(0.1 \mu \mathrm{M}-10 \mu \mathrm{M})$ from $1 \mu \mathrm{M}$ did not change the response pattern, which suggests that the S1P response is not dose- or time-dependent. Since S1P can be rapidly degraded by S1P phosphatase and S1P lyase, we also administered $1 \mu \mathrm{M}$ S1P $7 \mathrm{x}$ every $10 \mathrm{~min}$ for $1 \mathrm{~h}$ to maximize the downstream effects of S1P. The repeated treatments of S1P every 10 min maintained the peak resistance for $1 \mathrm{~h}$. Once the S1P treatment was stopped, however, electrical resistance gradually decreased to the baseline level after $1 \mathrm{~h}$. Electrical resistance across cell monolayers treated with BSA (7x, 10 min each) was not significantly changed (Fig. 3B).

S1P increased insoluble VE-cadherin and insoluble $\beta$-catenin at intercellular junctions in confluent cell monolayers.

One potential mechanism for the S1P-induced increase in endothelial electrical resistance is an increase in homophilic VE-cadherin binding. To look at this possible effect of S1P on the adherens junctions, cytoskeleton preserving buffer containing 
Figure 3
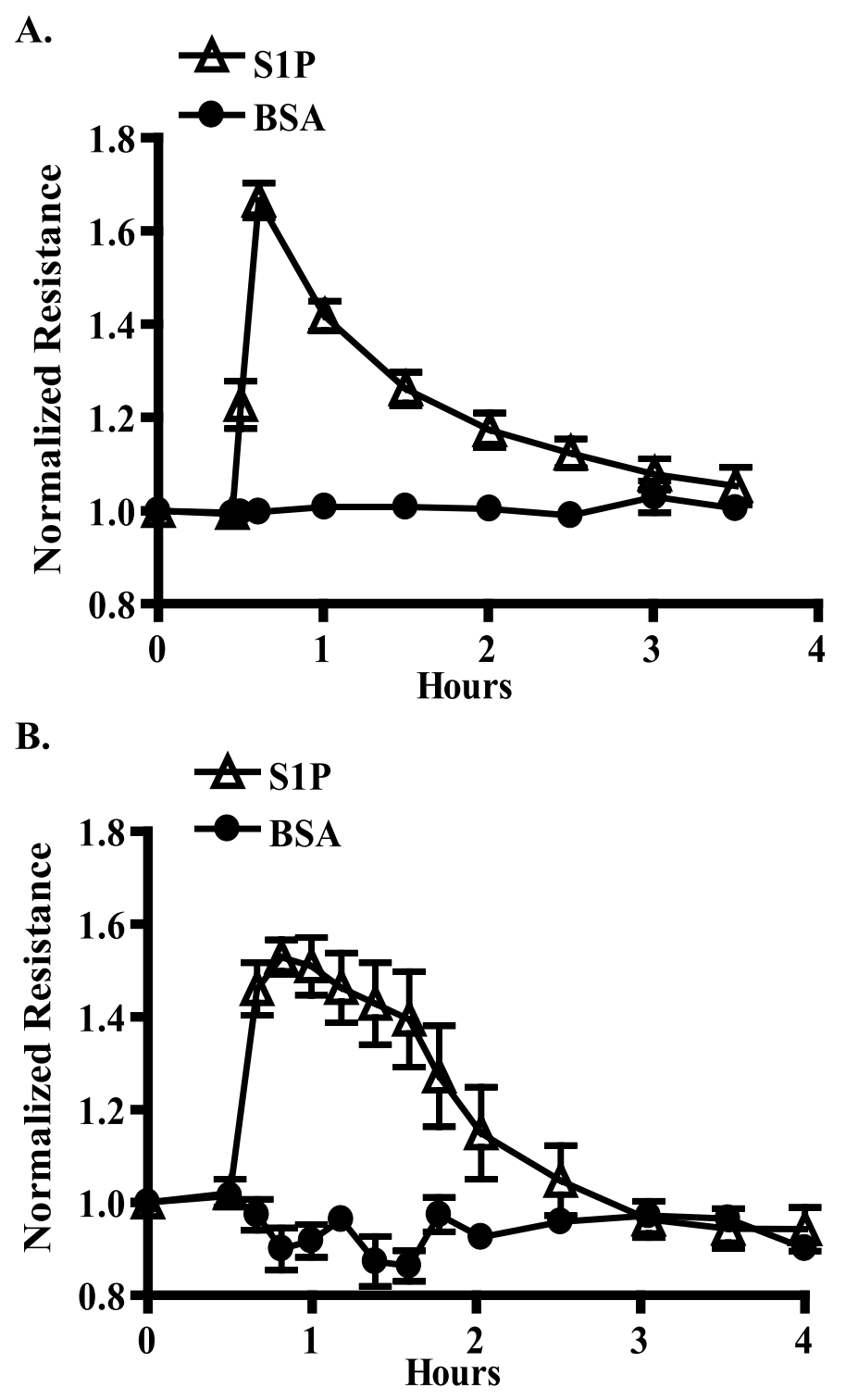
Figure 3. S1P rapidly increased transcellular electrical resistance. HUVEC monolayers grown on ECIS cultureware $\left(0.8 \mathrm{~cm}^{2} /\right.$ well $)$ were carefully washed $3 \mathrm{x}$ with MCDB-131 culture medium and incubated in MCDB-131 medium without serum for $2 \mathrm{~h}$. After these cells were treated with $1 \mu \mathrm{M} \mathrm{S1P}$ (one or $7 \mathrm{x}, 10$ min each) or BSA as a control, transcellular electrical resistance was continuously measured for $2.5 \mathrm{~h}$. A) After S1P treatment, the electrical resistance across HUVEC monolayers increased rapidly, peaked at $10 \mathrm{~min}$, and gradually came back to baseline value after $1 \mathrm{~h}$. Electrical resistance across control cell monolayers treated with BSA did not change $(n=8)$. B) Repeated S1P treatments $(7 x)$ every 10 min maintained the peak resistance for $1 \mathrm{~h}$. Once the S1P treatment was stopped, the electrical resistance gradually came back to the baseline value after $1 \mathrm{~h}$. The resistance across control cell monolayers treated with BSA was not significantly changed $(n=6)$. 
0.5\% Triton X-100 (CSK-Tx buffer) was used to extract soluble proteins not linked to the cytoskeleton, as previously described by Nagafuchi and Takeichi (65). After the challenge of Triton X-100, some of the VE-cadherin and $\beta$-catenin, presumably the soluble proteins, were removed from cell-cell contacts, but insoluble VE-cadherin and $\beta$-catenin, defined as being bound to the actin cytoskeleton and forming strong cellcell adhesions, remained at intercellular junctions. Within 10 min of S1P treatment, more insoluble VE-cadherin and $\beta$-catenin were localized at intercellular junctions as compared to the BSA control treatment (Fig. 4A), which suggests that S1P rapidly increased the interaction of the VE-cadherin/ $\beta$-catenin complex to the insoluble cytoskeleton and possibly also increased the amount of VE-cadherin and $\beta$-catenin at intercellular junctions. Furthermore, S1P also prevented the formation of gaps between cells, which indicates a stronger cell-cell adhesion (Fig. 4B).

S1P translocated Rac1 to the periphery of cells and increased the association of Rac1 with IQGAP1.

Rac1 has been implicated in tightening of the adherens contacts (20), and S1P is known to increase the activity of Rac1. Immunocytochemistry studies showed that S1P treatment translocated Rac1 from the cytoplasm to the cell periphery (Fig. 5B). Previous studies by Kaibuchi and co-workers (21) have demonstrated in epithelial cells that active Rac1 interacts with IQGAP1. To determine if Rac1 activated by S1P interacts with IQGAP1 in endothelial cells, HUVECs were seeded on 6-well dishes for $24 \mathrm{~h}$ and treated with BSA or $1 \mu \mathrm{M} \mathrm{S1P}$ for $10 \mathrm{~min}$. Cells were lysed in immunoprecipitation buffer and one-tenth of the whole cell lysate was saved for immunoblotting. The rest of the cell lysate was immunoprecipitated for IQGAP1 or IgG as a control, and then immunoblotted for Rac1. Association of IQGAP1 with 
Figure 4

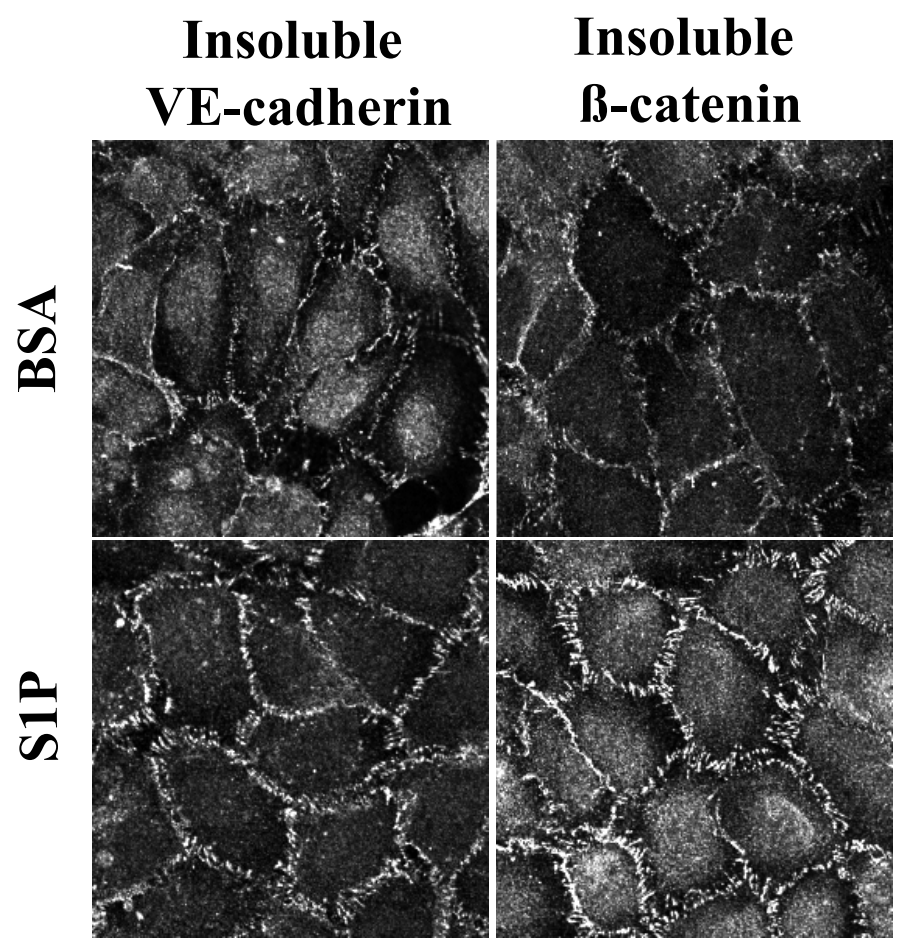


Figure 4. S1P increased insoluble VE-cadherin and insoluble $\beta$-catenin at intercellular junctions. Confluent HUVEC monolayers grown on glass coverslips were treated with $1 \mu \mathrm{M}$ S1P for 10 min or with BSA as a control. cells were permeabilized first (CSK-Tx) with cytoskeleton preserving buffer containing $0.5 \%$ Triton X-100 to extract soluble proteins before application of primary antibodies to VE-cadherin and $\beta$-catenin. After S1P treatment, insoluble VE-cadherin and $\beta$ catenin were increased as compared to BSA treatment. Magnification bar $=10 \mu \mathrm{m}$. 
Figure 5

A.

IP: IQGAP1

IB: Rac1

Cell Lysated

IB: Rac1

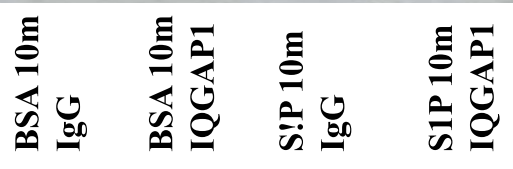

B.

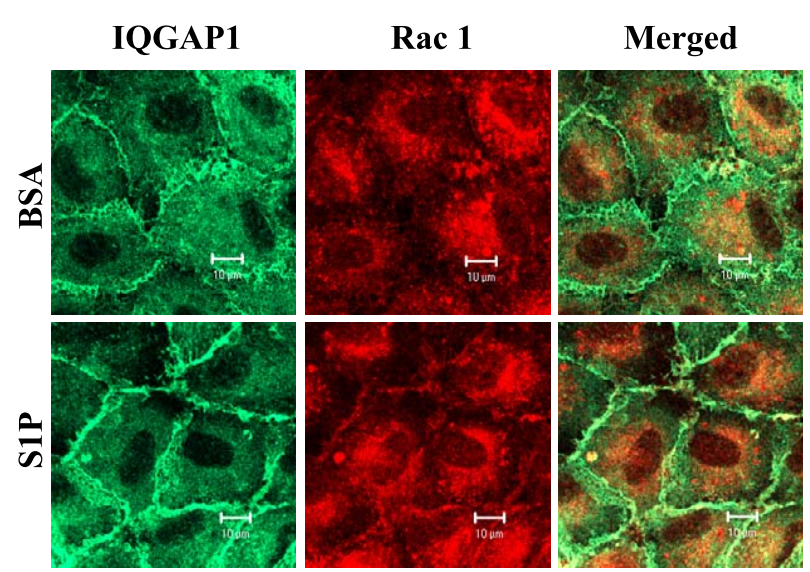


Figure 5. S1P increased IQGAP1 association with Rac1. A) HUVECs were lysed in immunoprecipitation buffer and one-tenth of the whole cell lysate was saved for immunoblotting. The rest of the cell lysate was immunoprecipitated for IQGAP1 or IgG as a control, and then immunoblotted for Rac1. Association of IQGAP1 with Rac1 was dramatically increased at 10 min after S1P treatment, and the protein level of Rac1 in each group of cells was similar. B) Cells were fixed and incubated with anti-IQGAP1 polyclonal and anti-Rac1 monoclonal antibody, which were visualized, respectively, with Alexa Fluor 488-labeled goat anti-rabbit IgG (green) and Alexa Fluor 594-labeled goat anti-mouse IgG (red). S1P induced the translocation of Rac1 to intercellular junctions, where Rac1 colocalized with IQGAP1. Magnification bar $=10 \mu \mathrm{m}$. 
Rac1 was increased nearly 4 fold within 10 min of S1P treatment (Fig. 5A). Immunocytochemistry studies showed that S1P induced co-localization of Rac1 and IQGAP1 at the cell periphery, which also suggests that S1P treatment increased the association of Rac1 with IQGAP1.

IQGAP1 colocalizes with Rac1 at membrane ruffles and in the cytoplasm of subconfluent cells, and complexes with calmodulin in the cytoplasm of HUVECs.

In subconfluent cells, IQGAP1 and Rac1 colocalized in the cytoplasm and at the membrane ruffles of untreated cells (Fig. 6). For both subconfluent and confluent cells, IQGAP1 colocalized with calmodulin in the cytoplasm but not at the periphery of cells (Fig. 7B). Co-immunoprecipitaton showed that calmodulin specifically complexed with IQGAP1 in HUVECs (Fig. 7A).

Insoluble IQGAP1 colocalizes with actin filaments at leading edges of subconfluent cells.

In subconfluent cells, IQGAP1 colocalized with actin filaments (phalloidin stained) at the membrane ruffles of cell leading edges (Fig. 8A). Triton extraction did not remove IQGAP1 at the membrane ruffles, which suggested that IQGAP1 at the leading edge of the cell is insoluble and bound to the cytoskeleton (Fig. 8B).

Interaction of IQGAP1 with VE-cadherin and catenins at cell-cell contacts.

IQGAP1 associates with E-cadherin and catenins in epithelial cell, so I initially determined by immunoprecipitation and immunofluoresence microscopy if IQGAP1 associates with proteins of the adherens junction in HUVECs. Control cell lysates were incubated with an antibody to IQGAP1 or IgG, the latter to determine 
Figure 6

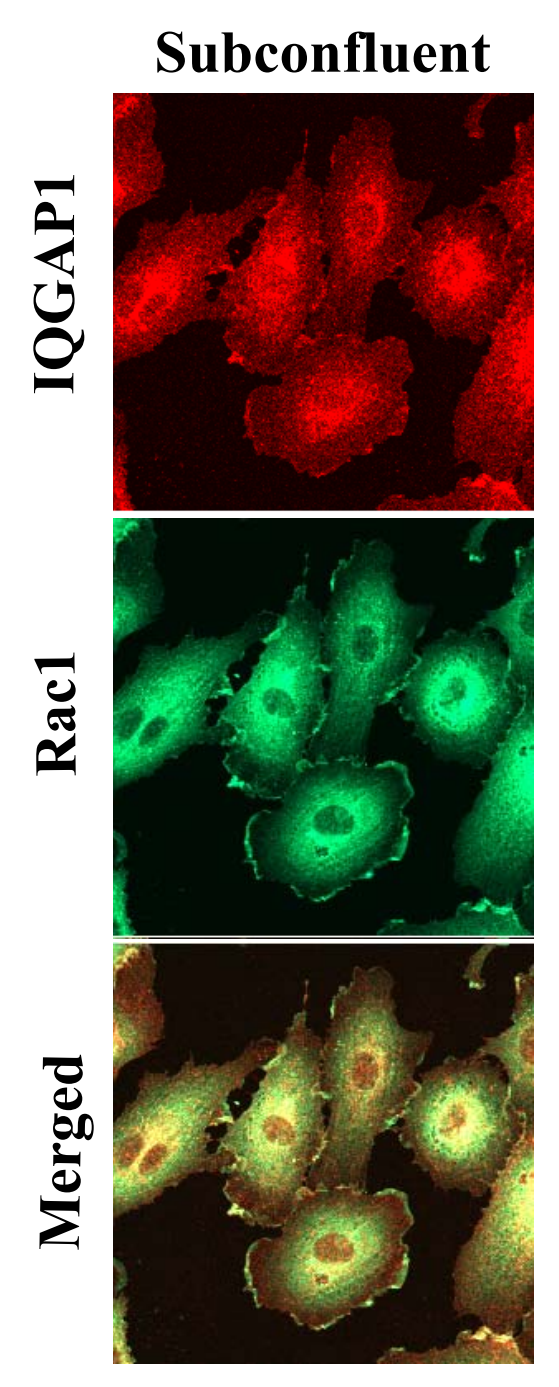


Figure 6. IQGAP1 colocalized with Rac1 at membrane ruffles and in the cytoplasm in subconfluent monolayers. Subconfluent cell monolayers were fixed and stained with anti-IQGAP1 polyclonal and anti-Rac1 monoclonal antibodies, which were visualized, respectively, with Alexa Fluor 488-labeled goat anti-rabbit IgG (green) and Alexa Fluor 594-labeled goat anti-mouse IgG (red). IQGAP1 colocalized with Rac1 at both membrane ruffles and in the cytoplasm of the subconfluent cells. Magnification bar $=10 \mu \mathrm{m}$. 
Figure 7

A.

Calmodulin

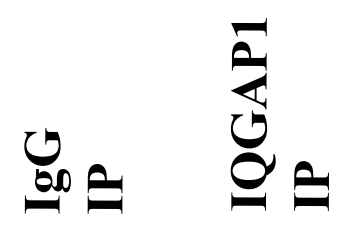

B.

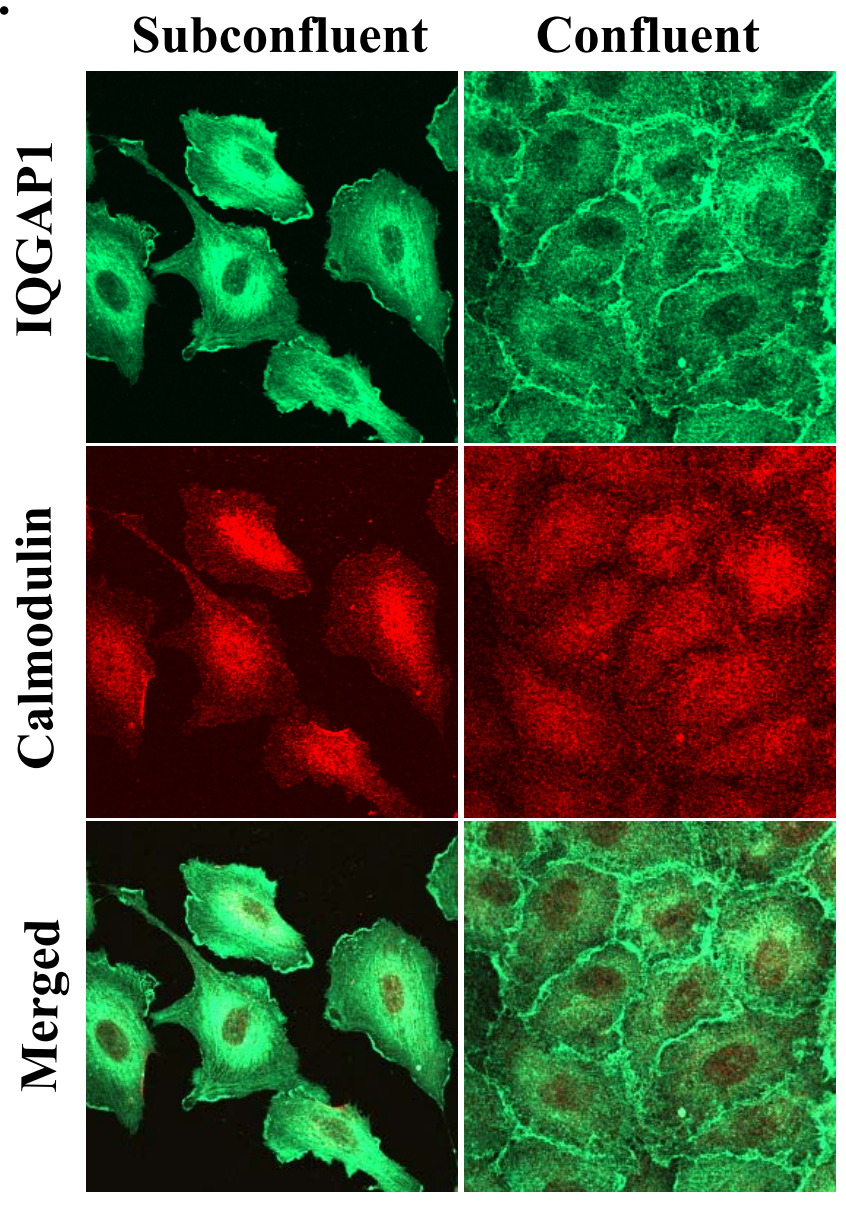


Figure 7. IQGAP1 complexed with calmodulin in the cytoplasm. A) HUVEC cell lysate was immunoprecipitated for IQGAP1 or IgG as a control, and then immunoblotted for calmodulin. IQGAP1 specifically associated with calmodulin but not the IgG control. B) Both confluent and subconfluent cells were fixed and incubated with anti-IQGAP1 polyclonal and anti-calmodulin monoclonal antibody, which were visualized, respectively, with Alexa Fluor 488-labeled goat anti-rabbit IgG (green) and Alexa Fluor 594-labeled goat anti-mouse IgG (red). For both subconfluent and confluent cells, IQGAP1 colocalized with calmodulin in the cytoplasm but not at the periphery of cells. Magnification bar $=10 \mu \mathrm{m}$. 
Figure 8

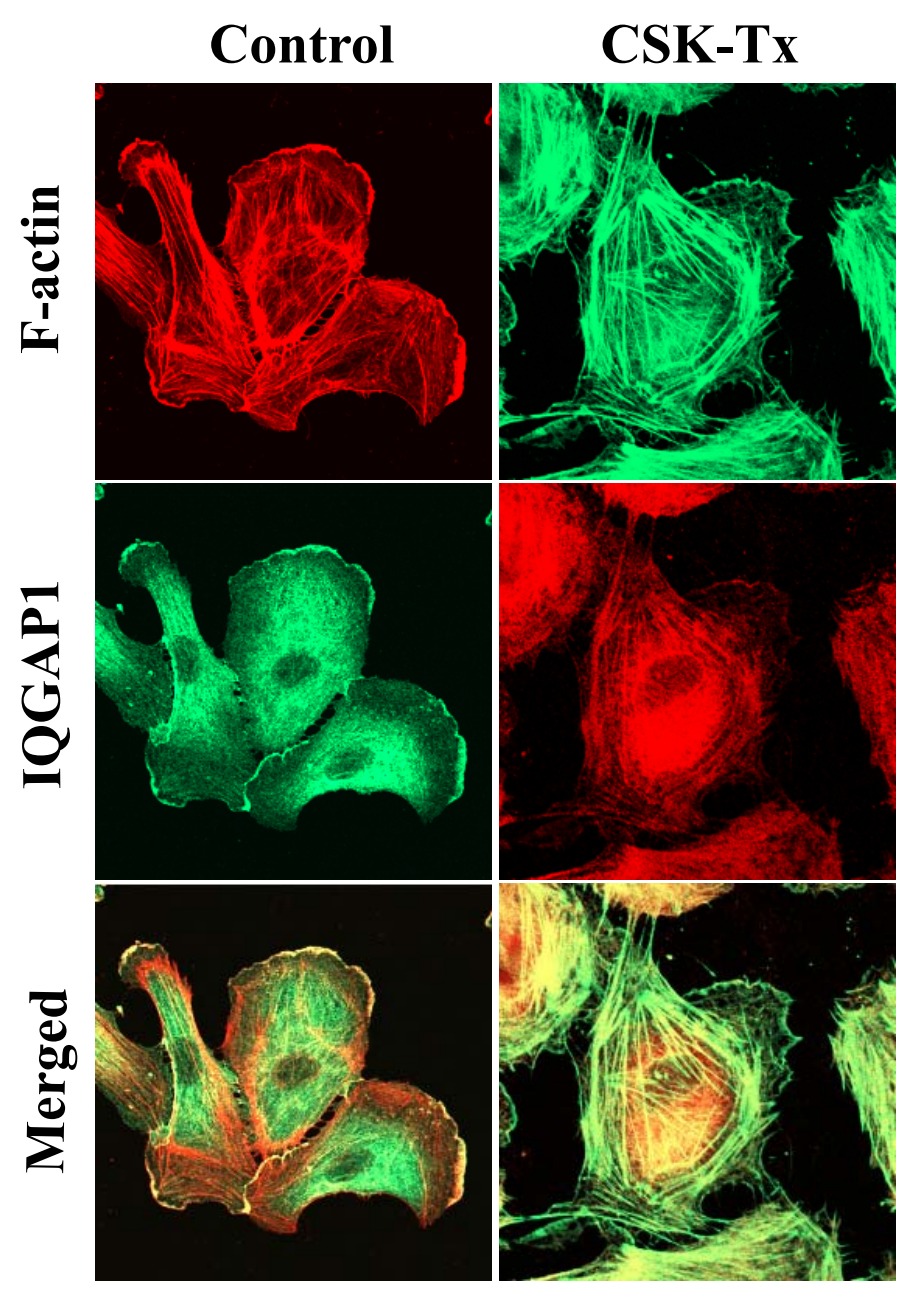


Figure 8. Insoluble IQGAP1 colocalized with actin filaments at membrane ruffles of subconfluent cell monolayers. Subconfluent HUVEC monolayers grown on glass coverslips were fixed first (Control) or permeabilized first (CSK-Tx) with cytoskeleton preserving buffer containing $0.5 \%$ Triton X-100 to extract soluble proteins before application of an anti-IQGAP1 antibody and phalloidin. In subconfluent cells, IQGAP1 colocalized with actin filaments (phalloidin stained) at the membrane ruffles of the leading edges of cells. IQGAP1 at the membrane ruffles was Triton-insoluble. Magnification bar $=10 \mu \mathrm{m}$. 
antibody specificity. Immunoprecipitates were resolved by SDS-PAGE and probed with antibodies to VE cadherin and the catenins, $\beta, \gamma, \alpha$, and p120. These proteins formed specific complexes with IQGAP1 in HUVEC monolayers (Fig. 9 A-E). Localization of IQGAP1 in confluent endothelial cell monolayers was also viewed by immunofluorescence microscopy following co-incubation with primary antibodies to IQGAP1 and VE-cadherin, or one of the catenins, $\beta, \gamma$, $\alpha$, or p120 (Fig. 9 F-J), or calmodulin, or Rac1. IQGAP1 was localized in the cytoplasm and at cell-cell contacts (Fig. 9, IQGAP1). In the cytoplasm, IQGAP1 was evenly distributed and partially colocalized with Rac1 and calmodulin (Fig. 5,7). At the cell periphery, IQGAP1 colocalized with VE-cadherin and the catenins (Fig. 9 F-J, Merged).

IQGAP1 did not complex with the tight junction proteins, occludin, claudin-5, and $\mathrm{ZO}-1$.

Since there are no reports of the association of IQGAP1 with tight junction proteins, I measured the protein levels of occludin, claudin-5, and ZO-1 in HUVECs and MDCK cells by immunoblotting, localized these proteins in the cells by immunofluorescence microscopy, and finally determined if these proteins associated with IQGAP1 in HUVECs by immunoprecipitation. Low protein levels of occludin and ZO-1 were present in HUVECs as compared with MDCK cells (Fig. 10 A, B). The protein level of claudin-5, an endothelial-specific member of the claudin family, was also low in HUVECs (Fig. 10 A, B). Compared to the immunofluorescent staining of IQGAP1, staining of occludin was very weak. Both claudin-5 and ZO-1 localized at intercellular junctions, but neither protein associated with IQGAP1, as depicted by immunoprecipitation or immunofluorescence microscopy (Fig. 10C).

Junctional IQGAP1 was detergent extractable. 


\section{Figure 9}

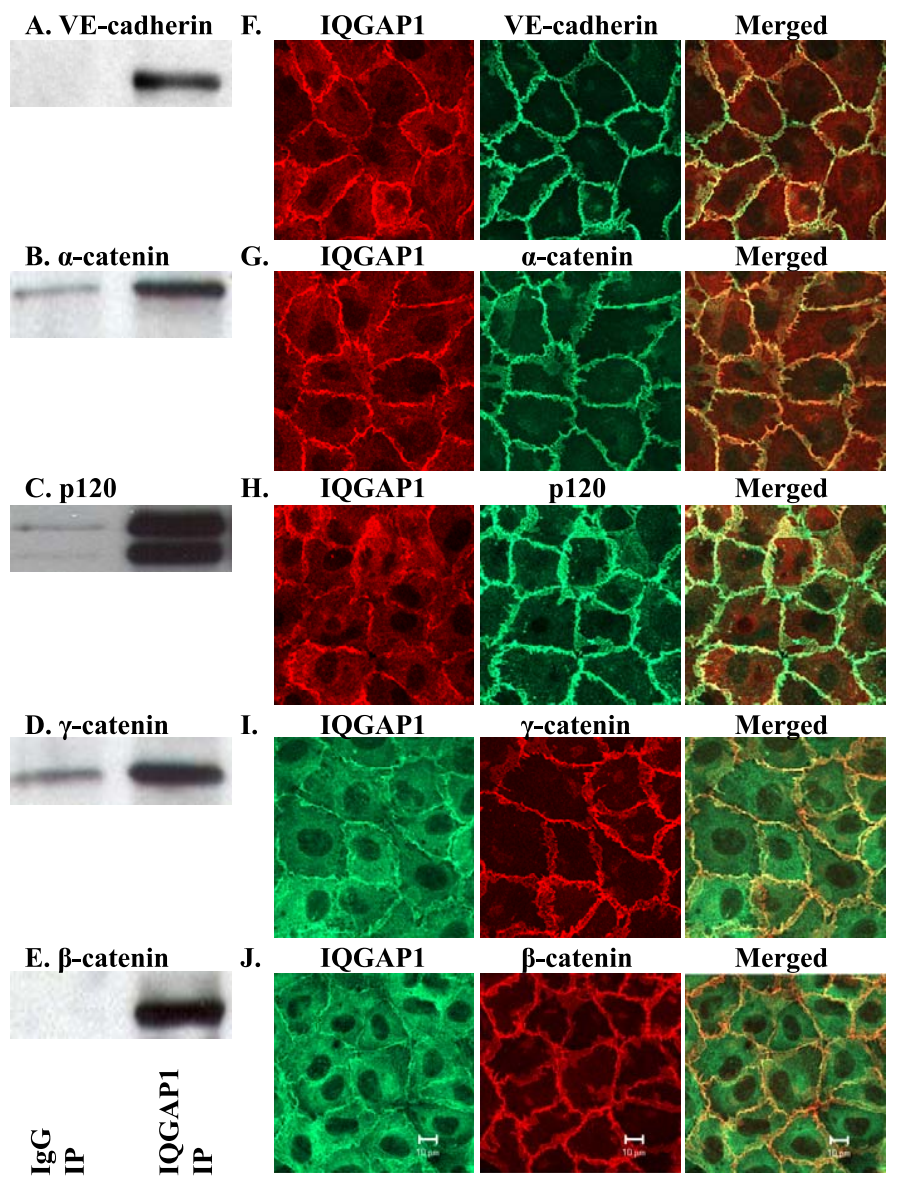


Figure 9. Interaction of IQGAP1 with VE-cadherin and catenins, $\beta, \gamma$, $\alpha$, and p120. HUVEC lysates were immunoprecipitated with antibodies to IQGAP1 or IgG. A-E) Representative immunoblots from three independent experiments demonstrated that IQGAP1 associates with VE-cadherin and catenins, $\beta, \gamma, \alpha$, and p120. F-J) Confluent HUVEC monolayers were processed for immunofluorescence microscopy using monoclonal antibodies visualized with Alexa Fluor 594-labeled goat anti-mouse IgG (red) or polyclonal antibodies visualized with Alexa Fluor 488-labeled goat antirabbit IgG (green). Note co-localization of IQGAP1 with VE-cadherin and all four catenins (Merged). Magnification bars $=10 \mu \mathrm{m}$. 


\section{Figure 10}

A.

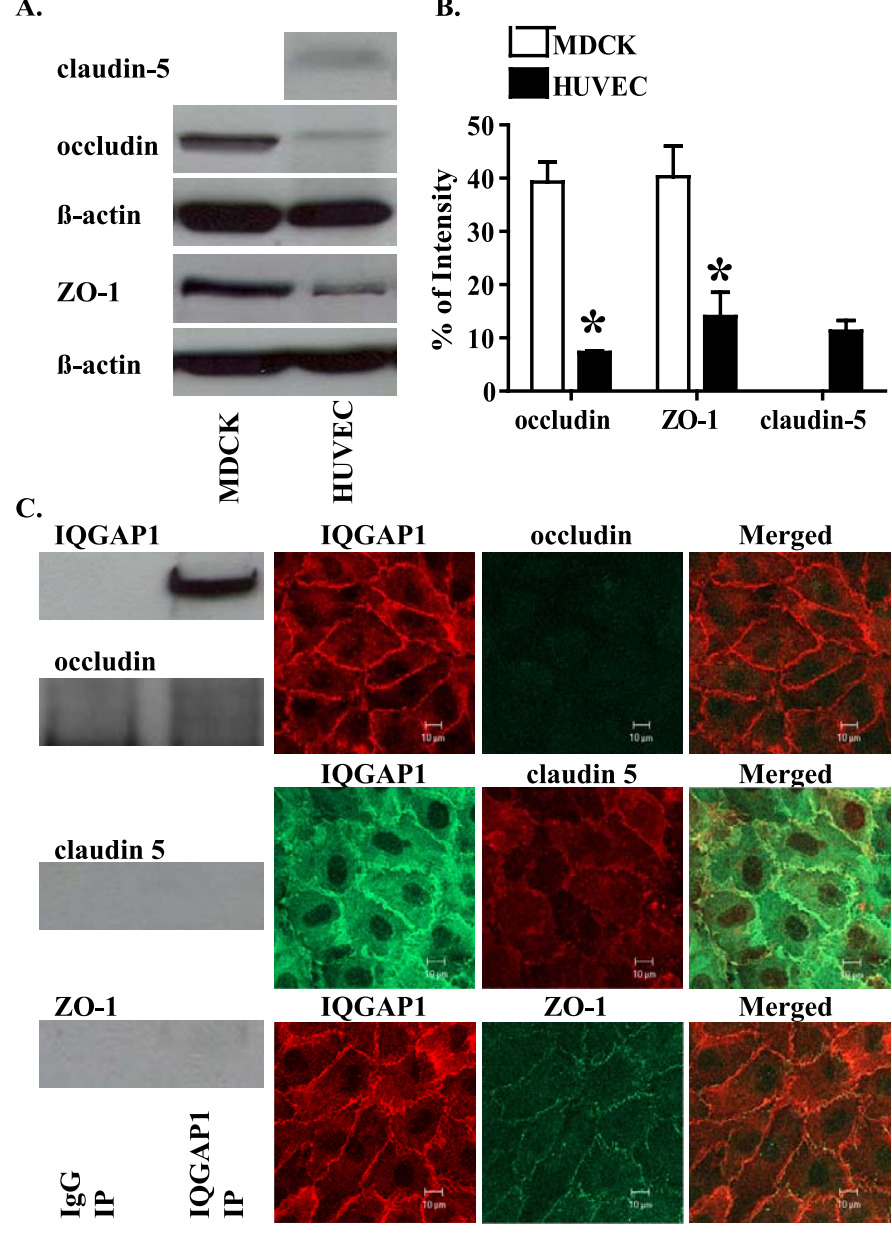




\section{Figure 10. IQGAP1 did not complex with tight junction proteins, occludin,}

claudin-5, and ZO-1. A, B) MDCK and HUVEC lysates were probed with antibodies to occludin and ZO-1. Representative immunoblots (A) and quantification after normalization to $\beta$-actin of four independent immunoblots (B) demonstrated that protein levels of occludin and ZO-1 were low in HUVECs, as compared to MDCK cells. C) HUVEC lysates were immunoprecipitated with antibodies to IQGAP1 or IgG and immunoblotted with antibodies to occludin, claudin-5, and ZO-1. Representative immunoblots from four independent experiments demonstrated that IQGAP1 did not associate with occludin, claudin-5, and ZO-1 in HUVECs. Confluent HUVEC monolayers were also processed for immunofluorescence microscopy using monoclonal antibodies visualized with Alexa Fluor 594-labeled goat anti-mouse IgG (red) or polyclonal antibodies visualized with Alexa Fluor 488-labeled goat anti-rabbit IgG (green). Note that claudin-5 and ZO-1 were observed at intercellular junctions, whereas occludin staining was weak as compared to IQGAP1 staining. Magnification bars $=10 \mu \mathrm{m}$. 
To determine whether the IQGAP1 observed at intercellular junctions complexes with adherens junction proteins associated with the insoluble cytoskeleton, HUVEC monolayers were permeabilized first with CSK-Tx buffer to remove soluble proteins and then fixed with 4\% paraformaldehyde. In control cells, both IQGAP1 and VE-cadherin were co-localized at cell-cell contacts (Fig. 11A, Control). After removal of soluble proteins by permeabilization with Triton X-100, most of the IQGAP1 was absent from intercellular junctions (Fig. 11A, CSK-Tx) and no longer co-localized with insoluble (cytoskeletal-associated) VE-cadherin (Fig. 11A, CSK-Tx) or $\beta$-catenin. A few strands of IQGAP1 at the cell periphery (Fig. 11A, IQGAP1 and CSK-Tx) were resistant to detergent extraction. Junctional IQGAP1 did not colocalize with the cortical actin ring in control cells. But in Triton-treated cells, most of the junctional IQGAP1 was extracted, and the remaining insoluble IQGAP1 colocalized with the peripheral ring of actin just interior to the cell membrane (Fig. 12). Reduction of IQGAP1 by siRNA.

HUVECs were seeded on 6-well dishes and transfected with IQGAP1 siRNA or scrambled siRNA by using oligofectamine. After $48 \mathrm{~h}$ of transfection with IQGAP1 siRNA, the protein level of IQGAP1 was reduced by 75\% (Fig. 13 A and B). Reduction of IQGAP1 by siRNA was also observed by immunofluorescence microscopy with an anti-IQGAP1 polyclonal antibody. HUVECs were transfected with IQGAP1 siRNA or scrambled siRNA in 6-well dishes. After 48 h, cells were trypsinized and reseeded onto precoated glass coverslips for another $24 \mathrm{~h}$. IQGAP1 siRNA, as compared with scrambled siRNA, dramatically reduced the immunofluorescent staining of IQGAP1 (Fig. 13C). The protein level of IQGAP1 was also reduced at 24 and $72 \mathrm{~h}$ after transfection with IQGAP1 siRNA (Fig. 14A). 
Figure 11

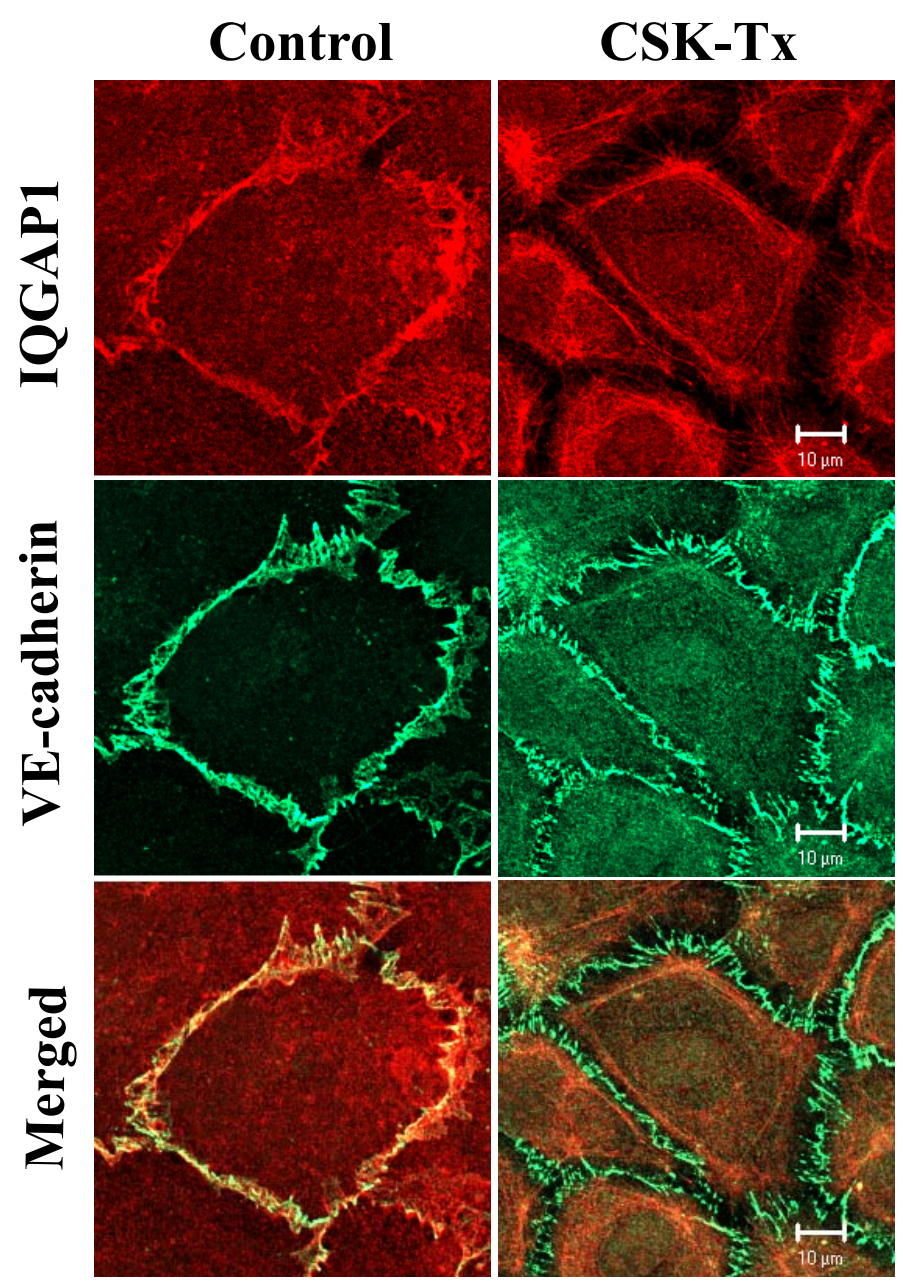


Figure 11. IQGAP1 was Triton-soluble at intercellular junctions. Confluent HUVEC monolayers grown on glass coverslips were fixed first (Control) or permeabilized first (CSK-Tx) with cytoskeleton preserving buffer containing 0.5\% Triton X-100 to extract soluble proteins before application of primary antibodies to IQGAP1 and VE-cadherin. Junctional IQGAP1 was sensitive to Tritonpermeabilization, whereas VE-cadherin was more resistant (CSK-Tx versus Control). Note co-localization (Merged) of IQGAP1 and VE-cadherin in Control column but not in CSK-Tx column. Magnification bars $=10 \mu \mathrm{m}$. 
Figure 12

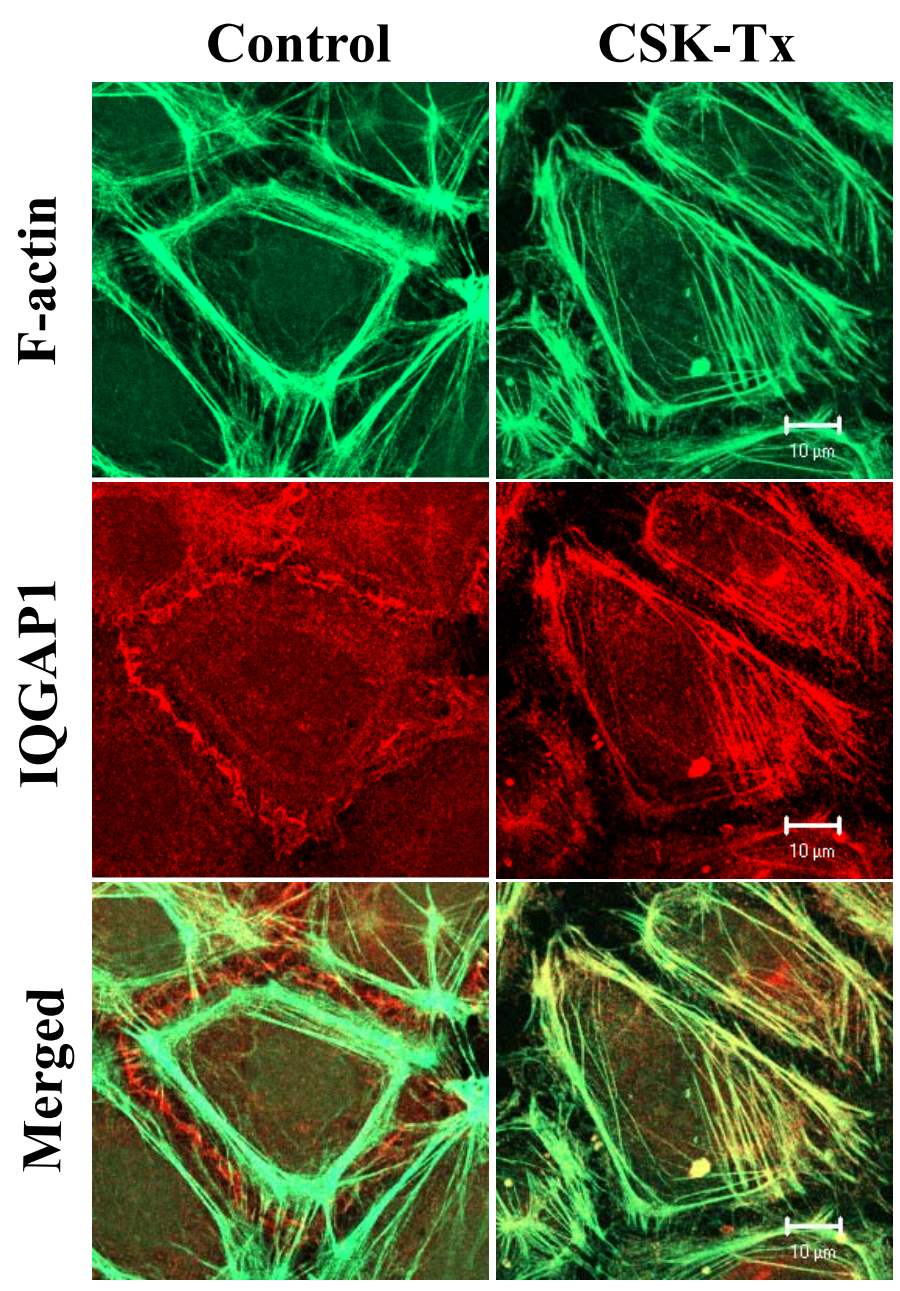


Figure 12. Junctional IQGAP1 colocalized with cortical actin filaments after

permeabilization. Confluent HUVEC monolayers grown on glass coverslips were fixed first (Control) or permeabilized first (CSK-Tx) with cytoskeleton preserving buffer containing $0.5 \%$ Triton X-100 to extract soluble proteins before application of antibodies to IQGAP1 and phalloidin. Junctional IQGAP1 did not colocalize with cortical actin ring in control cells, but after Triton-treatment, IQGAP1 co-localized with peripheral ring of actin just interior to the cell membrane. Magnification bars $=$ $10 \mu \mathrm{m}$. 


\section{Figure 13}

A.

\section{IQGAP1}

C.

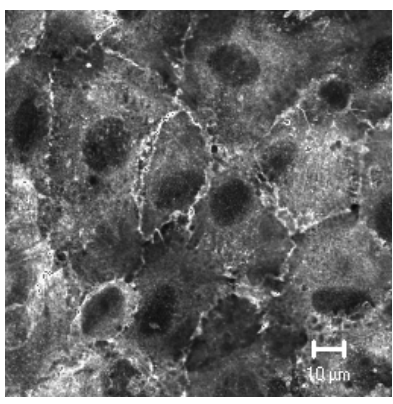

Scrambled siRNA
B.
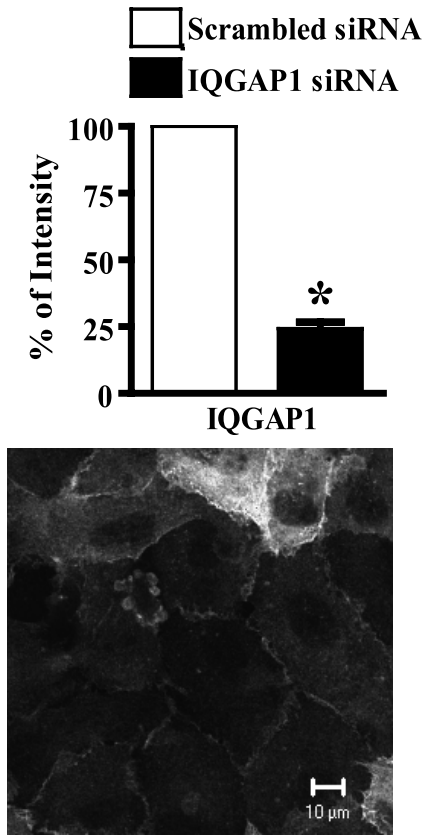

IQGAP1 siRNA 
Figure 13. Reduction of IQGAP1 by siRNA. HUVEC monolayers were transfected by oligofectamine with $0.4 \mu \mathrm{M}$ IQGAP1 siRNA or scrambled siRNA. A) Representative immunoblot demonstrated reduction of IQGAP1 by siRNA. B) Quantification of IQGAP1 after normalization to $\beta$-actin demonstrated reduction of IQGAP1 in cells transfected with IQGAP1 versus scrambled siRNA $(\mathrm{n}=16) . \mathrm{C})$ Immunofluorescent staining of IQGAP1 was dramatically reduced in cells transfected for $72 \mathrm{~h}$ with IQGAP1 siRNA. ${ }^{*} \mathrm{P}<0.05$ vs. scrambled siRNA (open bar). Magnification bars $=10 \mu \mathrm{m}$. 
Figure 14

A.

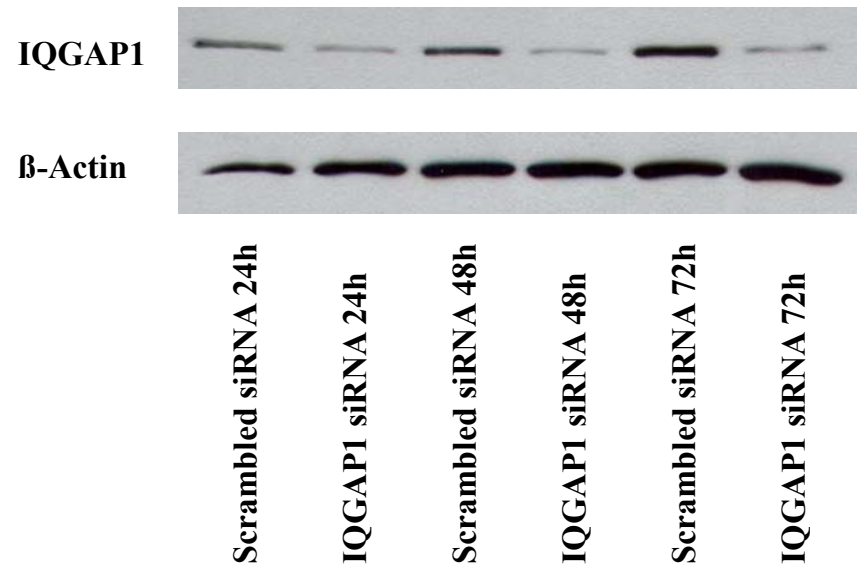

B.

IQGAP1

B-Actin

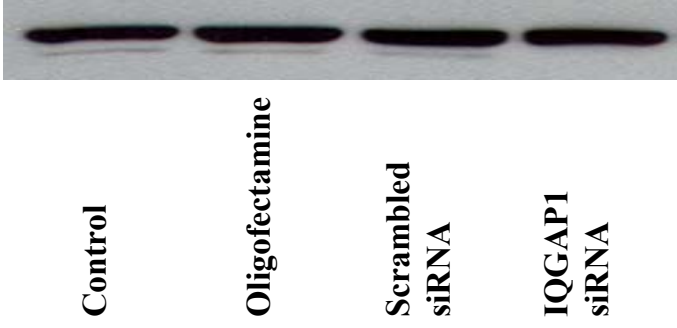


Figure 14. Toxicity and Knockdown Effect of IQGAP1 siRNA. A) HUVEC monolayers were transfected by oligofectamine with $0.27 \mu \mathrm{M}$ IQGAP1 siRNA or scrambled siRNA for $24 \mathrm{~h}, 48 \mathrm{~h}$, or $72 \mathrm{~h}$, and then equal volume of cell lysates were loaded. Representative immunoblot demonstrated that IQGAP1 protein level was reduced by siRNA after $24 \mathrm{~h}, 48 \mathrm{~h}$, and $72 \mathrm{~h}$. B) HUVEC monolayers were not transfected, or treated only with oligofectamine, or transfected by oligofectamine with $0.27 \mu \mathrm{M}$ IQGAP1 siRNA or scrambled siRNA, and then equal volume of cell lysates were loaded. Representative immunoblot demonstrated reduction of IQGAP1 by siRNA and no change in the protein levels of $\beta$-actin. 
Reduction of IQGAP1 was specific to transfection with IQGAP1 siRNA as cells transfected with a scrambled siRNA and oligofectamine alone had protein levels of IQGAP1 that were no different from untreated cells (Fig. 14 B). No significant cellular toxicity was detected by comparing the levels of IQGAP1 and $\beta$-actin in HUVECs that were untreated, oligofectamine-treated, or transfected with scrambled siRNA (Figs. 13A and 14A-B).

Basal electrical resistance was higher in IQGAP1 knockdown cells.

According to the hypothesis of Kaibuchi and co-workers (71), the binding of IQGAP1 to $\beta$-catenin disrupts the adherens junction and causes separation between adjacent cells. To determine if a reduction in IQGAP1 would induce the opposite result, an increase in endothelial barrier function, HUVECs were transfected directly on ECIS wells with $0.27 \mu \mathrm{M}$ IQGAP1 siRNA or scrambled siRNA in MCDB-131 containing oligofectamine (Fig. 15A). Electrical resistance across cell monolayers was continuously measured by ECIS. Basal electrical resistance of both siRNAtransfected groups started at $\sim 9,000$ ohms. In IQGAP1 knockdown cells, electrical resistance remained fairly constant, and from $60-80 \mathrm{~h}$ after transfection there was an 2,000 ohms difference between the IQGAP1 siRNA group and the scrambled siRNA (Fig. 15A). The above findings were confirmed by transfecting HUVECs in 6-well dishes for $48 \mathrm{~h}$, trypsinizing, seeding the scrambled siRNA- or IQGAP1 siRNAtransfected cells on ECIS wells, and continuously monitoring electrical resistance for an additional $50 \mathrm{~h}$. After $48 \mathrm{~h}$ of transfection and within five hours of seeding on the ECIS wells, electrical resistance of HUVEC monolayers was 8,200 and 6,700 ohms, respectively, for the IQGAP1 siRNA- and scrambled siRNA-treated groups (Fig. 15B). This difference of $\sim 1,500 \mathrm{ohms}$ in electrical resistance increased to $\sim 2,200$ ohms at $58 \mathrm{~h}$ and then decreased to $\sim 1,400 \mathrm{ohms}$ by $73 \mathrm{~h}$ after transfection. After 
ECIS, cells on the active electrode were immunostained for IQGAP1 to demonstrate reduction of this protein by siRNA and for VE-cadherin to count the cells and exclude any gain or loss of cells in both groups (Fig. $15 \mathrm{~B}$ ). With both methods of transfection, basal electrical resistance was higher from 50 to $80 \mathrm{~h}$ after transfection with IQGAP1 siRNA. It also important to note that similar responses were observed in cell monolayers either continuously exposed to a diluted concentration of oligofectamine (Fig. 15A) or having had oligofectamine removed during the process of reseeding the cells on the ECIS wells (Fig. 15B).

\section{IQGAP1 knockdown increased VE-cadherin.}

To begin to understand the cellular mechanism for the higher endothelial electrical resistance in IQGAP1 siRNA-treated cells, I measured the protein level of VE-cadherin in both IQGAP1 siRNA- and scrambled siRNA-transfected cells after 48 $\mathrm{h}$ of transfection. A representative immunoblot (Fig. 16A) and quantification of four immunoblots (Fig. 16B) from individual experiments demonstrated that IQGAP1 knockdown increased the protein level of VE-cadherin by almost $80 \%$, as compared to transfection with a scrambled siRNA. In these initial experiments, cell monolayers were exposed continuously to a diluted concentration of oligofectamine for $44 \mathrm{~h}$. To remove any potential adverse effects of oligofectamine, these experiments were repeated in cell monolayers in which oligofectamine was removed by washing at $4 \mathrm{~h}$ after the transfection period. The protein level of IQGAP1 increased in two of the three experiments in cell monolayers transfected with IQGAP1 siRNA, as compared to the levels in cells that were untreated, oligofectamine alone-treated, and scrambled siRNA-treated (Fig. $16 \mathrm{C}$ and D). In the third experiment, similar levels of IQGAP1 protein were observed in all four groups (Fig. 16E). 


\section{Figure 15}

A.

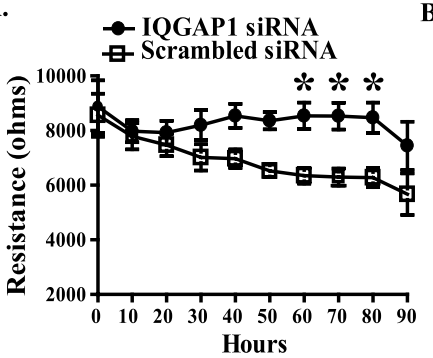

C.

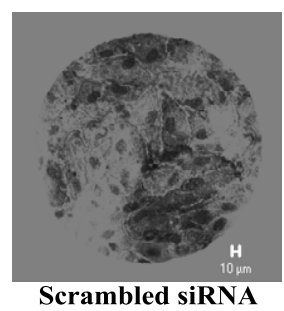

B.
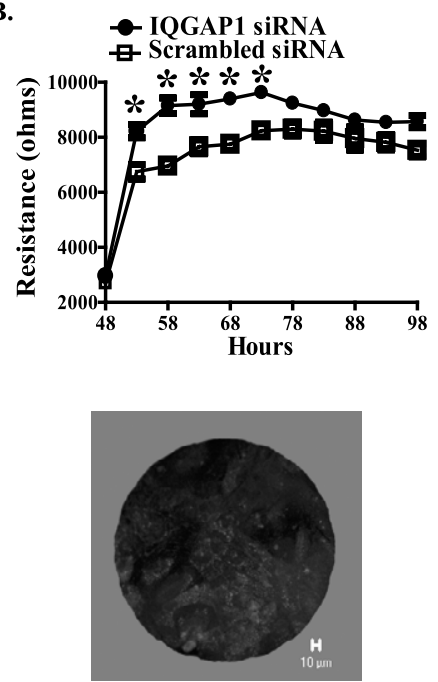

IQGAP1 siRNA 
Figure 15. Basal electrical resistance was higher in IQGAP1 knockdown cells. A) HUVEC monolayers seeded in ECIS (Electric Cell-substrate Impedance Sensing) wells were transfected with $0.27 \mu \mathrm{M}$ IQGAP1 or scrambled siRNA and continuously monitored by ECIS. Basal electrical resistance of cell monolayers was higher in IQGAP1 knockdown cells compared to scrambled siRNA- transfected cells ( $\mathrm{n}=17$ ). B) HUVEC monolayers were transfected in 6-well dishes for $48 \mathrm{~h}$, then trypsinized and seeded in ECIS wells. Basal electrical resistance of HUVEC monolayers was higher in cells transfected with IQGAP1 siRNA than with scrambled siRNA ( $\mathrm{n}=7)$. Inserts are representative micrographs of ECIS wells incubated with anti-IQGAP1 antibody after ECIS experimentation of cell monolayers transfected with IQGAP1 or scrambled siRNA. ${ }^{*} \mathrm{P}<0.05$ vs. scrambled siRNA (open squares) at specific time points. 
To observe the localization of the increased VE-cadherin in IQGAP1 knockdown cells, HUVECs were untreated, oligofectamine-treated, scrambled siRNA-treated, or IQGAP1 siRNA-treated in 6-well dishes for $48 \mathrm{~h}$, then trypsinized and seeded them on precoated glass coverslips for another $24 \mathrm{~h}$ to form confluent cell monolayers. Cell monolayers were fixed (Fig. 16F) and incubated with an anti-VEcadherin antibody to visualize VE-cadherin by immunofluorescence microscopy. Similar cell densities were observed in these groups, and no significant difference in the amount or localization of VE-cadherin was observed among these groups.

IQGAP1 knockdown decreased $N$-cadherin.

Interestingly, the protein level of $\mathrm{N}$-cadherin was decreased by $75 \%$ in HUVECs transfected with IQGAP1 siRNA for $48 \mathrm{~h}$ under the condition of continuous exposure to diluted oligofectamine for $44 \mathrm{~h}$ (Fig. $17 \mathrm{~A}$ and B). Following the repeat of these experiments in cell monolayers washed of oligofectamine, the protein level of $\mathrm{N}$-cadherin was decreased in three of three experiments (Fig. 17C-E).

IQGAP1 knockdown did not change protein levels of p120-, $\beta-, \gamma$, and $\alpha-$ catenins.

In contrast to the changes in protein levels for VE- and N-cadherins, protein levels of the catenins, p120, $\beta, \gamma$, and $\alpha$, were unchanged in IQGAP1 knockdown cells (Fig. $18 \mathrm{~A}$ and B). Neither the distribution patterns nor the intensities of $\mathrm{p} 120-\beta-, \gamma-$, and $\alpha$-catenins as visualized by immunofluorescence microscopy was changed after reduction of IQGAP1 (Fig. $18 \mathrm{C}-\mathrm{E}$ ).

$N$-cadherin associated with catenins (p120, $\beta, \gamma, \alpha)$ but not VE-cadherin or $I Q G A P 1$. 


\section{Figure 16}

A.

C.

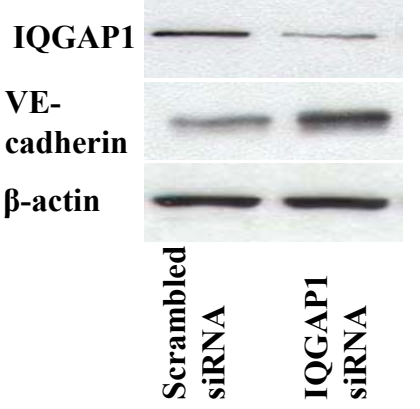

B. $\square$ Scrambled siRNA

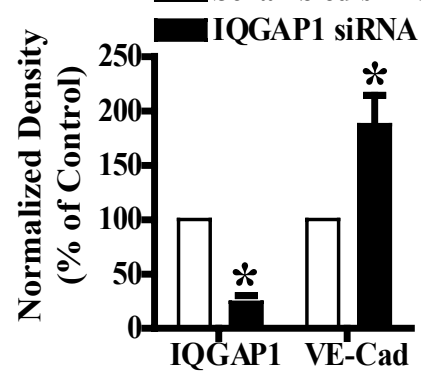

IQGAP1

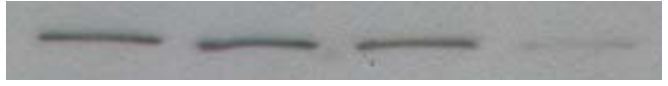

VE-cadherin

B-Actin

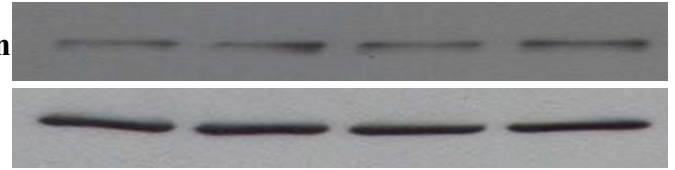

D.

IQGAP1

VE-cadherin

B-Actin
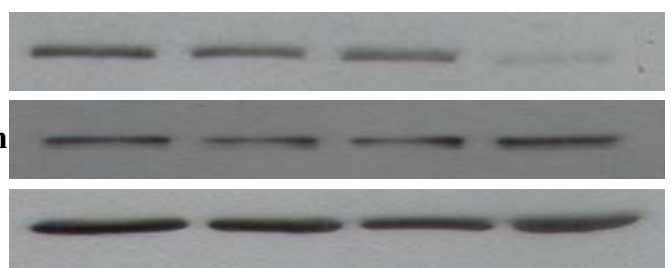

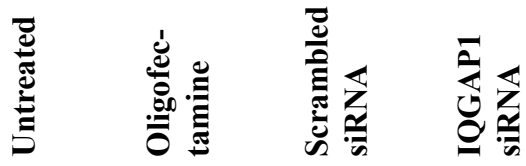




\section{Figure 16}

E.

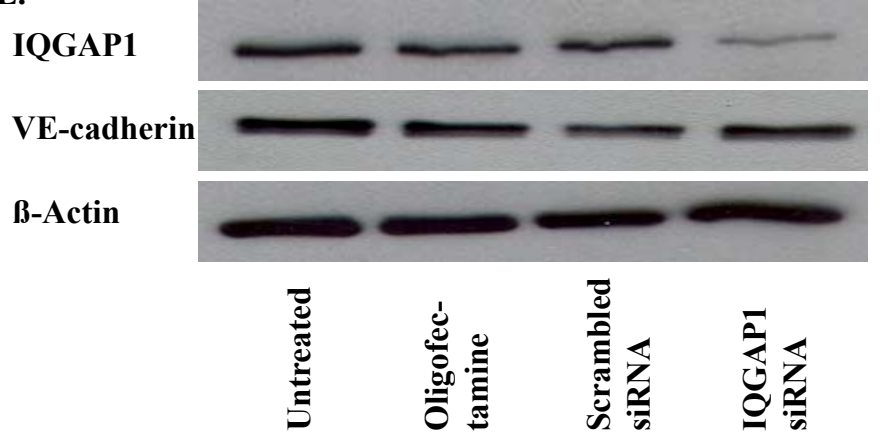

F.

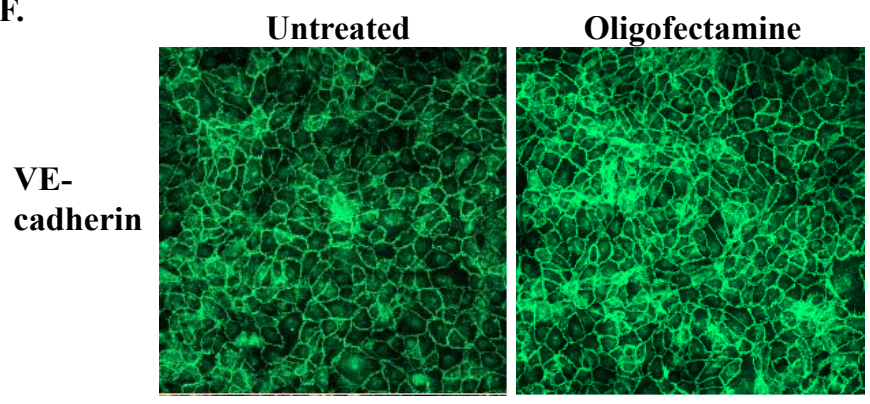

Scrambled siRNA

IQGAP1 SiRNA

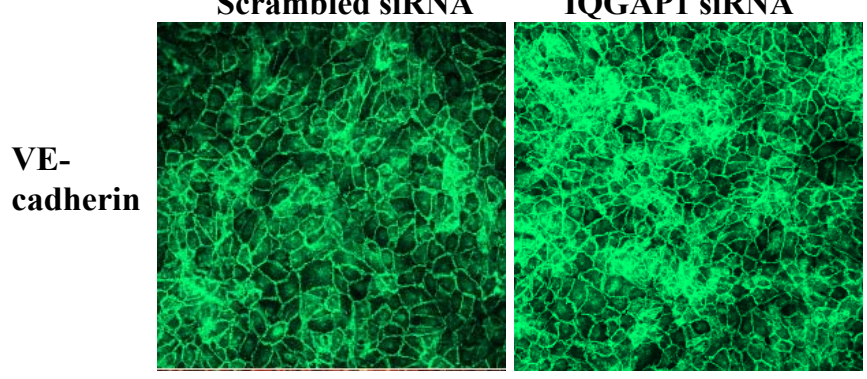


Figure 16. IQGAP1 knockdown increased VE-cadherin. HUVEC monolayers were transfected with IQGAP1 or scrambled siRNA, and cell lysates were probed with primary antibodies to IQGAP1, VE-cadherin, and $\beta$-actin. A,B) Representative immunoblot and quantification after normalization to $\beta$-actin of four independent immunoblots demonstrated that IQGAP1 knockdown increased protein level of VEcadherin (VE-Cad). C-E) VE-cadherin protein level was also measured inHUVECs were untransfected, oligofectamine-treated, scrambled siRNA-treated, or IQGAP1 siRNA-treated in 6-well dishes for $4 \mathrm{~h}$. The protein level of VE-cadherin increased in two of the three experiments in cell monolayers transfected with IQGAP1 siRNA, as compared to the levels in cells that were untreated, oligofectamine alone-treated, and scrambled siRNA-treated (C, D). In the third experiment, similar levels of IQGAP1 protein were observed in all four groups (E). F) HUVECs were untransfected, oligofectamine-treated, scrambled siRNA-treated, or IQGAP1 siRNA-treated in 6well dishes for $48 \mathrm{~h}$, trypsinized, and then seeded onto precoated glass coverslips for another $24 \mathrm{~h}$ to form confluent cell monolayers. Cells were fixed and incubated with anti-VE-cadherin antibody followed by goat anti-rabbit IgG conjugated to Alexa Fluor 488. No significant difference was observed among these groups. ${ }^{*} \mathrm{P}<0.05$ vs. respective scrambled siRNA (open bars). 


\section{Figure 17}

A.

C.

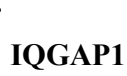

IQGAP1

N-

cadherin

$\beta$-actin

IQGAP1

N-cadherin

B-Actin

D.

IQGAP1

N-cadherin

B-Actin
B.

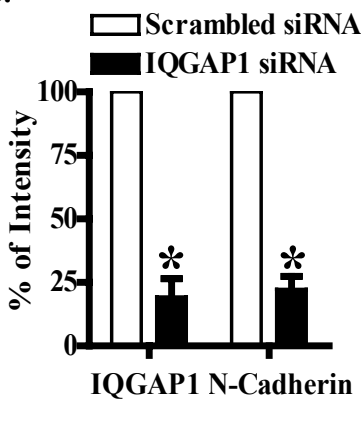




\section{Figure 17}

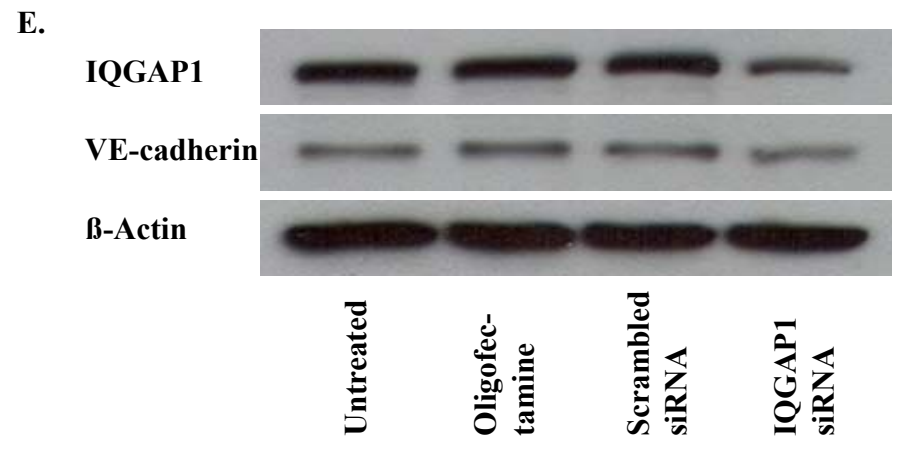


Figure 17. IQGAP1 knockdown decreased N-cadherin. HUVEC monolayers were transfected with IQGAP1 (IQ) or scrambled siRNA, and cell lysates were probed with primary antibodies to IQGAP1, N-cadherin, and $\beta$-actin. A,B) Representative immunoblot and quantification after normalization to $\beta$-actin of four independent immunoblots demonstrated that IQGAP1 knockdown decreased protein level of N-cadherin. C-E) N-cadherin protein level was also measured inHUVECs were untransfected, oligofectamine-treated, scrambled siRNA-treated, or IQGAP1 siRNA-treated in 6-well dishes for $4 \mathrm{~h}$. The protein level of $\mathrm{N}$-cadherin decreased in all of the three experiments in cell monolayers transfected with IQGAP1 siRNA, as compared to the levels in cells that were untreated, oligofectamine alone-treated, and scrambled siRNA-treated. ${ }^{*} \mathrm{P}<0.05$ vs. respective scrambled siRNA (open bars). 
Figure 18

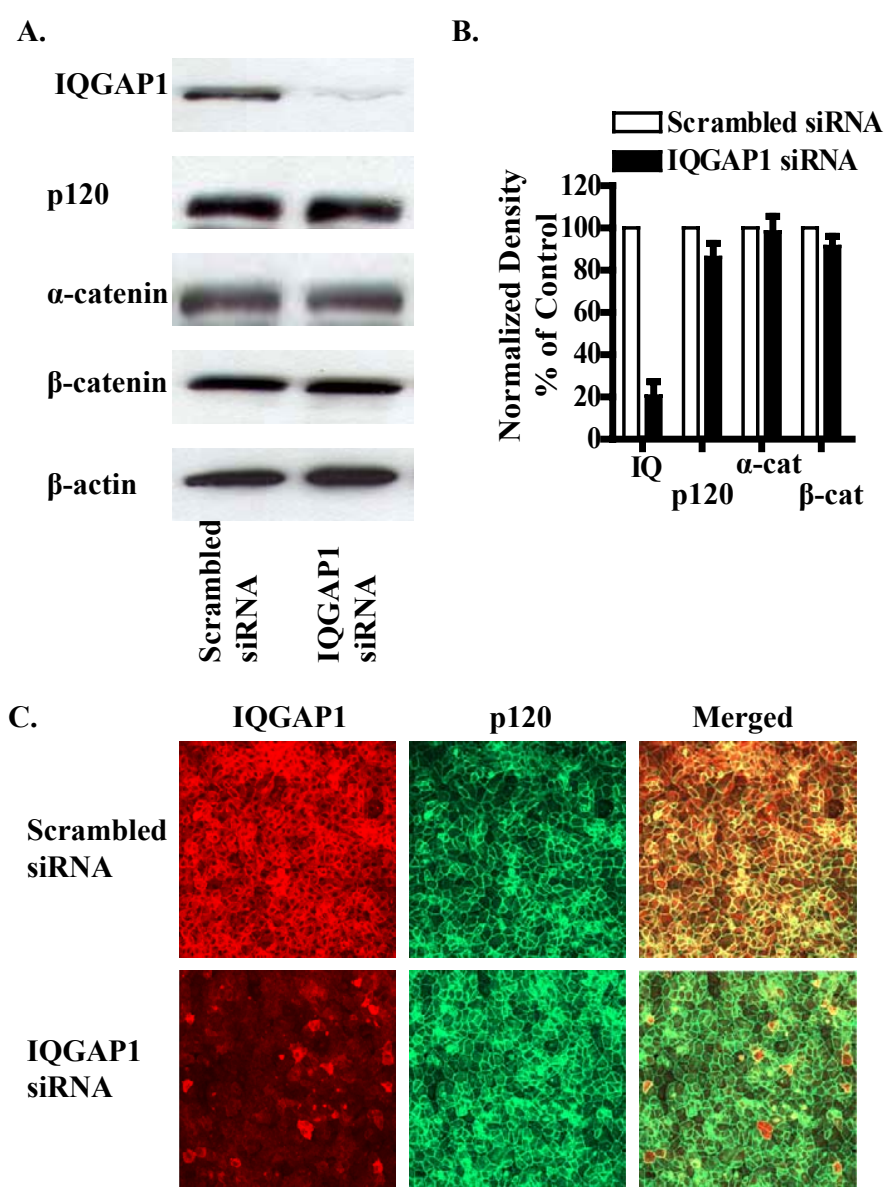




\section{Figure 18}

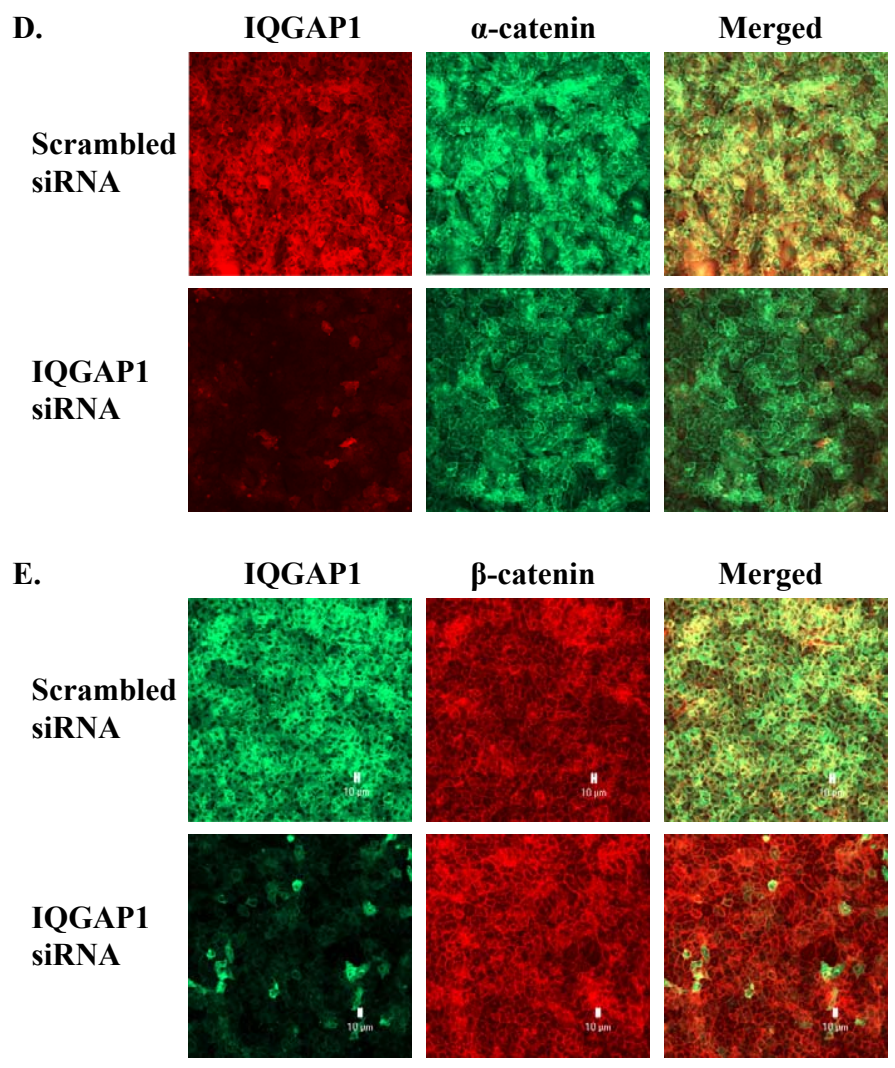


Figure 18. IQGAP1 knockdown did not change protein levels of p120-, $\beta$-, and $\alpha$ catenins. HUVEC monolayers were transfected with IQGAP1 (IQ) or scrambled siRNA, and cell lysates were probed with primary antibodies to IQGAP1, catenins (cat), p120, $\beta$, and $\alpha$, and $\beta$-actin. A, B) Representative immunoblot and quantification after normalization to $\beta$-actin of four independent immunoblots demonstrated that protein levels of catenins were unchanged in IQGAP1 knockdown cells. C, D, E) Both scrambled and IQGAP1 siRNA-transfected cells were stained for IQGAP1, catenins, p120, $\beta$, and $\alpha$, which were visualized with Alexa Fluor 488labeled goat anti-rabbit IgG (green) and Alexa Fluor 594-labeled goat anti-mouse IgG (red), respectively. Although IQGAP1 siRNA dramatically decreased the intensity of IQGAP1 staining, it did not change the intensities of p120-, $\beta$-, and $\alpha$-catenin staining. ${ }^{*} \mathrm{P}<0.05$ vs. respective scrambled siRNA (open bars). 
To determine the interaction of $\mathrm{N}$-cadherin with adherens junction proteins, we incubated cell lysates with antibodies to IQGAP1, VE-cadherin, p120-, $\beta-, \gamma-$, and $\alpha$-catenins, and IgG. Immunoprecipitates were resolved by SDS-PAGE and probed with an anti-N-cadherin antibody. $\mathrm{N}$-cadherin associated with $\mathrm{p} 120-, \beta-, \gamma-$, and $\alpha-$ catenins, but not with VE-cadherin or IQGAP1 (Fig. 19A). We conclude that Ncadherin forms similar complexes as VE-cadherin, but $\mathrm{N}$-cadherin does not directly associate with IQGAP1.

$\mathrm{N}$-cadherin was also distinguished from VE-cadherin with regard to the interaction with the insoluble cytoskeleton. Cells were either fixed first (Fig. 19B, Control) or permeabilized first (Fig. 19B, CSK-Tx) before administration of antibodies to VE- and N-cadherins. In control cells, both VE-cadherin and Ncadherin were present at intercellular junctions (Fig. 19B, Control). After removal of soluble proteins by detergent extraction, less N-cadherin was observed at intercellular junctions than VE-cadherin (Fig. 19B, CSK-Tx). These observations suggest that VE-cadherin is linked to a greater extent than $\mathrm{N}$-cadherin to the insoluble cytoskeleton. Since the linkage of cadherins to the actin cytoskeleton is thought to be essential for the formation of a strong intercellular adhesion, these findings would indicate that VE-cadherin mediates a much stronger cell-cell adhesion than $\mathrm{N}$ cadherin.

IQGAPI knockdown increased association of VE-cadherin with p120-and $\beta$ catenins; opposite response occurred with $N$-cadherin.

Next, I determined if the reduction in IQGAP1 affected the association of VEcadherin and $\mathrm{N}$-cadherin with the catenins. Lysates from HUVECs transfected with IQGAP1 siRNA or scrambled siRNA for $48 \mathrm{~h}$ were incubated with antibodies to $\mathrm{p} 120$ or $\beta$-catenin. The resultant immunoprecipitates were subjected to SDS-PAGE and 


\section{Figure 19}

A.

IB: N-cadherin

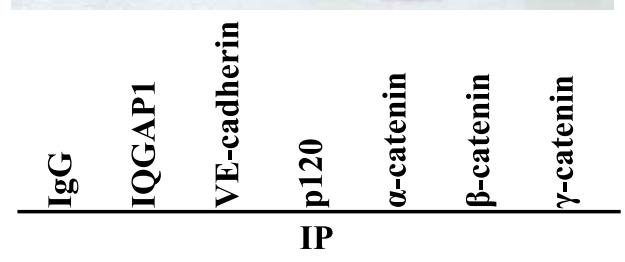

B.

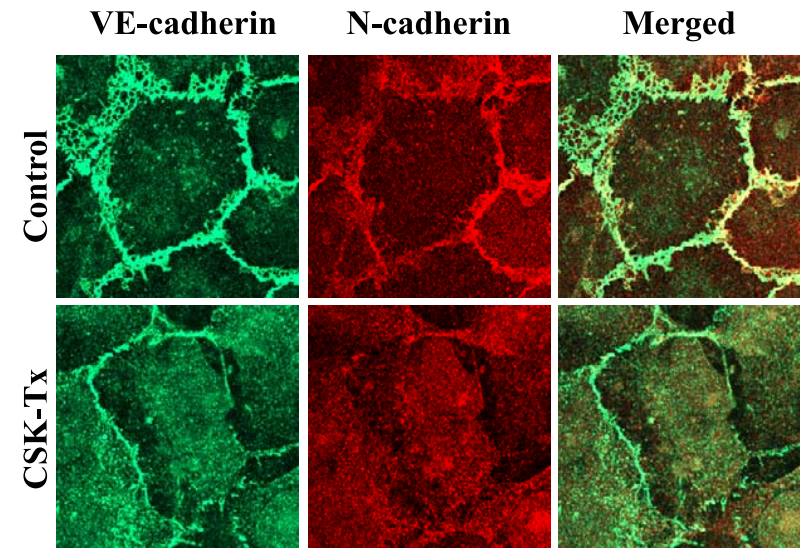


Figure 19. N-cadherin formed complexes with all four catenins and was less bound to cytoskeleton. A) HUVEC lysates were immunoprecipitated with polyclonal antibodies to IQGAP1, VE cadherin, p120, $\alpha$-catenin, or IgG or monoclonal antibodies to $\beta$-catenin or $\gamma$-catenin and probed with an anti-N-cadherin monoclonal antibody. N-cadherin formed immunocomplexes with catenins, $p 120, \beta$, $\gamma$, and $\alpha$, but not VE-cadherin or IQGAP1. Data represent three independent experimental determinations. B) Cells were fixed first (Control) or permeabilized first (CSK-Tx) and incubated with anti-VE-cadherin polyclonal and anti-N-cadherin monoclonal antibody, which were visualized, respectively with Alexa Fluor 488labeled goat anti- rabbit IgG (green) and Alexa Fluor 594-labeled goat anti-mouse IgG (red). Both N-cadherin and VE-cadherin were located at intercellular junctions . Note that more VE-cadherin was resistant to extraction with Triton X-100 than Ncadherin $(\mathrm{CSK}-\mathrm{Tx})$. Magnification bars $=10 \mu \mathrm{m}$. 
probed with antibodies to VE-cadherin, $\mathrm{N}$-cadherin, and $\beta$ - and $\alpha$-catenins.

Association of VE-cadherin with p120 was increased by almost $50 \%$ (Fig. 20 A and B) and that with $\beta$-catenin by $\sim 60 \%$ (Fig. $20 \mathrm{C}$ and D). In contrast, the associations of $\mathrm{N}$-cadherin with both p120 (Fig. $20 \mathrm{~A}$ and B) and $\beta$-catenin (Fig. $20 \mathrm{C}$ and D) were decreased by $50 \%$. Associations of p120 with $\beta$-catenin (Fig. $20 \mathrm{~A}$ and B) and of $\beta$ catenin with $\alpha$-catenin (Fig. $20 \mathrm{C}$ and D) were not changed by transfection with IQGAP1 siRNA. The increased and decreased associations of p120 and $\beta$-catenin with VE-cadherin and N-cadherin, respectively, were in line with the increased protein level of VE-cadherin and the decreased protein level of N-cadherin in IQGAP1 knockdown cells.

Expression of fusion protein, VE-cadherin- $\alpha$-catenin, increased the electrical resistance across HUVECs.

To determine the targets of IQGAP1 in the adherens junctional complex, I infected cells with an adenoviral construct expressing GFP-labeled VE-cadherin- $\alpha$ catenin as a fusion protein, which consists of amino acids (aa) 1-701 of VE-cadherin and aa 320-906 of $\alpha$-catenin. Since the binding sites of $\beta$-catenin in both VE-cadherin and $\alpha$-catenin were deleted, $\beta$-catenin cannot bind to this exogeneous fusion protein. By immunoblotting, a GFP-labeled protein at $140 \mathrm{kD}$ was found in infected cells but not in the control cells with equal loading of protein (Fig. 21B).

To detect the functional role of this fusion protein, confluent HUVEC monolayers were adenovirally infected with the construct expressing the VE cadherin$\alpha$-catenin fusion protein on ECIS (8W10) cultureware, and electrical resistance across cell monolayers was continuously measured. During the first $48 \mathrm{~h}$, electrical resistance of the PBScontrol group was maintained around $900 \mathrm{ohms}$, wherease the electrical resistance of the VE-cadherin- $\alpha$-catenin treated group started at $1,000 \mathrm{ohms}$ 


\section{Figure 20}

A.

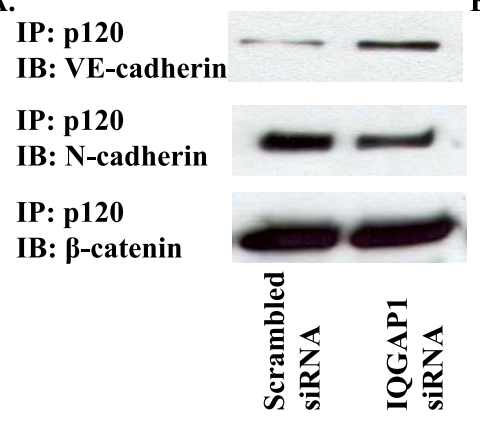

C.

IP: $\boldsymbol{\beta}$-catenin
IB: VE-cadherin
IP: $\boldsymbol{\beta}$-catenin
IB: $\boldsymbol{N}$-cadherin
IP: $\boldsymbol{\beta}$-catenin
IB: $\boldsymbol{\alpha}$-catenin

IP: $\boldsymbol{\beta}$-catenin

IP: $\boldsymbol{\beta}$-catenin

IP: $\boldsymbol{\beta}$-catenin

IB: $\alpha$-catenin
B.

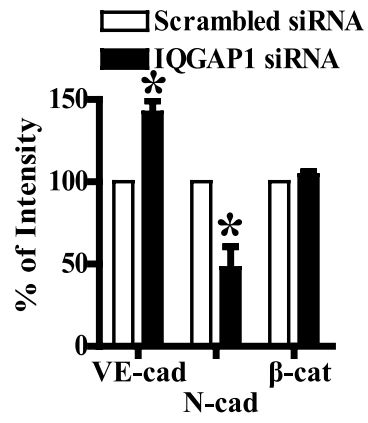

D.

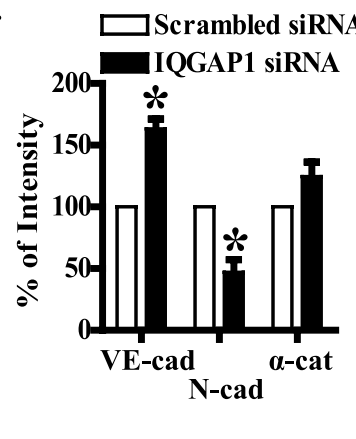


Figure 20. IQGAP1 knockdown increased association of VE-cadherin with p120 and $\boldsymbol{\beta}$-catenin; opposite effect occurred with $\mathbf{N}$-cadherin. HUVECs were seeded on 6-well dishes for $24 \mathrm{~h}$, and transfected with scrambled or IQGAP1 siRNA for another $48 \mathrm{~h}$. HUVEC lysates were immunoprecipitated with an anti-p120 polyclonal or an anti- $\beta$-catenin monoclonal antibody, and probed with antibodies to VE-cadherin, $\mathrm{N}$-cadherin, $\beta$-catenin, and $\alpha$-catenin. Representative immunoblots $(\mathrm{A}, \mathrm{C})$ and quantification of three independent immunoblots after normalization to $\beta$-actin (B,D) demonstrated that reduction of IQGAP1 increased and decreased, respectively, associations of p120 (A,B) and $\beta$-catenin $(\mathrm{C}, \mathrm{D})$ with VE-cadherin (VE-cad) and Ncadherin (N-cad). Association of p120 with $\beta$-catenin $(\beta$-cat, $A, B)$ or $\beta$-catenin with $\alpha$-catenin ( $\alpha$-cat, $\mathrm{C}, \mathrm{D})$ did not change. ${ }^{*} \mathrm{P}<0.05$ vs. respective scrambled siRNA (open bars). 
and reached 1,400 ohms. Thus, the basal electrical resistance contributed by control cells was increased $55 \%$ by infection of VE-cadherin- $\alpha$-catenin. From $48 \mathrm{~h}$ to $72 \mathrm{~h}$, electrical resistance was increased in both groups, but the resistance of the VEcadherin- $\alpha$-catenin treated group was still 400 ohms higher than that of the control group. Therefore, overexpressed VE-cadherin- $\alpha$-catenin increased the basal electrical resistance of HUVEC monolayers (Fig. 21C).

VE-cadherin- $\alpha$-catenin expression diminished IQGAPI located at intercellular junctions.

In the attempt to increase the p120-VE-cadherin association, confluent HUVEC monolayers grown on glass coverslips were infected with an adenoviral construct expressing GFP-labeled VE-cadherin- $\alpha$-catenin fusion protein for $48 \mathrm{~h}$, then fixed and stained for $\mathrm{p} 120, \beta$-catenin, and IQGAP1. In cells expressing VE-cadherin$\alpha$-catenin, p120 colocalized with GFP-labelled VE-cadherin- $\alpha$-catenin at intercellular junctions; fewer $\beta$-catenin molecules colocalized with GFP-labelled VE-cadherin- $\alpha$ catenin than p120; and most of the junctional IQGAP1 was diminished in cells expressing VE-cadherin- $\alpha$-catenin (Fig. 22). 


\section{Figure 21}

A.

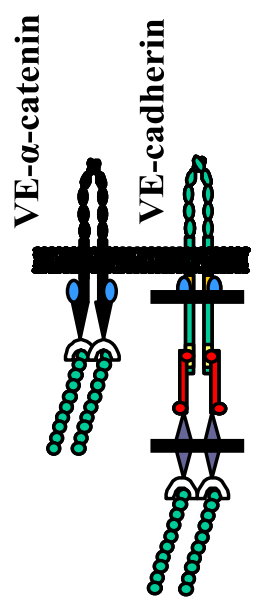

C.

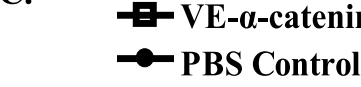

B. GFP-VE$\alpha$-catenin $\beta$-actin

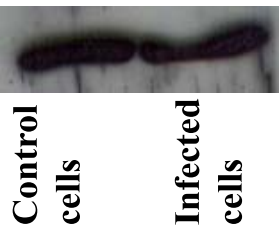

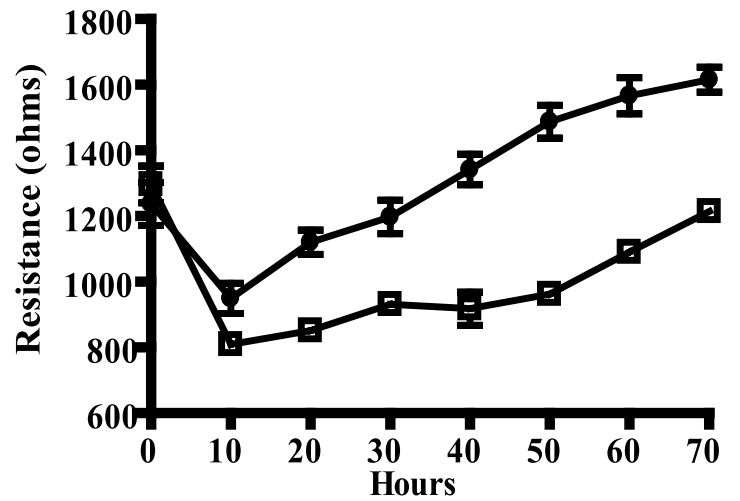


Figure 21. VE-cadherin- $\alpha$-catenin expression increased the electrical resistance across HUVECs. A) Confluent HUVEC monolayers were infected with an adenoviral construct expressing green fluorescent protein (GFP)-labeled VE-cadherin$\alpha$-catenin fusion protein for 48 h. Cell lysates were immunoblotted for GFP, and a GFP-labelled protein at $140 \mathrm{KD}$ was found in infected cells but not in the control cells with equal loading of proteins. B) Confluent HUVEC monolayers were infected with the construct expressing VE cadherin- $\alpha$ catenin fusion proteins on $8 \mathrm{~W} 10$ culturewares, and electrical resistance across cell monolayers was continuously measured. During the first $48 \mathrm{~h}$, electrical resistance of the PBS control group was maintained around 900 ohms, whereas the resistance of the VE cadherin- $\alpha$ catenin treated group started at 1,000 ohms and reached 1,400 ohms. The basal electrical resistance contributed by control cells was increased $55 \%$ by VE cadherin- $\alpha$ catenin infection. From $48 \mathrm{~h}$ to $72 \mathrm{~h}$, electrical resistance was increased in both groups and the resistance of VE cadherin- $\alpha$ catenin treated group was still 400 ohms higher than that of the control group. 


\section{Figure 22}

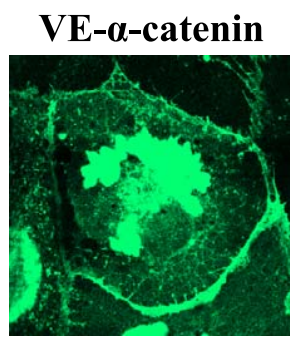

VE- $\alpha$-catenin

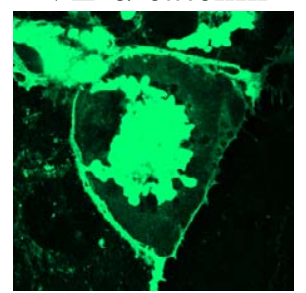

VE- $\alpha$-catenin

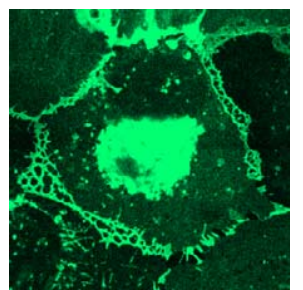

p120

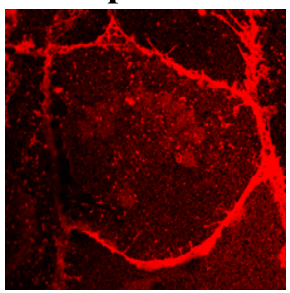

B-catenin

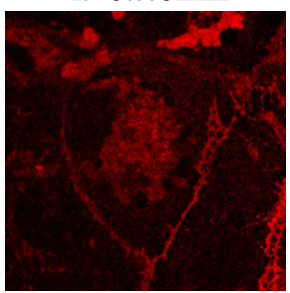

IQGAP1

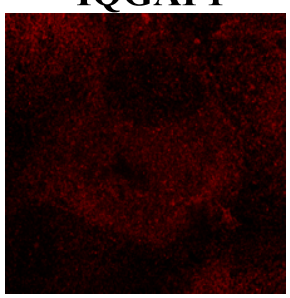

Merged

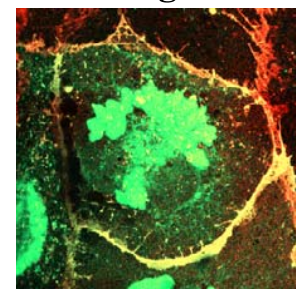

Merged

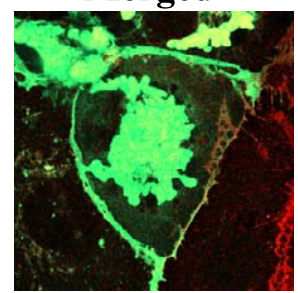

Merged

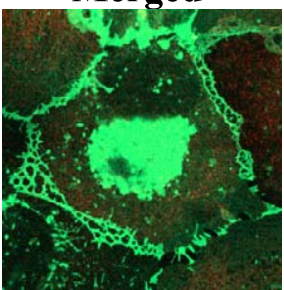


Figure 22. VE-cadherin- $\alpha$-catenin expression diminishes junctional IQGAP1. HUVECs were seeded onto precoated glass coverslips for $24 \mathrm{~h}$, then the confluent HUVEC monolayers were infected with an adenoviral construct expressing green fluorescent protein (GFP)-labeled VE- $\alpha$-catenin fusion protein for 48h. After fixation, these cells were stained for $\mathrm{p} 120, \beta$-catenin, or IQGAP1. In cells expressing VEcadherin- $\alpha$-catenin, p120 colocalized with GFP-labelled VE-cadherin- $\alpha$-catenin at intercellular junctions. Less $\beta$-catenin colocalized with GFP-labelled VE-cadherin- $\alpha$ catenin at intercellular junctions than p120. And most junctional IQGAP1 was diminished in cells expressing VE-cadherin- $\alpha$-catenin. Magnification bar $=10 \mu \mathrm{m}$. 


\section{DISCUSSION}

I demonstrated in this dissertation that 1) S1P increased the association of IQGAP1 with Rac1, 2) S1P increased insoluble VE-cadherin and $\beta$-catenin at intercellular junctions, 3) IQGAP1 was associated with proteins comprising the endothelial adherens junction, i.e. VE-cadherin and the catenins, 4) a reduction in IQGAP1 enhanced the integrity of the endothelial barrier, 5) IQGAP1 knockdown increased the protein level of VE-cadherin and the interaction of VE-cadherin with p120- and $\beta$-catenins, and 6) IQGAP1 knockdown decreased the protein level of Ncadherin and the interaction of $\mathrm{N}$-cadherin with $\mathrm{p} 120$ - and $\beta$-catenins. IQGAP1 at intercellular junctions appeared to be soluble in its association with VE-cadherin but insoluble in its association with the actin ring structure just adjacent to the cell periphery. N-cadherin formed complexes with p120-, $\beta$-, $\gamma$-, and $\alpha$-catenins but not with VE-cadherin or IQGAP1. After detergent extraction, more insoluble VEcadherin and less N-cadherin were observed at intercellular junctions in HUVECs, indicating that VE-cadherin associates to a greater extent than $\mathrm{N}$-cadherin with the insoluble cytoskeleton. Low levels of the tight junction proteins, occludin, claudin-5, and ZO-1, as compared to the levels in MDCK cells, were observed in HUVECs, and these proteins were not complexed with IQGAP1. We suggest that IQGAP1 knockdown can enhance the barrier function of vascular endothelia by increasing the protein level of VE-cadherin and the association of VE-cadherin with $\beta$-catenin and the actin cytoskeleton. The increased interaction of p120 with VE-cadherin could also contribute to the enhanced barrier function via stabilization and an increase in VEcadherin protein. As a result of the decrease in N-cadherin, more p120 and $\beta$-catenin may be available to interact with VE-cadherin. 
Junctions between endothelial cells consist of tight junctions and adherens junctions. And expression and organization of tight junctions and adherens junctions varies in endothelial cells at different locations in the vascular tree. In HUVECs, I found that the protein levels of occludin and ZO-1 were much lower than those in MDCK cells that have fully developed and well-organized, tight junctions. Compared to the level of $\beta$-actin, the relatively low protein levels of claudin-5, occludin, and ZO-1 in HUVECs indicate that tight junctions are poorly organized in HUVECs. Although claudin-5 and ZO-1 were found at intercellular junctions, IQGAP1 did not co-immunoprecipitate with these proteins, which suggests that IQGAP1 does not complex with these proteins. Therefore, we conclude that tight junctions are less expressed and organized in HUVECs and that IQGAP1 does not interact with tight junction proteins in endothelial cells.

According to the Kaibuchi hypothesis, the association of IQGAP1 with Ecadherin and $\beta$-catenin can be disrupted by GTP-bound Rac1 (21). Since S1P has been shown to activate Rac 1, I hypothesized that S1P treatment may also disrupt the IQGAP1-VE-cadherin association. I first looked at the S1P effect on endothelial cellcell adhesion, and found that S1P treatment rapidly increased the electrical resistance across HUVEC monolayers, confirming an earlier reported finding (Garcia). This $\mathrm{S} 1 \mathrm{P}$ effect was diminished within $1 \mathrm{~h}$, and the S1P response was not affected by changing the S1P dose from $0.1 \mu \mathrm{M}$ to $10 \mu \mathrm{M}$, which may be due to a negative feedback mechanism or the metabolism of S1P. To further explore the mechanism, I gave S1P every $10 \mathrm{~min}$ for $1 \mathrm{~h}$ and found that repeated S1P treatments every $10 \mathrm{~min}$ maintained the peak resistance. Maintenance of the response would argue against internalization of the Edg-receptor. However, the increased electrical resistance did slowly decline over the period of the seven treatments of S1P, which might argue for 
a slow internalization of the receptors. A more likely explanation isthat termination of the S1P effect was due to the metabolism of S1P, possibly by phosphatases and/or lysases in the serum.

Since S1P treatment rapidly enhanced the endothelial barrier, I further explored its effect on adherens junctions and found that S1P increased insoluble VEcadherin and insoluble $\beta$-catenin at intercellular junctions in confluent cell monolayers, which indicates that $\mathrm{S} 1 \mathrm{P}$ induces the formation of more adherens junctions bound to actin cytoskeleton. And S1P treatment also prevented formation of gaps between cells during the permeabilization and processing procedures for light microscopy, which indicates a stronger cell-cell adhesion. The finding that S1P increased insoluble VE-cadherin and insoluble $\beta$-catenin at intercellular junctions confirms the previous reports $(46,56)$ that S1P increased the localization of junctional VE-cadherin and the catenins within 30-60 min of treatment. Dominant-negative Rac1 polypeptide prevented the S1P-induced localization of VE-cadherin and $\beta$ catenin to intercellular junctions (50). However, in the present study, S1P increased the amount of junctional VE-cadherin as well as $\beta$-catenin within $10 \mathrm{~min}$, which temporally corresponds with the rapid increase in electrical resistance that peaks around 10 min after treatment with S1P. S1P also translocated Rac1 to the periphery of cells and increased the association of Rac1 with IQGAP1, as demonstrated by coimmunoprecipitation and immunofluorescence microscopy. Together, these findings suggest that S1P may increase insoluble VE-cadherin and $\beta$-catenin by activating Rac1 and dissociating IQGAP1 from adherens junction complexes. However, there was no microscopical verification of a reduction in IQGAP1 at intercellular junctions upon treatment with S1P. 
To further characterize IQGAP1 in endothelial cells, I found that IQGAP1 colocalizes with Rac1 at membane ruffles and with Rac1 and calmodulin in the cytoplasm of subconfluent cells. In subconfluent cells, IQGAP1 colocalized with actin filaments (phalloidin stained) at the membrane ruffles of the leading edges of cells. Triton extraction did not remove IQGAP1 at the membrane ruffles, which suggests that these proteins are insoluble and bound to the cytoskeleton. Mataraza et al. (53) found that overexpression of IQGAP1 in Swiss 3T3 cells enhanced cell migration in a Cdc42- and Rac1-dependent manner, and knock down of IQGAP1 decreased cell motility. Fukata et al. (2002) found that activated Cdc42/Rac1 complexes with IQGAP1 and CLIP-170, enhancing the interaction between IQGAP1 and CLIP-170, and recruiting GFP-CLIP-170 to the leading edge and the base of filopodia. Watanabe et al. (2004) also showed that IQGAP1 directly interacts with APC and both colocalize with Rac1 and Cdc42 at the leading edge. Therefore, IQGAP1 may promote cell polarization and migration by stabilizing both microfilaments and microtubules at the leading edge.

IQGAP1 binds to E-cadherin and $\beta$-catenin, but not to $\alpha$-catenin, in L cells expressing E-cadherin (EL cells) (45). In MDCK cells, IQGAP1 co-localizes with $\alpha$ catenin as viewed by immunofluorescence microscopy (44) and interacts at its carboxy terminal domain with $\beta$-catenin and E-cadherin $(8,71)$. Upon binding to $\beta$ catenin, IQGAP1 competitively interferes with the binding of $\alpha$-catenin to the Ecadherin/ $\beta$-catenin complex and dissociates cell-cell contacts, presumably by unlinking the complex from the actin cytoskeleton $(22,45)$. The content of IQGAP1 at epithelial adherens junctions appears to be determined by the activity of Racl or Cdc42. Treatment of MDCK cells with a phorbol ester reduces Rac1 activity, increases the association of IQGAP1 with $\beta$-catenin, and displaces $\alpha$-catenin from the 
adherens junction (22). The opposite response occurs upon activation of Rac1 or Cdc42, i.e. removal of IQGAP1 from the cadherin-catenin complex and enhancement of cell-cell contacts $(21,45)$. IQGAP1 also binds avidly to calmodulin. An antagonist of calmodulin induced the disassociation of IQGAP1 from calmodulin and increased the association of IQGAP1 with E-cadherin at the periphery of MCF-7 human breast epithelial carcinoma cells (52). Together, these findings indicate that IQGAP1 can interact with proteins in the cytoplasm and at the plasma membrane where IQGAP1 can regulate the epithelial adherens junction.

In HUVECs, I found that IQGAP1 formed complexes with VE-cadherin and $\beta-, \gamma-, \alpha-$ and p120-catenins at cell-cell contacts. Furthermore, the IQGAP1 associated with junctional VE-cadherin appeared to be soluble, i.e. not bound to the cytoskeleton, as Triton X-100 extracted most of the IQGAP1, except for a few strands, at the cell periphery. This observation supports Kaibuchi's hypothesis that soluble IQGAP1 interacts with and can be removed from adherens junction proteins, thus contributing to the dynamic regulation of the adherens junction $(46,71)$. There was also a ring of IQGAP1 just interior to VE-cadherin that was resistant to detergent extraction, thus considered insoluble, and was co-localized with the peripheral band of actin. IQGAP1 did not interact with N-cadherin. Under control conditions, Ncadherin was located diffusely throughout the endothelial cell $(67,82)$ and also localized at intercellular junctions (56). Using co-immunoprecipitation, we found that all of the catenins, $\mathrm{p} 120, \beta, \gamma$, and $\alpha$, formed complexes with N-cadherin but that VEcadherin and IQGAP1 did not.

I found an inverse relationship between the protein levels of VE-cadherin and N-cadherin after transfection with IQGAP1 siRNA. The protein level of VE-cadherin was increased and that of $\mathrm{N}$-cadherin decreased after the reduction of IQGAP1 in 
HUVECs. The protein levels of the catenins, p120, $\beta, \gamma$, or $\alpha$, were unchanged. Although there were changes in protein levels, as determined by Western blotting, no changes in the amount or localization of these protein, the cadherins and catenins, were observed by light microscopy. In other cell types, varying the content of IQGAP1 at intercellular junctions has produced varying results in terms of the protein level of E-cadherin. Reduction of IQGAP1 by siRNA decreased the accumulation of E-cadherin, $\beta$-catenin, and actin filaments at contacts between MDCK cells (71). IQGAP1 knockdown also decreased VE-cadherin at cell-cell contacts in HUVECs, but did not change the protein level of VE-cadherin (110). Translocation of IQGAP1 from calmodulin present in the cyptoplasm to E-cadherin at the cell membrane, induced in MCF-7 cells by a calmodulin antagonist, decreased the level of E-cadherin (52). Overexpression of IQGAP1, however, did not change the protein level of Ecadherin and $\alpha$ - or $\beta$-catenin in EL cells (45). Our findings of an inverse relationship of the protein levels of VE- and N-cadherins is also in contrast to the findings of Luo and Radice (56) who observed that a reduction of N-cadherin by siRNA led to a decrease in VE-cadherin as well as p120 in HUVECs.

The above finding of an inverse relationship in the protein levels of VE- and $\mathrm{N}$-cadherin following a reduction of IQGAP1 was observed initially in cell monolayers continuously exposed to a diluted concentration of oligofectamine. Because continuous exposure of oligofectamine, which could have formed micells even if diluted, may adversely effecte the cells, the above experiments were repeated after removing the oligofectamine by washing at $4 \mathrm{~h}$ after the transfection period. Similar findings were observed as above in three additional experiments; protein level of VE-cadherin increased in two of three experiments and the proten leve of Ncadherin decreased in three of three experiments. 
There was also an inverse relationship in the associations of p120 and $\beta$ catenin with VE-cadherin and N-cadherin in IQGAP1 knockdown cells. VE-cadherin interacted to a greater and $\mathrm{N}$-cadherin to a lesser extent with p120 and $\beta$-catenin. This makes sense, as there would be more VE-cadherin protein to interact with these catenins and vice versa for $\mathrm{N}$-cadherin. However, within the past two years, a series of papers have highlighted the importance of p120 in the stabilization and turnover of VE-cadherin $(14,39,105,106)$. Collectively, these papers demonstrated that binding of p120 to the juxtamembrane domain of cadherins regulates the protein levels of these cadherins. Decreasing the protein level of p120 by siRNA or overexpression of the juxtamembrane region of VE-cadherin reduced VE-cadherin protein and decreased endothelial barrier function (39). Overexpression of p120 alone or coexpression with the juxtamembrane region increased VE-cadherin and its localization at intercellular junctions. Therefore, stabilization of VE-cadherin relies on the binding of p120. On the other hand, the lack of p120 binding targets VE-cadherin to degradation through an endocytic pathway involving clathrin (106). Interestingly, Ncadherin may participate in this regulation. Unpublished observations by a collaborator (Dr. Peter Vincent, Albany Medical College) indicated that overexpression of $\mathrm{N}$-cadherin induces a decrease in VE-cadherin, and p120 associates preferentially with the increased N-cadherin. Although not addressed in this study, the increased associations of p120- and $\beta$-catenins with VE-cadherin could have resulted from removing a potential antagonistic effect of IQGAP1 on the binding of these two catenins to VE-cadherin. Also, the decreased association of these two catenins with $\mathrm{N}$-cadherin may have resulted in the increased availability of these catenins for VE-cadherin. 
IQGAP1 knockdown had a positive influence on basal barrier function, as assessed by the continuous measurement of electrical resistance across HUVEC monolayers. Endothelial electrical resistance was higher in those cell monolayers transfected with IQGAP1 siRNA as compared with transfection of a scrambled siRNA. The potential mechanism for this positive effect on barrier function may be an increase in homophilic VE-cadherin binding between adjacent endothelial cells. This notion is supported by the demonstrations in IQGAP1 knockdown cells of an increased protein level of VE-cadherin and association of VE-cadherin with $\beta$-catenin. In contrast to the findings for VE-cadherin, the protein level of N-cadherin and the association of $\mathrm{N}$-cadherin with $\beta$-catenin were decreased, and $\mathrm{N}$-cadherin was less resistant to detergent extraction in IQGAP1 knockdown cells. I conclude from these findings that an increased linkage of VE-cadherin and/or a decreased linkage of $\mathrm{N}$ cadherin to the cytoskeleton contributed to the higher electrical resistance in IQGAP1 knockdown cells.

The increased association of p120 with VE-cadherin could also induce lateral clustering or cis-dimerization of adjacent VE-cadherins (111) and/or could stabilize VE-cadherin protein $(14,39,105)$, both effects having a positive influence on the endothelial barrier. Equivocal results, however, have been obtained with regard to p120 and its role in cell-cell adhesion. Whereas in some studies the juxtamembrane region of the cadherins and in particular p120 was found to enhance cell-cell adhesion and maintain the cobble-stone morphology of cell monolayers $(97,111)$, other studies have concluded that the juxtamembrane region and p120 prevent lateral clustering of the cadherins (72). The amino-terminus of p120 may be the key to this adhesive activity as it contains a number of phosphorylation residues for tyrosine and serine/threonine that appear to effect cell-cell adhesion $(72,73)$. 
Vice versa, an increased presence of IQGAP1 at adherens junctions might decrease VE- or E-cadherin and increase N-cadherin; an inverse relationship that characterizes the migratory phenotype of epithelial cells when they transition from epithelium to mesenchymal or fibroblast-like cells. IQGAP1 has been identified as one of many cell-adhesion-related genes upregulated by transforming growth factor $\beta$, a known mediator of epithelial to mesenchymal transition (107). IQGAP1 is also expressed in poorly differentiated adenocarcinomas (63) and in diffuse-type gastric tumors exhibiting impaired cell-cell adhesion (96) and has been implicated in cohort migration of carcinoma cells (87). Our findings of an inverse relationship in the expression of VE-cadherin and N-cadherin coupled with enhancement of endothelial barrier function further implicate the involvement of IQGAP1 in adhesive activities between endothelial cells.

The presence of IQGAP1 at the cell periphery may destabilize the adherens junction by interfering with the association of VE-cadherin with p120 or $\beta$-catenin. By infecting HUVECs with an adenoviral construct expressing a GFP-labeled VEcadherin- $\alpha$-catenin fusion protein, which lacks the $\beta$-catenin binding domain on VEcadherin and $\alpha$-catenin, I found that expression of the VE-cadherin- $\alpha$-catenin fusion protein increased endothelial electrical resistance, which may be due to more VEcadherin on the membrane and more VE-cadherin linked to the actin cytoskeleton, similar to the outcomes mediated by IQGAP1 knockdown, or an enhanced interaction of $\alpha$-catenin to the actin cytoskeleton. Localization of GFP expression with p120, $\beta$ catenin, and IQGAP1 by immunofluorescence microscopy revealed that GFP and p120 were co-localized. The staining of $\beta$-catenin was low and not co-loclized with GFP and probably only represented endogenous $\beta$-catenin. There was minimal to no staining of IQGAP1, similar to the results observed in IQGAP1 knockdown cells. 
The low level of IQGAP1 staining is to be expected since the fusion protein lacks any of the binding sites for $\beta$-catenin. However, it is also possible that expression of the VE-cadherin- $\alpha$-catenin fusion protein caused a reduction in localization of IQGAP1 at intercellular junctions as the increase in binding of p120 to the fusion protein competitively excluded IQGAP1. This would be the expected result if one of the primary binding site for IQGAP1 on VE-cadherin is the p120-binding domain on the juxtamembrane region of VE-cadherin, indicatinge that IQGAP1 mainly targets at the p120-VE-cadherin association in the complex. Although IQGAP1 has been reported to bind VE-cadherin at the carbocy terminus of IQGAP1 (Kaibuchi, Sacks), the binding site on VE-cadherin has yet to be determined. 


\section{CONCLUSION}

Reduction of IQGAP1 by siRNA increased the basal electrical resistance across endothelial cell monolayers in association with increases in the protein level of VE-cadherin and the associations of VE-cadherin with p120 and $\beta$-catenin as well as the cytoskeleton. Based on these findings in IQGAP1 knockdown cells, it is attractive to hypothesize, as depicted in Figure 23, that the overexpression of IQGAP1 at endothelial adherens junctions disrupts the binding of p120 and $\beta$-catenin to VEcadherin, causing the destabilization of VE-cadherin and a decrease in VE-cadherin protein. The end result might be a decrease in endothelial barrier function. Furthermore, activation of Rac1 by S1P might remove IQGAP1 from adherens junctions, promoting the binding of p120 to VE-cadherin, and thus stabilizing VEcadherin, increasing its linkage to the actin cytoskeleton, and enhancing endothelial cell-cell adhesion. 
Figure 23

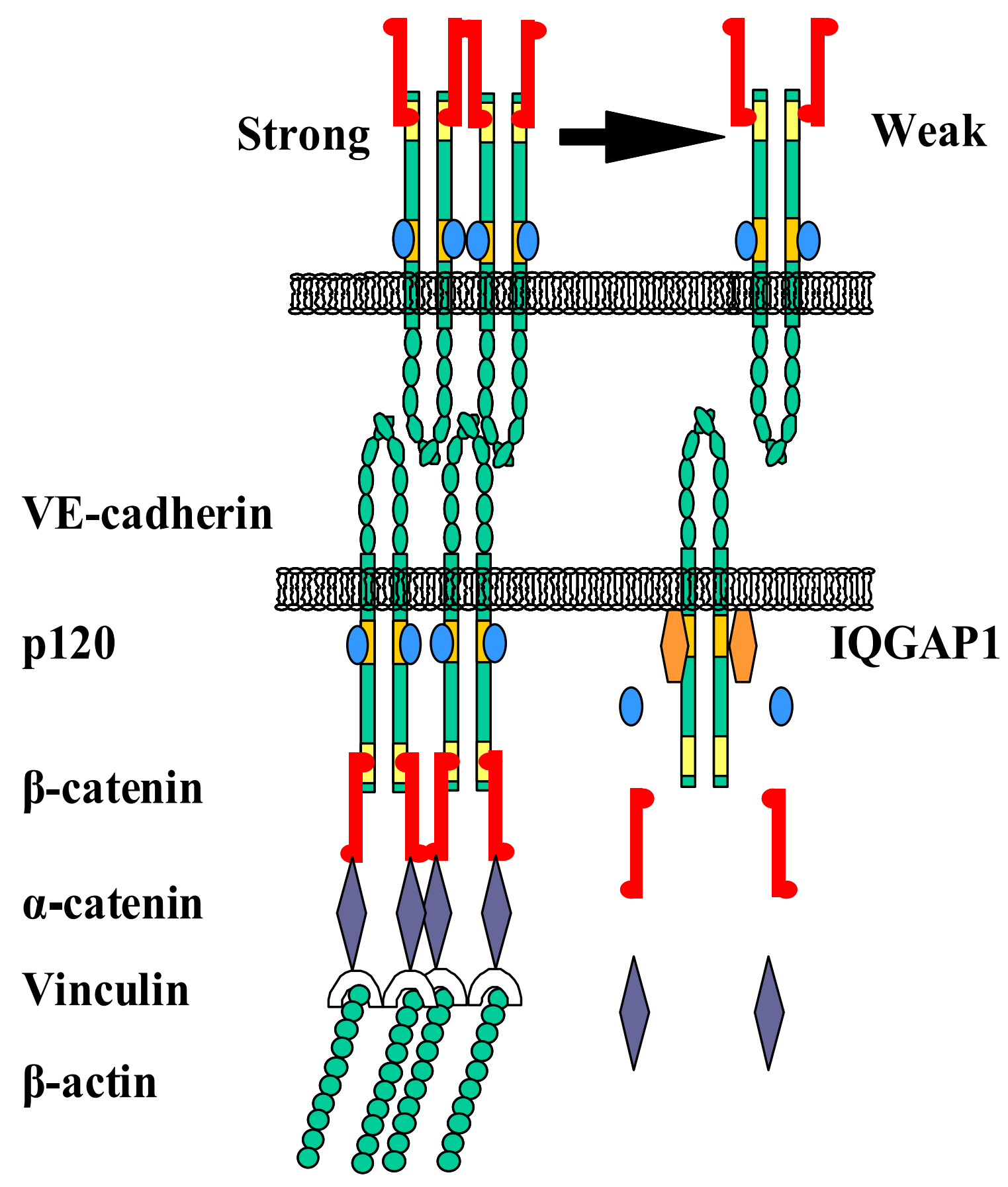


Figure 23. Our hypothesis. In human umbilical vein endothelial cells (HUVECs), IQGAP1 disrupts the association of p120 with VE-cadherin, destabilizing endothelial adherens junctions, decreasing VE-cadherin and increasing N-cadherin. 


\section{References:}

1. Ali J, Liao F, Martens E, and Muller WA. Vascular endothelial cadherin (VE-cadherin): cloning and role in endothelial cell-cell adhesion. Microcirculation 4: 267-277, 1997.

2. Bashour AM, Fullerton AT, Hart MJ, and Bloom GS. IQGAP1, a Rac- and Cdc42-binding protein, directly binds and cross-links microfilaments. J Cell Biol 137: 1555-1566, 1997.

3. Bazzoni G. The JAM family of junctional adhesion molecules. Curr Opin Cell Biol 15: 525-530, 2003.

4. Bazzoni G and Dejana E. Endothelial cell-to-cell junctions: molecular organization and role in vascular homeostasis. Physiol Rev 84: 869-901, 2004.

5. Behrens J, von Kries JP, Kuhl M, Bruhn L, Wedlich D, Grosschedl R, and Birchmeier W. Functional interaction of beta-catenin with the transcription factor LEF-1. Nature 382: 638-642, 1996.

6. Braga V. The crossroads between cell-cell adhesion and motility. Nat Cell Biol 2: E182-184, 2000.

7. Braga VM, Machesky LM, Hall A, and Hotchin NA. The small GTPases Rho and Rac are required for the establishment of cadherin-dependent cell-cell contacts. J Cell Biol 137: 1421-1431, 1997.

8. Briggs MW and Sacks DB. IQGAP proteins are integral components of cytoskeletal regulation. EMBO Rep 4: 571-574, 2003.

9. Carmeliet P, Lampugnani MG, Moons L, Breviario F, Compernolle V, Bono F, Balconi G, Spagnuolo R, Oostuyse B, Dewerchin M, Zanetti A, Angellilo A, Mattot V, Nuyens D, Lutgens E, Clotman F, de Ruiter MC, Gittenberger-de Groot A, Poelmann R, Lupu F, Herbert JM, Collen D, and Dejana E. Targeted 
deficiency or cytosolic truncation of the VE-cadherin gene in mice impairs VEGFmediated endothelial survival and angiogenesis. Cell 98: 147-157, 1999.

10. Cook TA, Nagasaki T, and Gundersen GG. Rho guanosine triphosphatase mediates the selective stabilization of microtubules induced by lysophosphatidic acid. J Cell Biol 141: 175-185, 1998.

11. Corada M, Liao F, Lindgren M, Lampugnani MG, Breviario F, Frank R, Muller WA, Hicklin DJ, Bohlen P, and Dejana E. Monoclonal antibodies directed to different regions of vascular endothelial cadherin extracellular domain affect adhesion and clustering of the protein and modulate endothelial permeability. Blood 97: 1679-1684, 2001.

\section{Corada M, Mariotti M, Thurston G, Smith K, Kunkel R, Brockhaus M,} Lampugnani MG, Martin-Padura I, Stoppacciaro A, Ruco L, McDonald DM, Ward PA, and Dejana E. Vascular endothelial-cadherin is an important determinant of microvascular integrity in vivo. Proc Natl Acad Sci U S A 96: 9815-9820, 1999.

13. Daub H, Gevaert K, Vandekerckhove J, Sobel A, and Hall A. Rac/Cdc42 and p65PAK regulate the microtubule-destabilizing protein stathmin through phosphorylation at serine 16. J Biol Chem 276: 1677-1680, 2001.

14. Davis MA, Ireton RC, and Reynolds AB. A core function for p120-catenin in cadherin turnover. J Cell Biol 163: 525-534, 2003.

15. Dejana E, Corada M, and Lampugnani MG. Endothelial cell-to-cell junctions. Faseb J 9: 910-918, 1995.

16. Drees F, Pokutta S, Yamada S, Nelson WJ, and Weis WI. Alpha-catenin is a molecular switch that binds E-cadherin-beta-catenin and regulates actin-filament assembly. Cell 123: 903-915, 2005. 
17. Etienne-Manneville S and Hall A. Cdc42 regulates GSK-3beta and adenomatous polyposis coli to control cell polarity. Nature 421: 753-756, 2003.

18. Etienne-Manneville S and Hall A. Integrin-mediated activation of Cdc42 controls cell polarity in migrating astrocytes through PKCzeta. Cell 106: 489-498, 2001.

19. Fey EG, Wan KM, and Penman S. Epithelial cytoskeletal framework and nuclear matrix-intermediate filament scaffold: three-dimensional organization and protein composition. J Cell Biol 98: 1973-1984, 1984.

20. Fukata M and Kaibuchi K. Rho-family GTPases in cadherin-mediated cellcell adhesion. Nat Rev Mol Cell Biol 2: 887-897, 2001.

\section{Fukata M, Kuroda S, Nakagawa M, Kawajiri A, Itoh N, Shoji I,} Matsuura Y, Yonehara S, Fujisawa H, Kikuchi A, and Kaibuchi K. Cdc42 and Rac1 regulate the interaction of IQGAP1 with beta-catenin. J Biol Chem 274: 2604426050, 1999.

\section{Fukata M, Nakagawa M, Itoh N, Kawajiri A, Yamaga M, Kuroda S, and} Kaibuchi K. Involvement of IQGAP1, an effector of Rac1 and Cdc42 GTPases, in cell-cell dissociation during cell scattering. Mol Cell Biol 21: 2165-2183, 2001.

\section{Fukata M, Watanabe T, Noritake J, Nakagawa M, Yamaga M, Kuroda S,} Matsuura Y, Iwamatsu A, Perez F, and Kaibuchi K. Rac1 and Cdc42 capture microtubules through IQGAP1 and CLIP-170. Cell 109: 873-885, 2002.

\section{Gainor JP, Morton CA, Roberts JT, Vincent PA, and Minnear FL.} Platelet-conditioned medium increases endothelial electrical resistance independently of cAMP/PKA and cGMP/PKG. Am J Physiol Heart Circ Physiol 281: H1992-2001, 2001. 


\section{Garcia JG, Liu F, Verin AD, Birukova A, Dechert MA, Gerthoffer WT,}

Bamberg JR, and English D. Sphingosine 1-phosphate promotes endothelial cell barrier integrity by Edg-dependent cytoskeletal rearrangement. J Clin Invest 108: 689701, 2001.

26. Goode BL, Drubin DG, and Barnes G. Functional cooperation between the microtubule and actin cytoskeletons. Curr Opin Cell Biol 12: 63-71, 2000.

27. Guo M, Wu MH, Granger HJ, and Yuan SY. Transference of recombinant VE-cadherin cytoplasmic domain alters endothelial junctional integrity and porcine microvascular permeability. J Physiol 554: 78-88, 2004.

28. Hall A. Rho GTPases and the actin cytoskeleton. Science 279: 509-514, 1998.

29. Hla T, Lee MJ, Ancellin N, Liu CH, Thangada S, Thompson BD, and Kluk M. Sphingosine-1-phosphate: extracellular mediator or intracellular second messenger? Biochem Pharmacol 58: 201-207, 1999.

30. Hobson JP, Rosenfeldt HM, Barak LS, Olivera A, Poulton S, Caron MG, Milstien S, and Spiegel S. Role of the sphingosine-1-phosphate receptor EDG-1 in PDGF-induced cell motility. Science 291: 1800-1803, 2001.

31. Hordijk PL, ten Klooster JP, van der Kammen RA, Michiels F, Oomen LC, and Collard JG. Inhibition of invasion of epithelial cells by Tiam1-Rac signaling. Science 278: 1464-1466, 1997.

32. Huber AH, Stewart DB, Laurents DV, Nelson WJ, and Weis WI. The cadherin cytoplasmic domain is unstructured in the absence of beta-catenin. A possible mechanism for regulating cadherin turnover. J Biol Chem 276: 12301-12309, 2001. 
33. Huber AH and Weis WI. The structure of the beta-catenin/E-cadherin complex and the molecular basis of diverse ligand recognition by beta-catenin. Cell 105: 391-402, 2001.

34. Ilan N, Cheung L, Pinter E, and Madri JA. Platelet-endothelial cell adhesion molecule-1 (CD31), a scaffolding molecule for selected catenin family members whose binding is mediated by different tyrosine and serine/threonine phosphorylation. J Biol Chem 275: 21435-21443, 2000.

35. Ilan N and Madri JA. PECAM-1: old friend, new partners. Curr Opin Cell Biol 15: 515-524, 2003.

36. Imamura Y, Itoh M, Maeno Y, Tsukita S, and Nagafuchi A. Functional domains of alpha-catenin required for the strong state of cadherin-based cell adhesion. J Cell Biol 144: 1311-1322, 1999.

\section{Ishizaki T, Morishima Y, Okamoto M, Furuyashiki T, Kato T, and}

Narumiya S. Coordination of microtubules and the actin cytoskeleton by the Rho effector mDia1. Nat Cell Biol 3: 8-14, 2001.

38. Itoh RE, Kurokawa K, Ohba Y, Yoshizaki H, Mochizuki N, and Matsuda M. Activation of rac and cdc42 video imaged by fluorescent resonance energy transfer-based single-molecule probes in the membrane of living cells. Mol Cell Biol 22: 6582-6591, 2002.

39. Iyer S, Ferreri DM, DeCocco NC, Minnear FL, and Vincent PA. VEcadherin-p120 interaction is required for maintenance of endothelial barrier function. Am J Physiol Lung Cell Mol Physiol 286: L1143-1153, 2004.

40. Izumi G, Sakisaka T, Baba T, Tanaka S, Morimoto K, and Takai Y. Endocytosis of E-cadherin regulated by Rac and Cdc42 small G proteins through IQGAP1 and actin filaments. J Cell Biol 166: 237-248, 2004. 
41. Kamiguchi $\mathbf{H}$ and Lemmon V. IgCAMs: bidirectional signals underlying neurite growth. Curr Opin Cell Biol 12: 598-605, 2000.

42. Kroschewski R, Hall A, and Mellman I. Cdc42 controls secretory and endocytic transport to the basolateral plasma membrane of MDCK cells. Nat Cell Biol 1: 8-13, 1999.

43. Kuroda S, Fukata M, Fujii K, Nakamura T, Izawa I, and Kaibuchi K. Regulation of cell-cell adhesion of MDCK cells by Cdc42 and Rac1 small GTPases. Biochem Biophys Res Commun 240: 430-435, 1997.

44. Kuroda S, Fukata M, Kobayashi K, Nakafuku M, Nomura N, Iwamatsu A, and Kaibuchi K. Identification of IQGAP as a putative target for the small GTPases, Cdc42 and Rac1. J Biol Chem 271: 23363-23367, 1996.

45. Kuroda S, Fukata M, Nakagawa M, Fujii K, Nakamura T, Ookubo T, Izawa I, Nagase T, Nomura N, Tani H, Shoji I, Matsuura Y, Yonehara S, and Kaibuchi K. Role of IQGAP1, a target of the small GTPases Cdc42 and Rac1, in regulation of E-cadherin- mediated cell-cell adhesion. Science 281: 832-835, 1998. 46. Kuroda S, Fukata M, Nakagawa M, and Kaibuchi K. Cdc42, Rac1, and their effector IQGAP1 as molecular switches for cadherin-mediated cell-cell adhesion. Biochem Biophys Res Commun 262: 1-6, 1999.

47. Lamarche $\mathbf{N}$ and Hall A. GAPs for rho-related GTPases. Trends Genet 10: 436-440, 1994.

48. Lampugnani MG, Corada M, Caveda L, Breviario F, Ayalon O, Geiger B, and Dejana E. The molecular organization of endothelial cell to cell junctions: differential association of plakoglobin, beta-catenin, and alpha-catenin with vascular endothelial cadherin (VE-cadherin). J Cell Biol 129: 203-217, 1995. 
49. Lampugnani MG, Resnati M, Raiteri M, Pigott R, Pisacane A, Houen G, Ruco LP, and Dejana E. A novel endothelial-specific membrane protein is a marker of cell-cell contacts. J Cell Biol 118: 1511-1522, 1992.

50. Lee MJ, Thangada S, Claffey KP, Ancellin N, Liu CH, Kluk M, Volpi M, Sha'afi RI, and Hla T. Vascular endothelial cell adherens junction assembly and morphogenesis induced by sphingosine-1-phosphate. Cell 99: 301-312, 1999.

51. Li S, Wang Q, Chakladar A, Bronson RT, and Bernards A. Gastric hyperplasia in mice lacking the putative Cdc42 effector IQGAP1. Mol Cell Biol 20: 697-701, 2000.

52. Li Z, Kim SH, Higgins JM, Brenner MB, and Sacks DB. IQGAP1 and calmodulin modulate E-cadherin function. J Biol Chem 274: 37885-37892, 1999.

53. Li Z and Sacks DB. Elucidation of the interaction of calmodulin with the IQ motifs of IQGAP1. J Biol Chem 278: 4347-4352, 2003.

54. Liaw CW, Cannon C, Power MD, Kiboneka PK, and Rubin LL. Identification and cloning of two species of cadherins in bovine endothelial cells. Embo J 9: 2701-2708, 1990.

55. Liu F, Verin AD, Wang P, Day R, Wersto RP, Chrest F J, English DK, and Garcia JG. Differential regulation of sphingosine-1-phosphate- and VEGFinduced endothelial cell chemotaxis. Involvement of G(ialpha2)-linked Rho kinase activity. Am J Respir Cell Mol Biol 24: 711-719, 2001.

56. Luo Y and Radice GL. N-cadherin acts upstream of VE-cadherin in controlling vascular morphogenesis. J Cell Biol 169: 29-34, 2005.

57. Mateer SC, Morris LE, Cromer DA, Bensenor LB, and Bloom GS. Actin filament binding by a monomeric IQGAP1 fragment with a single calponin homology domain. Cell Motil Cytoskeleton 58: 231-241, 2004. 
58. McVerry BJ and Garcia JG. Endothelial cell barrier regulation by sphingosine 1-phosphate. J Cell Biochem 92: 1075-1085, 2004.

59. Mehta D, Konstantoulaki M, Ahmmed GU, and Malik AB. Sphingosine 1phosphate-induced mobilization of intracellular $\mathrm{Ca} 2+$ mediates rac activation and adherens junction assembly in endothelial cells. J Biol Chem 280: 17320-17328, 2005. 60. Michel CC and Curry FE. Microvascular permeability. Physiol Rev 79: 703761, 1999.

61. Milici AJ, Watrous NE, Stukenbrok H, and Palade GE. Transcytosis of albumin in capillary endothelium. J Cell Biol 105: 2603-2612, 1987.

62. Minnear FL, Zhu L, and He P. Sphingosine 1-phosphate prevents plateletactivating factor-induced increase in hydraulic conductivity in rat mesenteric venules: pertussis toxin sensitive. Am J Physiol Heart Circ Physiol 289: H840-844, 2005.

63. Miyamoto S, Baba H, Kuroda S, Kaibuchi K, Fukuda T, Maehara Y, and Saito T. Changes in E-cadherin associated with cytoplasmic molecules in well and poorly differentiated endometrial cancer. Br J Cancer 83: 1168-1175, 2000.

64. Muller WA, Weigl SA, Deng X, and Phillips DM. PECAM-1 is required for transendothelial migration of leukocytes. J Exp Med 178: 449-460, 1993.

65. Nagafuchi A and Takeichi M. Cell binding function of E-cadherin is regulated by the cytoplasmic domain. Embo J 7: 3679-3684, 1988.

66. Narumiya S. The small GTPase Rho: cellular functions and signal transduction. J Biochem (Tokyo) 120: 215-228, 1996.

67. Navarro P, Ruco L, and Dejana E. Differential localization of VE- and Ncadherins in human endothelial cells: VE-cadherin competes with $\mathrm{N}$-cadherin for junctional localization. J Cell Biol 140: 1475-1484, 1998. 
68. Nieman MT, Prudoff RS, Johnson KR, and Wheelock MJ. N-cadherin promotes motility in human breast cancer cells regardless of their E-cadherin expression. J Cell Biol 147: 631-644, 1999.

69. Noren NK, Liu BP, Burridge K, and Kreft B. p120 catenin regulates the actin cytoskeleton via Rho family GTPases. J Cell Biol 150: 567-580, 2000.

70. Noritake J, Fukata M, Sato K, Nakagawa M, Watanabe T, Izumi N, Wang S, Fukata Y, and Kaibuchi K. Positive role of IQGAP1, an effector of Rac1, in actin-meshwork formation at sites of cell-cell contact. Mol Biol Cell 15: 1065-1076, 2004.

71. Noritake J, Watanabe T, Sato K, Wang S, and Kaibuchi K. IQGAP1: a key regulator of adhesion and migration. J Cell Sci 118: 2085-2092, 2005.

72. Ohkubo T and Ozawa M. p120(ctn) binds to the membrane-proximal region of the E-cadherin cytoplasmic domain and is involved in modulation of adhesion activity. J Biol Chem 274: 21409-21415, 1999.

73. Ozawa M and Ohkubo T. Tyrosine phosphorylation of p120(ctn) in v-Src transfected L cells depends on its association with E-cadherin and reduces adhesion activity. J Cell Sci 114: 503-512, 2001.

74. Paik JH, Skoura A, Chae SS, Cowan AE, Han DK, Proia RL, and Hla T. Sphingosine 1-phosphate receptor regulation of N-cadherin mediates vascular stabilization. Genes Dev 18: 2392-2403, 2004.

75. Palazzo AF, Cook TA, Alberts AS, and Gundersen GG. mDia mediates Rho-regulated formation and orientation of stable microtubules. Nat Cell Biol 3: 723729, 2001.

76. Palka HL and Green KJ. Roles of plakoglobin end domains in desmosome assembly. J Cell Sci 110 ( Pt 19): 2359-2371, 1997. 


\section{Peng X, Hassoun PM, Sammani S, McVerry BJ, Burne MJ, Rabb H,}

Pearse D, Tuder RM, and Garcia JG. Protective effects of sphingosine 1-phosphate in murine endotoxin-induced inflammatory lung injury. Am J Respir Crit Care Med 169: 1245-1251, 2004.

78. Philippova M, Ivanov D, Tkachuk V, Erne P, and Resink TJ. Polarisation of T-cadherin to the leading edge of migrating vascular cells in vitro: a function in vascular cell motility? Histochem Cell Biol 120: 353-360, 2003.

79. Rampon C, Prandini MH, Bouillot S, Pointu H, Tillet E, Frank R, Vernet M, and Huber P. Protocadherin 12 (VE-cadherin 2) is expressed in endothelial, trophoblast, and mesangial cells. Exp Cell Res 302: 48-60, 2005.

80. Reynolds AB and Carnahan RH. Regulation of cadherin stability and turnover by p120ctn: implications in disease and cancer. Semin Cell Dev Biol 15: 657663, 2004.

81. Reynolds AB, Herbert L, Cleveland JL, Berg ST, and Gaut JR. p120, a novel substrate of protein tyrosine kinase receptors and of p60v-src, is related to cadherin-binding factors beta-catenin, plakoglobin and armadillo. Oncogene 7: 24392445, 1992.

82. Salomon D, Ayalon O, Patel-King R, Hynes RO, and Geiger B.

Extrajunctional distribution of N-cadherin in cultured human endothelial cells. J Cell Sci 102 ( Pt 1): 7-17, 1992.

83. Schmelz M and Franke WW. Complexus adhaerentes, a new group of desmoplakin-containing junctions in endothelial cells: the syndesmos connecting retothelial cells of lymph nodes. Eur J Cell Biol 61: 274-289, 1993. 
84. Schmelz M, Moll R, Kuhn C, and Franke WW. Complexus adhaerentes, a new group of desmoplakin-containing junctions in endothelial cells: II. Different types of lymphatic vessels. Differentiation 57: 97-117, 1994.

85. Seidensticker MJ and Behrens J. Biochemical interactions in the wnt pathway. Biochim Biophys Acta 1495: 168-182, 2000.

86. Shikata Y, Birukov KG, and Garcia JG. S1P induces FA remodeling in human pulmonary endothelial cells: role of Rac, GIT1, FAK, and paxillin. J Appl Physiol 94: 1193-1203, 2003.

87. Shimao Y, Nabeshima K, Inoue T, and Koono M. Complex formation of IQGAP1 with E-cadherin/catenin during cohort migration of carcinoma cells. Its possible association with localized release from cell-cell adhesion. Virchows Arch 441: 124-132, 2002.

88. Simionescu M, Simionescu N, and Palade GE. Segmental differentiations of cell junctions in the vascular endothelium. The microvasculature. J Cell Biol 67: 863885, 1975.

89. Spiegel S and Merrill AH, Jr. Sphingolipid metabolism and cell growth regulation. Faseb J 10: 1388-1397, 1996.

90. Spring CM, Kelly KF, O'Kelly I, Graham M, Crawford HC, and Daniel JM. The catenin p120ctn inhibits Kaiso-mediated transcriptional repression of the beta-catenin/TCF target gene matrilysin. Exp Cell Res 305: 253-265, 2005.

91. Sugimoto N, Imoto I, Fukuda Y, Kurihara N, Kuroda S, Tanigami A, Kaibuchi K, Kamiyama R, and Inazawa J. IQGAP1, a negative regulator of cellcell adhesion, is upregulated by gene amplification at 15q26 in gastric cancer cell lines HSC39 and 40A. J Hum Genet 46: 21-25, 2001. 
92. Takahashi K, Nakanishi H, Miyahara M, Mandai K, Satoh K, Satoh A, Nishioka H, Aoki J, Nomoto A, Mizoguchi A, and Takai Y. Nectin/PRR: an immunoglobulin-like cell adhesion molecule recruited to cadherin-based adherens junctions through interaction with Afadin, a PDZ domain-containing protein. J Cell Biol 145: 539-549, 1999.

93. Takai Y, Irie K, Shimizu K, Sakisaka T, and Ikeda W. Nectins and nectinlike molecules: roles in cell adhesion, migration, and polarization. Cancer Sci 94: 655-667, 2003.

94. Takai Y, Sasaki T, and Matozaki T. Small GTP-binding proteins. Physiol Rev 81: 153-208, 2001.

95. Takaishi K, Sasaki T, Kotani H, Nishioka H, and Takai Y. Regulation of cell-cell adhesion by rac and rho small G proteins in MDCK cells. J Cell Biol 139: 1047-1059, 1997.

96. Takemoto H, Doki Y, Shiozaki H, Imamura H, Utsunomiya T, Miyata H, Yano M, Inoue M, Fujiwara Y, and Monden M. Localization of IQGAP1 is inversely correlated with intercellular adhesion mediated by e-cadherin in gastric cancers. Int J Cancer 91: 783-788, 2001.

97. Thoreson MA, Anastasiadis PZ, Daniel JM, Ireton RC, Wheelock MJ, Johnson KR, Hummingbird DK, and Reynolds AB. Selective uncoupling of p120(ctn) from E-cadherin disrupts strong adhesion. J Cell Biol 148: 189-202, 2000.

98. Tschugguel W, Zhegu Z, Gajdzik L, Maier M, Binder BR, and Graf J. High precision measurement of electrical resistance across endothelial cell monolayers. Pflugers Arch 430: 145-147, 1995.

99. van de Wetering $\mathbf{M}$, de Lau W, and Clevers $\mathbf{H}$. WNT signaling and lymphocyte development. Cell 109 Suppl: S13-19, 2002. 
100. Vasioukhin V, Bauer C, Degenstein L, Wise B, and Fuchs E. Hyperproliferation and defects in epithelial polarity upon conditional ablation of alpha-catenin in skin. Cell 104: 605-617, 2001.

101. Vincent PA, Xiao K, Buckley KM, and Kowalczyk AP. VE-cadherin: adhesion at arm's length. Am J Physiol Cell Physiol 286: C987-997, 2004.

102. Vouret-Craviari V, Bourcier C, Boulter E, and van Obberghen-Schilling E. Distinct signals via Rho GTPases and Src drive shape changes by thrombin and sphingosine-1-phosphate in endothelial cells. J Cell Sci 115: 2475-2484, 2002.

103. Weis S, Cui J, Barnes L, and Cheresh D. Endothelial barrier disruption by VEGF-mediated Src activity potentiates tumor cell extravasation and metastasis. $J$ Cell Biol 167: 223-229, 2004.

104. Weissbach L, Settleman J, Kalady MF, Snijders AJ, Murthy AE, Yan YX, and Bernards A. Identification of a human rasGAP-related protein containing calmodulin-binding motifs. J Biol Chem 269: 20517-20521, 1994.

105. Xiao K, Allison DF, Buckley KM, Kottke MD, Vincent PA, Faundez V, and Kowalczyk AP. Cellular levels of p120 catenin function as a set point for cadherin expression levels in microvascular endothelial cells. J Cell Biol 163: 535545, 2003.

106. Xiao K, Garner J, Buckley KM, Vincent PA, Chiasson CM, Dejana E, Faundez V, and Kowalczyk AP. p120-Catenin regulates clathrin-dependent endocytosis of VE-cadherin. Mol Biol Cell 16: 5141-5151, 2005.

107. Xie L, Law BK, Aakre ME, Edgerton M, Shyr Y, Bhowmick NA, and Moses HL. Transforming growth factor beta-regulated gene expression in a mouse mammary gland epithelial cell line. Breast Cancer Res 5: R187-198, 2003. 
108. Yamada KM and Geiger B. Molecular interactions in cell adhesion complexes. Curr Opin Cell Biol 9: 76-85, 1997.

109. Yamada S, Pokutta S, Drees F, Weis WI, and Nelson WJ. Deconstructing the cadherin-catenin-actin complex. Cell 123: 889-901, 2005.

110. Yamaoka-Tojo M, Tojo T, Won Kim H, Hilenski L, Patrushev NA, Zhang L, Fukai T, and Ushio-Fukai M. IQGAP1 Mediates VE-Cadherin-Based Cell-Cell Contacts and VEGF Signaling at Adherence Junctions Linked to Angiogenesis. Arterioscler Thromb Vasc Biol, 2006.

111. Yap AS, Niessen CM, and Gumbiner BM. The juxtamembrane region of the cadherin cytoplasmic tail supports lateral clustering, adhesive strengthening, and interaction with p120ctn. J Cell Biol 141: 779-789, 1998.

112. Yuan SY. Protein kinase signaling in the modulation of microvascular permeability. Vascul Pharmacol 39: 213-223, 2002. 